\title{
ASPECTOS BIOECOLÓGICOS DE Culex quinquefasciatus e Ochlerotatus scapularis, ABRIGADOS EM HABITATS DO PARQUE ECOLÓGICO DO TIETÊ NA CIDADE DE SÃO PAULO, SP.
}

\section{Regiane Maria Tironi de Menezes}

Tese de Doutorado apresentada ao Departamento de Epidemiologia da Faculdade de Saúde Pública da Universidade de São Paulo para obtenção do Grau de Doutor.

Área de concentração: Epidemiologia

Orientador: Prof. Livre DoCente Delsio Natal

São Paulo 2002

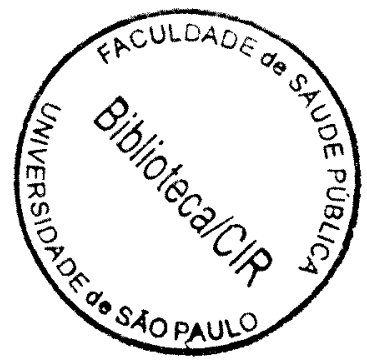


A minha sobrinha, Melissa.

Biblioteca, CIR AACULDADE DE SAŨDE PÜ inUVERSIDANE DE SAO rAL 


\section{AGRADECIMENTOS}

Ao professor Delsio Natal pela dedicação e orientação

Aos membros da banca examinadora, Iná Kakitani, Gisela Yuka Shimizu, Mario Antônio Navarro da Silva, Francisco Chiaravalotti Neto, Antônio Ismael Paulino da Costa, Aristides de Almeida Rocha, pelas correções e sugestões

A Superintendência de Controle de Endemias (SUCEN) e ao Superintendente Dr. Luiz Jacinto da Silva pela oportunidade oferecida.

A Rosa Maria Tubaki, Renata Henrique de Ramos, Maria Aparecida Silva Santos e Juliana Telles de Deus, do Laboratório de Entomologia da Superintendência de Controle de Endemias (SUCEN), pelo apoio dispensado.

A Paulo Urbinatti e Walter Ceretti do laboratório de Triatomíneos e Culicídeos do Departamento de Epidemiologia da FSP/USP, pelo apoio durante todas as coletas realizadas.

A Márcia Gutierrez de Souza, Joyce Montes e Carolina Cunha, pela participação durante as atividades de campo e laboratório.

Ao Marcelo Sciarretta Sebastião e a Leni Pires das Mercês, do Departamento de Epidemiologia da FSP/USP, pelo auxílio na confecção e montagem das fotos do Parque Ecológico.

Ao Professor Cláudio Santos Ferreira pela confecção do summary.

A Márcia Bicudo de Paula do laboratório de Entomologia do Departamento de Epidemiologia da FSP/USP, por me receber no laboratório e por toda a atençâo que me foi dispensada nas semanas em que realizei coletas e dissecções.

Ao Daniel Flores do Departamento de Epidemiologia da FSP/USP, pela confecção do croqui do Parque Ecológico.

A minha família pelo apoio de sempre. 


\section{RESUMO}

Menezes, RMT. Aspectos Bioecológicos de Culex quinquefasciatus e Ochlerotatus scapularis abrigados em habitats do Parque Ecológico do Tietê na Cidade de São Paulo, SP, Brasil; 2002. [Tese de Doutorado - Faculdade de Saúde Pública da USP].

Objetivos. Diante da importância epidemiológica de Culex quinquefasciatus e Ochlerotatus scapularis e da conhecida dominância dessas populações em áreas do Parque Ecológico do Tietê, objetivou-se estudar ao longo das estações do ano aspectos bioecológicos das duas populações abrigadas em diferentes habitats. Métodos. Realizaram-se coletas quinzenais nos diferentes habitats com auxilio de aspirador a bateria. O estado físiológico e o tamanho do corpo das fêmeas das duas populaçð̃es foi verificada em laboratório a partir de amostras aleatórias de cada habitat. Resultados. A proporção entre os sexos revelou um maior predomínio de machos entre os habitats, esta diferença foi mais significante para Culex quinquefasciatus. Ochlerotatus scapularis apresentou um percentual maior de fềmeas paridas comparado a Culex quinquefasciatus nos diferentes habitats. Essa diferença foi significante $\operatorname{com}\left(\chi^{2}=16.6 \mathrm{e} p=0,01\right)$. A distribuição de fêmeas paridas e nulíparas de Culex quinquefasciatus nos habitats do interior do parque, foi mais significante $\left(\chi^{2}=28,7\right.$ e p < 0,001) comparada à distribuição de Ochlerotatus scapularis $\left(\chi^{2}=13,8\right.$ e $p=0,01$ ). As fêmeas paridas dos mosquitos foram numericamente mais expressivas ao longo da estação chuvosa, nos habitats da periferia e interior do parque. As duas populações apresentaram fêmeas nos estágios III de Christophers e Mer com o intestino totalmente cheio de sangue vermelho, indício de discordância gonotrófica. Culex quinquefasciatus foi estatisticamente maior que Ochlerotatus scapularis ( $\mathrm{p}<0,001$ ), em relação ao tamanho do corpo, apresentando diferença estatística significante tanto no período de chuva quanto no de seca $(H=69,9$ e $P<0,001)$. O coeficiente de regressão $\left(B_{1}=-14.9\right)$ e o coeficiente de correlação $(r=-0,62)$ indicaram para Culex quinquefasciatus um efeito negativo do tamanho sobre as fêmeas paridas. A função do tamanho não se explicou em 
fêmeas nulíparas e de machos de Culex quinquefasciatus, indica a proximidade do criadouro. O tamanho do corpo de Culex quinquefasciatus é maior que Ochlerotatus scapularis. O efeito do tamanho do corpo sobre o número de fềmeas paridas foi negativo. Culex quinquefasciatus e Ochlerotatus scapularis apresentaram discordância gonotrófica. As fềmeas paridas de Ochlerotatus scapularis estiveram em consonância com altas temperaturas e com os picos de densidade de fềmeas. Existe diferença estatisticamente significante na distribuição de fềmeas paridas e nulíparas das duas populações entre os habitats estudados.

Descritores: Bioecológico, Culex quinquefasciatus, Ochlerotatus scapularis, estado fisiológico, tamanho do corpo. 


\section{SUMMARY}

Menezes, RMT. Aspectos Bioecológicos de Culex quinquefasciatus e Ochlerotatus scapularis, abrigados em habitats do Parque Ecológico do Tietê, na cidade de São Paulo, SP. [Bioecological aspects of Culex quinquefasciatus and Ochlerotatus scapularis from habitats of the Ecological Park by the river Tietê, City of São Paulo, SP]. São Paulo (BR); 2002. [Tese de Doutorado - Faculdade de Saúde Publica da Universidade de São Paulo].

Objectives. In view of the epidemiological importance of Culex quinquefasciatus and Ochlerotatus scapularis, and the well-known dominance of populations of both species in the Park, a plan was worked out for studying some of their bioecological aspects along the seasons, during two years, in its various habitats. Methods. Specimens were collected fortnightly from selected habitats with the aid of a batterypowered vacuum pump. Physiological stage and body size of female mosquitoes from random samples of both species, collected from all selected habitats, were determined at the laboratory. Results. Populations of both species, from all sampled habitats, had a significantly higher proportion of males. The ratio of parous to nulliparous Ochlerotatus scapularis was significantly higher than the ratio of parous to nulliparous Culex quinquefasciatus $\left(\chi^{2}=16,6\right.$ and $\left.p=0.01\right)$. Culex quinquefasciatus showed a higher intrinsic variation of this ratio among habitats inside the Park $\left(\chi^{2}=28.7\right.$ and $\left.\mathrm{p}=0.001\right)$ than Ochlerotatus scapularis $\left(\chi^{2}=13.8\right.$ and $p=.01$ ). During the rainy season, the population of parous females, irrespective of the species, was numerically superior, both in sites inside and on the periphery of the Park. Populations of both species included females in Christophers \& Mer's stage III with their guts full of red blood, which conflicted with gonotrophic data. The specimens of Culex quinquefasciatus were found to be significantly larger than those of Ochlerotatus scapularis $(\mathrm{p}<0.001)$, this difference remaining statistically significant when data from mosquitoes collected along the dry and rainy seasons were analyzed $(H=69.9$ and $p<0.001)$. The coefficients of regression $\left(\beta_{1}=-14.9\right)$ and of correlation $(r=-0.62)$ were suggestive of a negative effect of size on the parity of Culex quinquefasciatus, but not on the parity of Ochlerotatus scapularis 
$(r=-0.42)$. Conclusions. The higher proportion of males and of nulliparous females of Culex quinquefasciatus suggested a proximity of their breeding sites. Culex quinquefasciatus body is larger than that of Ochlerotatus scapularis. Body size and the proportion of parous females were observed to be negatively correlated. Culex quinquefasciatus and Ochlerotatus scapularis showed gonotrophic disagreement. The proportion of parous Ochlerotatus scapularis was in agreement with the observed high temperatures and female density peaks. A statistically significant difference was found in the distribution of nulliparous and parous females of both species, among the habitats under study.

Descriptors: Bioecological, Culex quinquefasciatus, Ochlerotatus scapularis, physiological stage, body size. 


\section{ÍNDICE}

1.INTRODUÇÃo

1.1 Potencial Epidemiológico de Culex quinquefasciatus e Ochlerotatus scapularis01

1.2 Importância do estudo de aspectos bioecológicos dos mosquitos Culex quinquefasciatus e Ochlerotatus scapularis no Parque Ecológico do Tietê.

2.0BJETIVOS

2.1 Objetivo Geral

2.2 Objetivos Específicos

3.MATERIAL E MÉTOdos

3.1 Área de Estudo

3.2 Procedimentos em campo

3.3 Procedimentos em laboratório

3.4 Tratamento dos dados

\section{Resultados}

4.1 Distribuição de Culex quinquefasciatus e Ochlerotatus scapularis segundo sexo em diferentes habitats.

4.2 Distribuição de fêmeas nulíparas e paridas de Culex quinquefasciatus e Ochlerotatus scapularis em diferentes habitats, no Parque Ecológico do Tietê. 21

4.3 Distribuição de fêmeas paridas e nulíparas de Culex quinquefasciatus e Ochlerotatus scapularis ao longo das estações do ano no interior e periferia do Parque Ecológico do Tietê.

4.4 Fases do desenvolvimento ovariano dos mosquitos segundo os diferentes habitats e ao longo das estações do ano.

4.5 Influência da variação sazonal no tamanho dos mosquitos.

$4.6 \mathrm{O}$ efeito do tamanho no estado de paridade das fềmeas de Ochlerotatus scapularis e Culex quinquefasciatus. 
5.2 Distribuição de fêmeas paridas e nulíparas entre os habitats e ao longo das diferentes estaç̃es climáticas.

5.3 Fases do desenvolvimento ovariano dos mosquitos, segundo os diferentes habitats e estaçðes do ano.

5.4 Variação sazonal no tamanho nas populações de Culex quinquefasciatus e Ochlerotatus scapularis.

$5.5 \mathrm{O}$ efeito do tamanho do corpo de Culex quinquefasciatus e Ochlerotatus scapularis sobre a paridade dos mesmos.

6. Conclusóns

7. REFERÊNCIAS BIBLIOGRÁFICAS

\section{ANEXOS}

Anexo 1. Apresentação tabular da distribuição de fêmeas nuliparas e paridas de Ochlerotatus scapularis segundo os diferentes habitats e datas coleta

Anexo 2. Apresentação tabular da distribuição de fêmeas nuliparas e paridas de Culex quinquefasciatus segundo os diferentes habitats e datas de coleta

Anexo 3. Aspecto paisagístico dos habitats de coleta do Parque Ecológico do Tietê na cidade de São Paulo 


\section{INTRODUÇÃO}

\subsection{PotenCial EPIDEMológico De Culex quinquefasciatus e Ochlerotatus scapularis}

Culex quinquefasciatus é um dos maiores táxons pertencente ao complexo Culex pipiens, juntamente com Culex pipiens pipiens L. (PRYOR e DALY, 1991). Tem sido reconhecido como nome válido para o mosquito tropical urbano que anteriormente era conhecido como Culex pipiens fatigans, reconhecido por alguns autores, como espécie classificada no gênero Culex e subgênero de mesmo nome (SIRIVANAKARN e WHITE, 1978; HARBACH e col. 1985).

Espécie largamente distribuída nas áreas tropicais e subtropicais, Culex quinquefasciatus ocorre nas porções meridionais da Ásia, na África, nas Américas, do sul dos Estados Unidos até a Argentina, e na Oceania. Devido a sua antropofilia e endofilia esta intimamente associada às habitações humanas e com o homem nas áreas urbanizadas (FORATTINI e col. 1993, CONSOLI E LOURENÇO-DE-OLIVEIRA, 1994).

Culex quinquefasciatus constitui o principal vetor de filariose bancroftiana em países da Ásia e África, considerados endêmicos para a doença. Focos localizados da infeç̧ão são encontrados na América do Sul, América Central, algumas ilhas do Caribe e grande parte das ilhas do Pacífico (OMS, 1988; WHO, 1992). É mosquito abundante nos habitats residenciais do Meio Oeste dos Estados Unidos, tendo sido incriminado como um importante vetor urbano durante epidemias de encefalite de Saint Louis 
(REISEN e col. 1992), largamente distribuída do Sul do Canadá até a Argentina (SAVAGE e col.1993). Foi encontrado naturalmente infectado com vírus da encefalite venezuelana no Panamá (CONSOLI e LOURENÇO-DE-OLIVEIRA, 1994).

Em nosso pais Culex quinquefasciatus representa um problema sério de Saúde Pública quando comparado às outras espécies do subgênero Culex. Transmitia a filariose em Manaus, Belém, Recife, Maceio, Salvador, Florianópolis e Porto Alegre, dentre outras localidades do país. Nos últimos 30 anos a incidência dessa doença baixou muito e, embora ocorra em índices quase nulos em algumas daquelas localidades, vem-se tornando um sério problema em Recife, Jaboatão e Olinda, no Estado de Pernambuco, e em Maceió, Alagoas. Também é considerado vetor secundário do vírus Oropouche em áreas do Estado do Pará (CONSOLI e LOURENÇO-DE-OLIVEIRA, 1994).

Em laboratório e estudos de campo tem-se demonstrado que grandes porcentagens de Culex quinquefasciatus se alimentam em canídeos, implicando na transmissão de dirofilariose em cães (NIEBYLSKI e MEEK, 1992).

Na baixada fluminense, Estado do Rio de Janeiro, Culex quinquefasciatus foi considerado vetor secundário de Dirofilaria immitis. A espécie é sugerida como a provável vetora do verme para felinos. LABARTHE (1998) afirma que, dada a freqüência da infecção canina em algumas áreas do país, supõe-se que o número de casos de dirofilariose em humanos venha sendo subestimado.

Culex quinquefasciatus também é responsável pelo incômodo que pode causar, quando existe a proximidade entre grandes populações deste inseto e aglomerados urbanos, freqüentemente em locais que não fazem a devida destinação do lixo e do esgoto, gerando condições favoráveis à proliferação da espécie. 
Segundo a reclassificação de REINERT (2000), o subgênero Ochlerotatus de Aedes elevou-se a categoria de gênero e foi separado em duas seções: A seção I do gênero Ochlerotatus inclui o subgênero do mesmo nome do qual pertence à espécie Ochlerotatus (Ochlerotatus) scapularis, anteriormente Aedes(Ochlerotatus) scapularis.

Ochlerotatus scapularis, reveste-se de grande importância epidemiológica pelo seu grau de adaptação às condições alteradas do meio ambiente, por sua antropofilia, endofilia e domiciliação (FORATTINI e col. 1995). Espécie vetora de arboviroses como febre amarela, encefalite eqüina e venezuelana, que acometem o homem e animais (ARNELL 1976), foi observada naturalmente infectada por formas evolutivas de filaria bancroftiana no Estado de Santa Catarina por RACHOU e col. (1955). Incriminada como vetora da encefalite pelo virus Rocio no Sudeste do Pais, teve sua competência vetorial comprovada em laboratório por MITCHELL e FORATTINI em 1984.

Recentemente Ochlerotatus scapularis foi incriminado como possivel vetor de dirofilariose, na cidade do Rio de Janeiro. Das sete espécies pertencentes ao gênero Dirofilaria encontradas no Brasil, são hospedeiros, o homem o cachorro e alguns animais silvestres (MACEDO e col. 1998).

No Brasil a distribuição confirmada dos casos humanos de dirofilariose é de 36 casos no Estado de São Paulo, quatro no Estado do Rio de Janeiro e um de origem desconhecida. No município de Mairiporã, próximo a Capital do Estado de São Paulo, $17 \%$ dos cães se apresentaram infectados (RODRIGUES-SILVA e col. 1995, CAMPOS e col. 1997). 


\subsection{IMPORTÂNCLA DO ESTUDO DE ASPECTOS BIOECOLÓGICOS DOS MOSQUTOS}

Culex quinquefasciatus E Ochlerotatus scapularis No PARQuE ECOLÓGICO Do TIETÊ.

A ocorrência de mosquitos Culicidae em maior ou menor abundância com maior ou menor capacidade vetorial já foi registrado na cidade de São Paulo, em área do Parque Ecológico do Tietê. SOUBIHE (1994) e COSTA (2000), realizaram levantamentos de mosquitos adultos (Diptera:Culicidae), no Parque Ecológico do Tietê, objetivando o estudo de parâmetros ecológicos a exemplo da frequência sazonal, freqüência horária, abundância, diversidade e hábito alimentar.

Os estudos realizados por SOUBIHE (1994), indicaram alta densidade de mosquitos culicidae no interior do Parque Ecológico. A autora, no periodo de dois anos, capturou 41.453 mosquitos, abrangendo 32 espécies ou grupos sendo: Culex(Culex)spp, Mansonia titilans, Ochlerotatus scapularis e Culex quinquefasciatus, os de maior ocorrência ordenadamente.

Nos estudos de COSTA (2000), ficou evidente a dominância das populações de Culex quinquefasciatus e Ochlerotatus scapularis, respectivamente primeira e segunda espécies mais abundantes, em detrimento de outras nas áreas do Parque Ecológico. Coletas em abrigos artificiais e naturais revelaram um percentual acentuado de Culex quinquefasciatus evidenciando que, durante o dia, essa espécie que tem hábito noturno, usa as áreas do Parque como abrigo.

Situado na planície de inundação do rio de mesmo nome, o Parque Ecológico do Tietê (PET), possuiu extensa área verde inserida no ecossistema urbano da cidade de 
São Paulo. Sendo um exemplo de ecossistema natural inserido em ecossistema urbano, o PET, sob o ponto de vista de FORATTINI (1992), representaria o ambiente biótico do ecossistema urbano-industrial.

O Parque Ecológico reúne todas as condiçð̃es para o desenvolvimento de mosquitos Culex quinquefasciatus e Ochlerotatus scapularis. O rio Tietê, na área do Parque, possui águas com elevada carga de poluentes orgânicos abastecendo lagoas no seu interior, e formando grandes criadouros que servem de locais de desenvolvimento para as populações de Culex quinquefasciatus. A espécie ainda utiliza córregos, afluentes do rio Tietê, que cortam o Parque Ecológico em sua periferia. Ochlerotatus scapularis utiliza alagadiços e outros criadouros de caráter natural e transitório presentes nos habitats de mata secundária, cobertos por bosques de eucaliptos, de margem de mata, ou modificados de campo-aberto, cuja vegetação representa abrigo para as populações de mosquitos.

O Parque Ecológico também apresenta uma grande quantidade de recurso alimentar para as populações dos mosquitos em estudo. Vertebrados, a exemplo de aves migratórias e autóctones, macacos, quatis, pacas, e outros animais silvestres livres ou vivendo em cativeiro ou semicativeiro (DAEE, 1989), representariam esse recurso.

É possível que, diante da diversidade de habitats presentes no Parque Ecológico do Tietê, possamos identificar diferenças significantes, com relação aos aspectos bioecológicos que pretendemos estudar para as duas populações de mosquitos.

Recentemente foi isolado por PEREIRA e col. (2001), o arbovirus Ilhéus em sangue de aves das espécies Sporophila caerulescens (papa-capim) e Molothrus bonariensis (chupim), residentes do Parque Ecológico e comuns no Estado de São 
Paulo. Os autores relatam que este é o primeiro isolamento do virus Ilhéus no Brasil, em aves silvestres, anteriormente obtido apenas no Panamá, Guianas Francesas e Trinidad. O vírus Ihéus apresenta ampla distribuição geográfica no Continente Americano, tendo sido detectado em mosquitos e diversos grupos de vertebrados, incluindo o homem.

A presença de anticorpos detectados no soro de aves das espécies Columbina talpacoti (rolina caldo-de-feijão), Geopelia cuneata (pombinha), Molothrus bonariensis e Sicalis flaveola (canário-da-terra), nos sagüis das espécies Callithrix jacchus e Callithrix penicillata, mantidos em cativeiro durante muitos anos no parque, no quati da espécie Nasua nasua, nascido e residente no parque, indica que o arbovírus continua circulando nas áreas do Parque Ecológico, expondo o homem ao risco de infecção (PEREIRA e col. 2001).

O homem encontra-se no entorno desse ambiente natural, podendo vir a ser infectado por agentes etiológicos a exemplo do arbovírus Ilhéus, que podem ser veiculados por Culex quinquefasciatus ou Ochlerotatus scapularis, sabidamente os mais abundantes, ou por outros mosquitos presentes no parque em menor abundância, a exemplo de Culex declarator, Culex nigripalpus, Culex (Mel.) ribeirenses, Culex (Cux.)bidens, Culex (Cux.)mollis, Culex(Cux.)sp. gr coronator, entre outras espécies, registradas por COSTA (2000) e SOUBIHE (1994).

A população humana mais próxima do contato com os mosquitos que se proliferam no Parque Ecológico do Tietê está representada pelos que residem em condições precárias em terrenos clandestinos pertencentes ao parque, em sua periferia, e por aqueles que trabalham ou que utilizam as áreas do parque nos finais de semana, buscando o lazer. Esta população, a exemplo dos animais do parque, representam 
recurso alimentar, possibilitando que os mosquitos, que proliferam nesse ecossistema, incluindo Ochlerotatus scapularis e Culex quinquefasciatus, possam desenvolver o seu ciclo gonotrófico.

Segundo FORATTINI (1996), entende-se como ciclo gonotrófico, ao suceder de fenômenos que ocorrem durante período que se inicia pela procura, execução e digestão de repasto sangüíneo e se conclui pela oviposição, denominado ainda por alguns autores de ciclo de oviposição. Uma fêmea de mosquito pode cumprir, durante sua vida, vários ciclos gonotróficos, distinguindo as que não ovipuseram (nulíparas) das que já ovipuseram ao menos um lote de ovos (paridas).

Em regiões tropicais, onde as mudanças de temperatura são menos acentuadas, a digestão do sangue e o desenvolvimento dos ovos tendem a processar-se num ritmo uniforme CHARLWOOD (1980). Esse desenvolvimento foi classificado por CHRISTOPHERS (1911) e MER (1936), em cinco estádios, tradicionalmente conhecidos como fases de Christophers e Mer.

Sabe-se que os mosquitos proliferam mais intensamente e são mais ativos na obtenção do alimento, em condições de temperatura que variam de $23^{\circ}$ a $27^{\circ} \mathrm{C}$, e que muitas espécies de mosquitos, a exemplo de Culex quinquefasciatus, como afirmam GOWDA e VIJAYAN (1993) e REISEN e col. (1992), desenvolvem melhor o ciclo gonotrófico para o estágio $\mathrm{V}$ de Christophers e Mer, nesta faixa de temperatura, portanto esperam-se encontrar altas proporções de fêmeas paridas ou na fase $V$ do desenvolvimento folicular nos diferentes habitats do parque Ecológico durante as estações em que as médias de temperatura correspondam a esta faixa de variação. 
A temperatura também é um dos fatores que regulam o tamanho médio do corpo do mosquito. Observações feitas por HARAMIS (1983), mostram que na primavera os mosquitos são maiores porque provem de larvas cujo desenvolvimento foi retardado no inverno. Nas estações subseqüentes as larvas, têm o seu desenvolvimento acelarado, resultando mosquitos menores.

Os resultados de estudos de variação de tamanho corpóreo do mosquito e seu significado com relação à obtenção do alimento (sangue), e transmissão de agentes etiológicos tem conduzido para prognósticos conflitantes.

Estudos de laboratório têm sugerido que mosquitos pequenos infectados por vírus, transmitem mais eficientemente do que mosquitos grandes. GRIMSTAD e HARAMIS (1984), observaram que larvas de Aedes triseriatus de criadouros pobres em alimento desenvolveram adultos pequenos que apresentaram alta taxa de infectividade ao vírus La Crosse, quando comparados aos indivíduos grandes.

NASCI (1986) e HARAMIS (1983), em estudos no campo evidenciaram que os mosquitos de tamanho pequeno, não vivem tanto quanto os grandes da mesma espécie, que tem um importante papel na transmissão de um agente etiológico, porque a probabilidade de obter o alimento, se infectar e posteriormente transmitir é maior do que a das coortes pequenas. Segundo os autores, as doenças veiculadas por culicideos podem estar relacionadas às condições ambientais que produzem grandes densidades de mosquitos, tão bem quanto às condições que produzem mosquitos grandes.

Visto que mosquitos de tamanho grande de populações naturais são mais bem sucedidos em obter o repasto sangüíneo, supõem-se encontrar neste estudo, mosquitos grandes com uma alta taxa de paridade. 
Alguns trabalhos no Brasil descreveram sobre aspectos relacionados à paridade e desenvolvimento ovariano para populações anofélicas, a exemplo de Anopheles aquasalis, Anopheles albitarsis s.l, Anopheles (Kerteszia)cruzii, e Aedes aegypti (BARATA 1988; KAKITANI 1992; MENDONZA e LOURENÇO-DE-OLIVEIRA 1996; KAKITANI e FORATTINI 2000; BARATA e col 2001).

A distribuição do tamanho do corpo das populações de mosquitos, bem como, a paridade e o desenvolvimento ovariano são aspectos associados à capacidade vetorial dessas populações. Já foram abordados conjuntamente na literatura de (Diptera:Culicidae) para algumas populações, como por exemplo: Anopheles gambiae, Culiseta melanura, Anopheles crucians, Anopheles darlingi, Mansonia dyari (LYIMO e TAKKEN 1993; LORENS e col 1990; HU e col 1993; LOUNIBOS e col 1995; LOUNIBOS e col 1990). Contudo são poucos os trabalhos que descreveram sobre esses aspectos para populações naturais e com potencial de veicular arbovírus.

Desta forma, diante da importância epidemiológica de Culex quinquefasciatus e Ochlerotatus scapularis e da conhecida dominância dessas populações em áreas do Parque Ecológico do Tietê, ecossistema natural inserido em ecossistema antrópico de alta densidade demográfica, decidiu-se por dar maior atenção às duas espécies de mosquitos em questão, ressaltando aspectos bioecológicos ainda não estudados para estes mosquitos, e relevantes para o entendimento da capacidade vetorial dessas espécies que proliferam em habitats do interior e periferia do parque. 


\section{OBJETIVOS}

\subsection{GERAL}

Conhecer aspectos bioecológicos de Culex quinquefasciatus e Ocherotatus scapularis abrigados em habitats do Parque Ecológico do Tietê, na cidade de São Paulo.

\subsection{ESPECÍFICOS}

Estudar a distribuição de Culex quinquefasciatus e Ochlerotatus scapularis segundo sexo em diferentes habitats do Parque Ecológico do Tietê, por meio de coletas em abrigos;

Para as espécies Culex quinquefasciatus e Ochlerotatus scapularis, estudar, ao longo das estações do ano:

- a paridade em seus abrigos, no interior e periferia do Parque Ecológico;

- o estado fisiológico das fêmeas (vazias, com sangue ou com ovos), em seus abrigos, no interior e periferia do Parque Ecológico;

- As possíveis variações sazonais no tamanho do corpo das populações.

Avaliar os possíveis efeitos do tamanho do corpo de Culex quinquefasciatus e Ochlerotatus scapularis em relação à paridade dessas populações. 


\section{MATERIAL E MÉTODOS}

\section{1. ÁREA DE ESTUDO}

Administrado pelo Departamento de Águas e Energia Elétrica de São Paulo (DAEE), O Parque Ecológico do Tietê (PET), ocupa duas áreas distintas ao longo do rio Tietê: uma área de 3000 hectares a oeste da Capital denominada Ilha de Tamboré e mais 14.000 hectares de área na zona leste da Capital denominada Parque Engenheiro Goulart (DAEE 1989).

A área escolhida para implantação deste projeto, Parque Engenheiro Goulart,

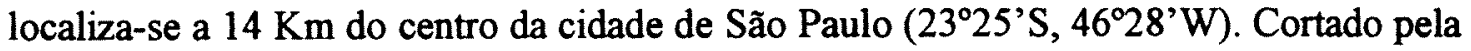
rodovia Airton Senna (SP-070), penetra em áreas pertencentes ao Munícipio de Guarulhos (DAEE 1989) (Figura 1).

A área de estudo foi delimitada em função de apresentar: áreas de mata residual com predominio de eucaliptos, áreas florestadas e abertas, um complexo de lagoas associadas ao rio Tietê, cujas águas apresentam alto teor de poluição e eutrofização, numerosos vertebrados silvestres, aves migratórias e autóctones, córregos afluentes do rio Tietê utilizados pela população humana habitante da periferia do Parque Ecológico (DAEE, 1989) Todas essas características favorecendo as populações de Ochlerotatus scapularis e Culex quinquefasciatus, no que diz respeito ao criadouro, abrigo e recurso alimentar.

Utilizado como área de lazer nos finais de semana, o PET, proporciona aos seus usuários uma série de atividades educacionais, recreativas, esportivas recebendo mensalmente cerca de 40 mil visitantes (DAEE, 1989). 

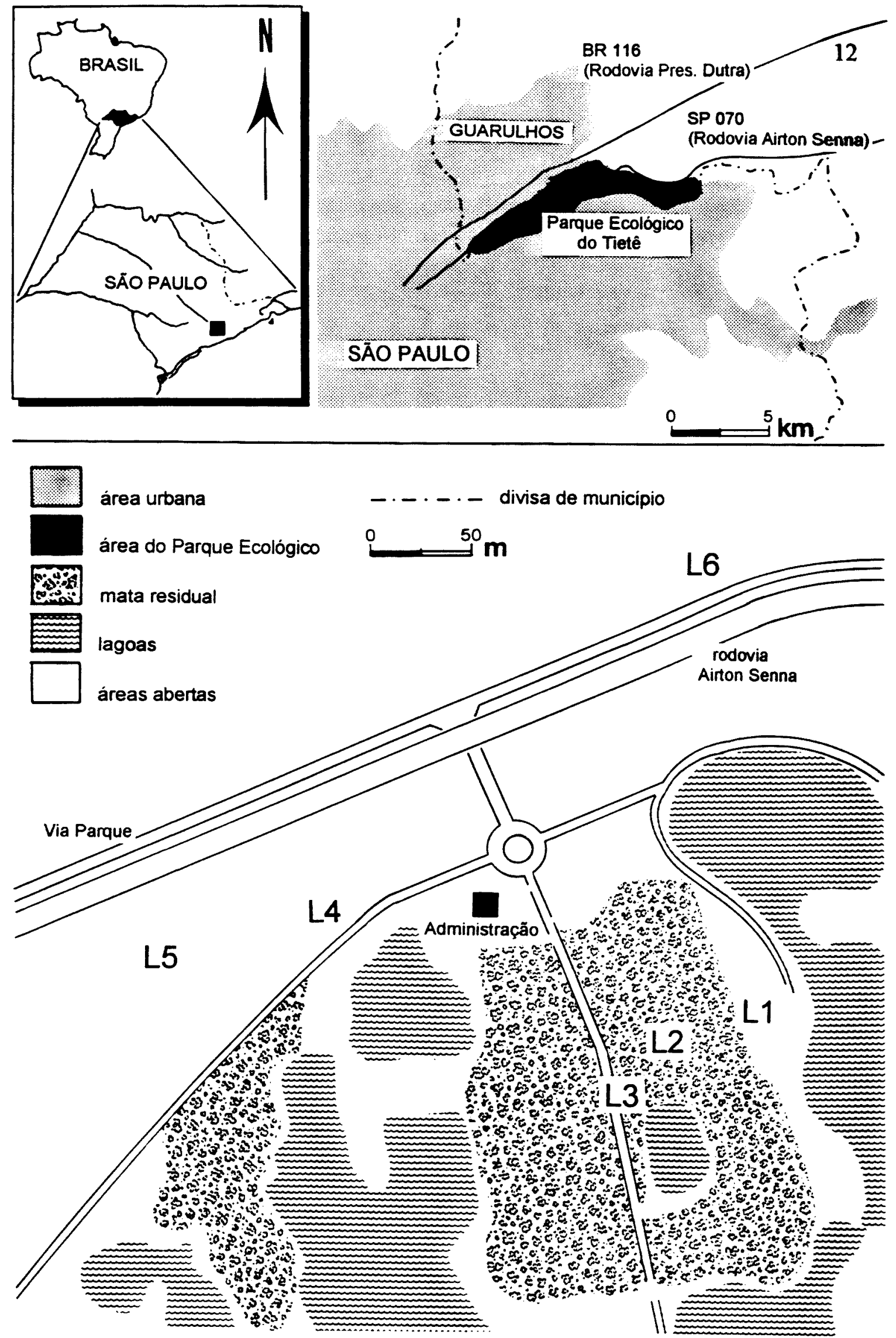

Figura 1. Localização dos habitats onde foram realizadas as coletas no Parque Ecológico do Tietê, cidade de São Paulo.(L-1 - habitat parcialmente coberto por eucaliptos, L-2 habitat de mata, L-3 - habitat de margem de mata, L-4 - habitat densamente coberto por eucaliptos, L-5 habitat de campo-brejo, L-6 - habitat de margem de riacho poluido) 


\subsection{PROCEDIMENTOS EM CAMPO}

Os mosquitos foram coletados quinzenalmente, durante o periodo de $25.1 \mathrm{II} .1999$ a 09.I.2001. As coletas foram realizadas em seis habitats, considerados abrigos para os mosquitos no Parque Ecológico do Tietê: L.1 - habitat semi coberto por eucaliptos, próximo à área de lazer, L.2 - habitat coberto por mata - mata residual, com presença de domicilio e de animais domiciliados, L.3 - habitat de margem de mata, próximo à área de recepção de animais silvestres, L.4 - habitat densamente coberto por Eucaliptos, com presença de domicilio e de animais domiciliados, L.5 - habitat de campo-brejo, adjacente a rodovia Airton-Senna (SP - 070), L.6 - habitat de margem de riacho poluído, área periférica ao parque com presença de inúmeros domicilios construidos de forma clandestina (Figura 1 e Figura 13, Anexo 3).

Para as coletas utilizou-se aspirador elétrico manual segundo modelo básico proposto por NASCI (1981). O aspirador era acionado por 15 minutos em movimento, em diferentes habitats do Parque Ecológico do Tietê, durante o período da manhã (Figura 14, Anexo 4 ).

Os exemplares coletados foram sacrificados no interior de sacos plásticos contendo algodão embebido em clorofórmio e colocados imediatamente em frascos plásticos, mantidos em geladeira de isopor com gelo reciclável, sendo posteriormente conduzidos ao laboratório.

Durante o período de 04.IV.2000 a 09.I.2001, uma amostra do material coletado foi utilizada para verificar o efeito do tamanho dos mosquitos no estado de paridade e a variação sazonal do tamanho do corpo das populações de mosquitos aqui estudadas. 
Dados climatológicos foram obtidos na Estação Meteorológica de Superfície do Aeroporto de Guarulhos, pertencente a INFRAERO - Empresa de Infraestrutura Aero Portuária, distante aproximadamente7 $\mathrm{Km}$ do Parque Ecológico do Tietê.

\subsection{PROCEDIMENTOS EM LABORATÓRIO}

No laboratório os mosquitos foram identificados, as fêmeas de Culex quinquefasciatus e Ochlerotatus scapularis foram separadas para dissecção, os machos foram contados e separados em caixinhas entomológicas, para posterior comparação com a proporção de fêmeas.

As fêmeas foram selecionadas das amostras para dissecção em um processo aleatório, onde ocorrendo até 33 fêmeas de mosquitos na amostra, 100\% delas eram dissecadas, de 34 a $123,23 \%+33$ eram dissecadas, de 124 a $409,5 \%+33$ eram dissecadas, acima de 409 fêmeas, $33+2,5 \%$ eram dissecadas.

Os mosquitos foram examinados, para determinar os estágios de SELLA (1920), processo de digestão do sangue ingerido, e dissecados para determinar os estádios de CHRISTOPHERS (1911) e MER (1936), para o desenvolvimento do ovo, segundo indicação de CHARLWOOD (1980).

Os ovários dissecados de acordo com a técnica divulgada por FORATINNI (1962), foram postos para secar em lâminas para a aplicação do método traqueal em microscópio, (DETINOVA, 1962), que tem sido amplamente utilizado com sucesso para determinar a proporção de fêmeas paridas. Este método consiste na observação das traqueíolas presentes nos ovários, sendo que fêmeas nuliparas apresentam traqueíolas 
enoveladas e fêmeas paridas (que desenvolveram ovos e ovipuseram), via de regra apresentam traqueíolas distendidas (HOC, 1996).

A avaliação do tamanho do corpo do mosquito foi feita utilizando-se o comprimento da asa (SIEGEL e col. 1994). As asas foram removidas e fixadas entre lâmina e lamínula com auxilio de bálsamo do Canadá. As medições foram realizadas da base da alula até a margem apical, excluindo as franjas, com uma ocular micrométrica de $20 X$.

\subsection{TRATAMENTO DOS DADOS}

Para analisarmos a distribuição por sexo das populações de Ochlerotatus scapularis e Culex quinquefasciatus nos diferentes habitats foi utilizado o teste do quiquadrado segundo as especificações de SIEGEL (1981).

A distribuição qui-quadrado também foi utilizada na verificação das proporções de fềmeas paridas e nuliparas em relação aos diferentes habitats.

O nível de significância de qui-quadrado, adotado nas duas situações foi o de $5 \%$ $(\alpha=0,05)$.

Análise de resíduos para as tabelas de contingência maiores que $2 \times 2$, foi realizada, segundo PEREIRA (1999), objetivando verificar diferenças entre as freqüências esperadas e observadas expressas em unidades de desvio padrão através da formula:

$$
\text { Zres }=0-E /(\sqrt{E} \sqrt{ }(1-T C / T G)(1-T L / T G))
$$

Onde: $O=$ Freqüência observada, $E=$ Freqüência esperada, $T G=$ Total geral da tabela, $\mathrm{TC}=$ Total da coluna, $\mathrm{TL}=$ Total da linha. 
Para o nível de significância de 5\%, houve excesso de ocorrências quando o resíduo foi superior a 1,96 e falta de ocorrências quando o residuo foi inferior a - 1,96. O excesso de ocorrências foi considerada a medida responsável pelos resultados do teste de qui-quadrado.

O teste não paramétrico de Kruskal-Wallis (SIEGEL 1981), foi utilizado quando se objetivou comparar a distribuição sazonal de fềmeas paridas e nuliparas de Culex quinquefasciatus e Ochlerotatus scapularis, no interior e periferia do Parque Ecológico.

Por ser o habitat de riacho poluído (periferia), um abrigo muito favorável ao Culex quinquefasciatus, e nem um pouco favorável para Ochlerotatus scapularis, na comparação da significância da distribuição sazonal, através do teste de Kruskal-Wallis, entre os estados fisiológicos (parida e nulipara) das duas espécies, julgou-se que a inflação numérica gerada por este habitat poderia criar um viés, e optou-se pelo agrupamento dos habitats do interior do parque e a separação do habitat de riacho poluido caracterizado como periferia do parque. O mesmo acontecendo quando da comparação através da análise do qui-quadrado paras as fêmeas paridas e nuliparas das duas espécies distribuídas nos diferentes habitats.

A comparação entre os comprimentos médios da asa, dentro de cada uma das espécies, nas estações seca e chuvosa, inverno-verão e primavera-outono (variáveis de agrupamento), foi feita através da análise de variância (ANOVA) e o teste de KruskalWallis $(\mathrm{H})$.

A análise de variância (ANOVA), de acordo com SOKAL e ROHLF (1981), foi utilizada quando foi possivel fazer as suposições de normalidade, e de homocedasticidade (variâncias homogêneas), das amostras comparadas. A 
homocedasticidade das variâncias das amostras comparadas foram verificadas através do teste de Bartletts com $95 \%$ de confiança.

Não obstante ambos os testes levassem às mesmas conclusões, preferiu-se o teste não paramétrico de Kruskal-Wallis $(\mathrm{H})$, quando o teste de Bartlett indicou heterocedasticidade (variâncias diferentes), das amostras comparadas, mesmo quando a mediana ou percentil 50 foi razoavelmente próximo da média, o que indicaria normalidade da distribuição.

Tanto para a ANOVA quanto para o teste de Kruskal-Wallis, o nível de significância adotado, foi o de $5 \%(0,05)$.

O efeito do tamanho sobre o número de fêmeas paridas foi verificado através da análise de regressão univariada, (segundo SOKAL e ROFLF, 1981), sendo a variável dependente $(y)$, número de fêmeas paridas por data de coleta, e a independente $(x)$ média do comprimento da asa do mosquito em $\mathrm{mm}$. As variáveis sofreram a transformação logarítmica, sugeridas por (SIEGEL e col. 1992; ULLOA e col. 1997; HU e col. 1993), para se evitar a heterocedasticidade.

Os bancos de dados foram criados utilizando-se o programa Foxpro 2.5 para Windows.

A distribuição qui-quadrado foi processada através do programa Excel para Windows versão 2000.

Analise de variância (ANOVA), a análise não paramétrica de Kruskal-Wallis e a análise de regressão, foram processadas através do programa Epi Info versão 6.04 (DEAN e col. 1994). 


\section{RESULTADOS}

\subsection{DISTRIBUIÇÃO DE Culex quinquefasciatus E Ochlerotatus scapularis} SEGUNDO SEXO EM DIFERENTES HABITATS.

A distribuição de Culex quinquefasciatus e Ochlerotatus scapularis segundo sexo nos diferentes habitats, que constituem abrigos para as duas populações investigadas no Parque Ecológico do Tietê, durante o período de 25.II.1999 a 09.1.2001, está representada nas tabelas 1 e 2 .

Observa-se que do total de 31.792 exemplares de Culex quinquefasciatus, $24.081(75,7 \%)$ foram constituídos por machos e $7.711(24,2 \%)$ por fêmeas da espécie. O habitat de margem de riacho poluído contribui com 25.969 exemplares, o maior número comparado aos outros habitats do parque, distribuídos em 6.227 $(24,0 \%)$ fêmeas e $29.742(76,0 \%)$ machos para aquele habitat (tabela 1$)$.

A segunda maior abundância de Culex quinquefasciatus foi no habitat semicoberto por eucaliptos, ocorrendo respectivamente, 1.319 (70,6\%) exemplares machos e $548(29,4 \%)$ fêmeas. Este habitat apresentou o maior número de fêmeas e de machos comparado aos outros, depois do habitat de margem de riacho poluído (Tabela 1).

Observa-se na tabela 1 , que $o$ percentual de machos de Culex quinquefasciatus, coletados nos diferentes habitats, foi sempre superior ao percentual de fêmeas. As variáveis qualitativas, habitat e sexo do mosquito, estiveram associadas com 5 graus de liberdade e qui-quadrado observado de 122,6. A associação foi altamente significante $(p<0,001)$. 
Tabela 1. Distribuição de Culex quinquefasciatus segundo sexo em diferentes habitats do Parque Ecológico do Tietê, na cidade de São Paulo, durante o período de 25.II.1999 a 09.I.2001.

\begin{tabular}{lrrrrr}
\hline habitat & \multicolumn{3}{c}{ sexo } \\
\cline { 2 - 6 } & fêmea & \multicolumn{1}{c}{$\%$} & macho & \multicolumn{1}{c}{$\%$} & Total \\
\hline L1 = semi coberto por eucaliptos & 548 & 29,4 & 1319 & 70,6 & 1867 \\
L2 = coberto por mata & 340 & 28,9 & 835 & 71,1 & 1175 \\
L3 = margem de mata & 246 & 26,2 & 692 & 73,8 & 938 \\
L4 = densamente coberto por eucaliptos & 191 & 14,5 & 1128 & 85,5 & 1319 \\
L5 = campo-brejo & 159 & 30,3 & 365 & 69,7 & 524 \\
L6 = margem de riacho poluído & 6227 & 24,0 & 19742 & 76,0 & 25969 \\
\hline Total & 7711 & 24,2 & $\mathbf{2 4 0 8 1}$ & 75,7 & 31792 \\
$\mathbf{X}^{2}$ ob $=\mathbf{1 2 2 , 6}$ & \multicolumn{5}{c}{$\mathbf{x}^{2}$ crtico (5g) $=\mathbf{2 0 , 5 1}$} \\
\hline
\end{tabular}

A análise de resíduos, revelou diferenças significativas entre as freqüências esperadas e observadas no nível de 5\%, para a distribuição percentual de fêmeas nos habitats: semicoberto por eucaliptos $($ Zres $=5,3)$, de mata $($ Zres $=3,8)$, e de campobrejo $($ Zres $=3,3)$.

A medida de maior responsabilidade pelos resultados do teste do quiquadrado foi provavelmente à ocorrência de $1128(85,5 \%)$ machos de Culex quinquefasciatus no habitat densamente coberto por eucaliptos, que correspondeu a um Zres de 8,5.

Na tabela 2, observa-se que do total de 6.351 exemplares de Ochlerotatus scapularis coletados nos diferentes habitats, $3.459(54,5 \%)$, foi constituído por fềmeas e $2.892(45,5 \%)$ por machos da espécie. O habitat coberto por mata, foi o que contribuiu com o maior número de exemplares (2.088), distribuídos em 1.149 $(55,0 \%)$ fềmeas e $939(45,0 \%)$ machos da espécie.

Excetuando o habitat margem de mata (tabela 2), a partição entre os sexos para Ochlerotatus scapularis nos diferentes habitats apresentou pequena diferença percentual. Neste habitat ocorreram: $201(26,6 \%)$ exemplares machos contra 556 $(73,4 \%)$ fêmeas. A freqüência de fêmeas também foi maior que a dos machos nos 
habitats de mata e densamente coberto por eucaliptos. Essa distribuição de percentual foi altamente significante com $(p<0,001), 5$ graus de liberdade e quiquadrado observado de 143,8 .

Tabela 2. Distribuição de Ochlerotatus scapularis segundo sexo em diferentes habitats do Parque Ecológico do Tietê, na cidade de São Paulo, durante o período de 25.II.1999 a 09.I.2001.

\begin{tabular}{|c|c|c|c|c|c|}
\hline \multirow[t]{2}{*}{ habitats } & \multicolumn{3}{|c|}{ sexo } & \multirow[b]{2}{*}{$\%$} & \multirow[b]{2}{*}{ Total } \\
\hline & fêmea & $\%$ & macho & & \\
\hline L1 = semi coberto por eucaliptos & 691 & 48,2 & 742 & 51,8 & 1433 \\
\hline $\mathrm{L} 2$ = coberto por mata & 1149 & 55,0 & 939 & 45,0 & 2088 \\
\hline $\mathrm{L} 3=$ margem de mata & 556 & 73,4 & 201 & 26,6 & 757 \\
\hline $\mathrm{L} 4=$ densamente coberto por eucaliptos & 762 & 52,3 & 694 & 47,7 & 1456 \\
\hline $\mathrm{L} 5=$ campo-brejo & 289 & 49,1 & 300 & 50,9 & 589 \\
\hline$L 6=$ margem de riacho poluído & 12 & 42,9 & 16 & 57,1 & 28 \\
\hline $\begin{array}{l}\text { Total } \\
X^{2} \text { ob }=143,8\end{array}$ & 3459 & 54,5 & $\begin{aligned} 2892 \\
\text { fitico }(5 \mathrm{gl})\end{aligned}$ & $\begin{array}{l}45,5 \\
20,51\end{array}$ & 6351 \\
\hline
\end{tabular}

A distribuição das freqüências esperadas e observadas de machos de Ochlerotatus scapularis nos habitats semi coberto por eucaliptos e de campo-brejo foram significativas, apresentando resíduos maiores que 1,96 , respectivamente com $($ Zres $=5,4)$ e $($ Zres $=2,8)$. Provavelmente a ocorrência de $556(73,4 \%)$ fềmeas no habitat margem de mata, que corresponde a um Zres de 11,2, seja a medida de maior responsabilidade pelos resultados do teste do qui-quadrado para a distribuição de Ochlerotatus scapularis segundo sexo nos diferentes habitats. 


\subsection{DISTRIBUIÇÃo de FÊMEAS NULÍPARAS E PARIDAS PARA AS ESPÉCIES DE Culex quinquefasciatus E Ochlerotatus scapularis EM DIFERENTES habitats, no Parque Ecológico do Tietê.}

As tabelas 13 e 14, que constam dos anexos 1 e 2, mostram o número de fêmeas paridas e nulíparas das populações de Culex quinquefasciatus e Ochlerotatus scapularis, dissecadas de amostras coletadas em diferentes habitats (abrigos), no decorrer de dois anos de coletas quinzenais, no Parque Ecológico do Tietê (PET).

Foram dissecadas 1424 fềmeas de Culex quinquefasciatus e 855 de Ochlerotatus scapularis, seguindo o padrão de amostragem citado em material e métodos.

A distribuição percentual das fêmeas paridas e nulíparas das duas populações de mosquitos nos diferentes habitats, pode ser verificada nas figuras 2 e 3 . Observase que foi coletado um percentual maior de fêmeas nulíparas em todos os habitats para as duas espécies estudadas comparado as fêmeas paridas, com exceção do habitat de margem de riacho poluído, para Ochlerotatus scapularis, onde o percentual maior foi para fêmeas paridas. Essa diferença foi bem acentuada para Culex quinquefasciatus. Para Ochlerotatus scapularis a diferença foi um pouco menor.

Na figura 2, nota-se $518(36,4 \%)$ de fềmeas nulíparas contra $78(5,5 \%)$ de fêmeas paridas de Culex quinquefasciatus, presentes no habitat de margem de riacho poluido, periferia do PET, os maiores percentuais para os dois estados fisiológicos comparados aos outros habitats do parque. Neste mesmo habitat Ochlerotatus scapularis apresentou três fêmeas paridas e uma nulípara (figura 3).

Excluindo o habitat de margem de riacho poluido, indicado pelas figuras 2 e 3, como preferencial para a proliferação de Culex quinquefasciatus, o teste do qui- 
quadrado indicou para esta espécie, que a diferença percentual entre fêmeas paridas e nuliparas registradas nos diferentes habitats (figura 2), é muito significante quando comparada às diferenças percentuais registradas para Ochlerotatus scapularis nos mesmos habitats (figura 3). A significância estatística dos valores percentuais registrados para o estado fisiológico de Culex quinquefasciatus foi constatada com quatro graus de liberdade, qui-quadrado observado de 28,7 e $(\mathrm{p}<0,001)$. Também com quatro graus de liberdade, os valores registrados para Ochlerotatus scapularis foram ( $p=0,01$ e qui-quadrado observado 13,8$)$.

A análise de resíduos revelou que a ocorrência de $25(1,8 \%)$ fêmeas paridas de Culex quinquefasciatus no habitat de campo-brejo, foi à medida de maior responsabilidade pelos resultados do teste do qui-quadrado, que correspondeu a um resíduo (Zres $=4,2)$, no nível de significância de $5 \%$.

Com relação a Ochlerotatus scapularis verificou-se que 107(12,5\%) fềmeas paridas registradas no habitat densamente coberto por eucaliptos foi a medida de maior impacto sobre o valor de qui-quadrado. O valor do resíduo verificado entre as freqüências esperadas e observadas foi de $($ Zres $=3,0)$.

Comparando-se o percentual de fêmeas paridas e nulíparas, de Culex quinquefasciatus, provenientes do habitat de margem de riacho poluído, periferia do parque, com fềmeas nas mesmas condições fisiológicas dissecadas para o total dos habitats no interior do parque (figura 2), obteve-se: $90(6,3 \%)$ paridas e $738(51,8 \%)$ nulíparas contra $78(5,5 \%)$ paridas e $518(36,4 \%)$ nuliparas da periferia. Constatouse que o valor de qui-quadrado observado para esses percentuais foi de 1,64, com $p=$ 0,20. Ou seja, não existe diferença estatísticamente significante.

Com relação ao percentual de distribuição de fêmeas paridas para Ochlerotatus scapularis e Culex quinquefasciatus nos diferentes habitats, verifica-se 
que, a primeira espécie apresentou um maior número de fêmeas paridas comparado à segunda. Essa diferença foi significante $(p=0,01$ e qui-quadrado observado $=16,6)$. Feita a mesma comparação para as fềmeas nuliparas o teste revelou um qui-quadrado de 31,5 , altamente significante com $(p<0,001)$.

Verificou-se através da análise de resíduos que, 21 fêmeas paridas de Culex quinquefasciatus presentes no habitat de margem de mata, foi à medida que mais contribuiu com o valor do qui-quadrado ( $\mathrm{Zres}=2,6$ ), no nível de $5 \%$.

$\mathrm{Na}$ comparação de fêmeas nulíparas de Ochlerotatus scapularis e Culex quinquefasciatus, entre os habitats pesquisados, observou-se que, 274 fêmeas nuliparas de Culex quinquefasciatus presentes no habitat semi coberto por eucaliptos, foi à medida de maior responsabilidade com relação associação verificada pelo teste do qui-quadrado. O resíduo observado entre as frequêencias esperada e observada foi de (Zres $=5,3)$, no nível de $5 \%$.

O habitat semi coberto por eucaliptos (figura 2), foi o que apresentou o maior percentual $274(19,2 \%)$, de fêmeas nuliparas de Culex quinquefasciatus, depois do habitat L-6. Os habitats de mata, margem de mata e densamente coberto por eucaliptos, apresentaram uma pequena diferença percentual em relação ao número de fêmeas nulíparas. Foram encontrados respectivamente os seguintes percentuais para esses habitats: $120(8,4 \%), 121(8,5 \%)$ e $137(9,6 \%)$, comparados ao total de fêmeas dissecadas de amostras de todos os habitats.

Excluindo o habitat de margem de riacho poluido, os habitats de campo brejo e margem de mata apresentaram os maiores percentuais de fêmeas paridas de Culex quinquefasciatus, respectivamente $25(1,8 \%)$ e $21(1,5 \%)$, comparado aos outros habitats (figura 2). 
Observa-se na figura 3 que, os maiores percentuais de fêmeas parida $107(12,5)$ e nulípara $130(15,2 \%)$ para Ochlerotatus scapularis, em relação ao total de fêmeas dissecadas em todos os habitats, foram verificados no habitat densamente coberto por eucaliptos.

Praticamente o mesmo percentual de distribuição de fêmeas nulíparas foi verificado para os habitats, semi coberto por eucaliptos, de mata e densamente coberto por eucaliptos. Foram registradas respectivamente nesses habitats: 124 $(14,5 \%), 123(14,4 \%)$ e $130(15,2 \%)$, fềmeas nulíparas em relação ao total de fềmeas dissecadas para Ochlerotatus scapularis em todos os habitats (figura 3).

\section{Culex quinquefasciatus}

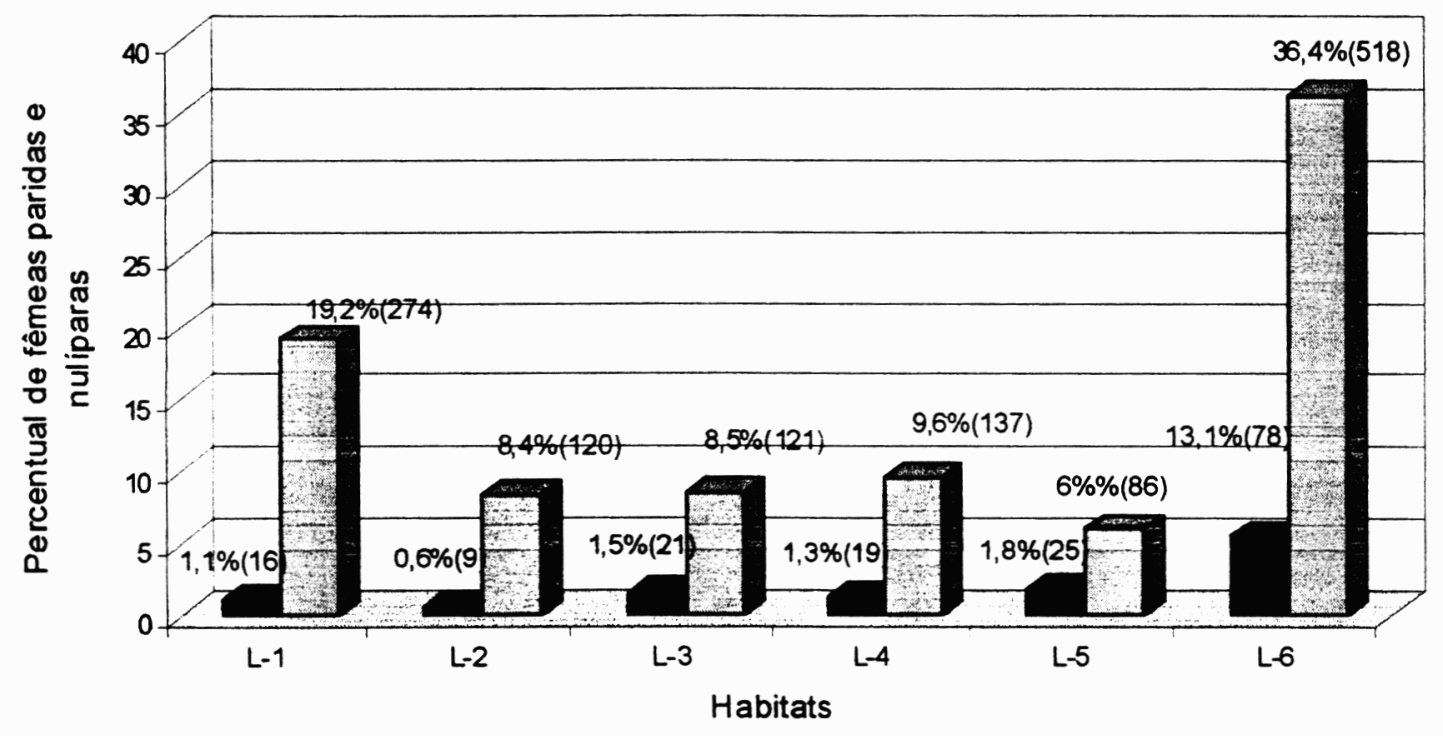

parida $\square$ nulipara

Figura 2. Percentual de fêmeas paridas e nuliparas de Culex quinquefasciatus, coletadas com aspirador em diferentes abrigos do Parque Ecológico do Tietê na cidade de São Paulo de 25.II.1999 a 09.I.2001

L- 1 = habitat semi coberto por eucaliptos, L-2 = habitat coberto por mata, L-3 = habitat de margem de mata, L-4- habitat densamente coberto por eucaliptos, L-5 = habitat aberto campo-brejo, L- $6=$ habitat aberto margem de riacho poluído. 


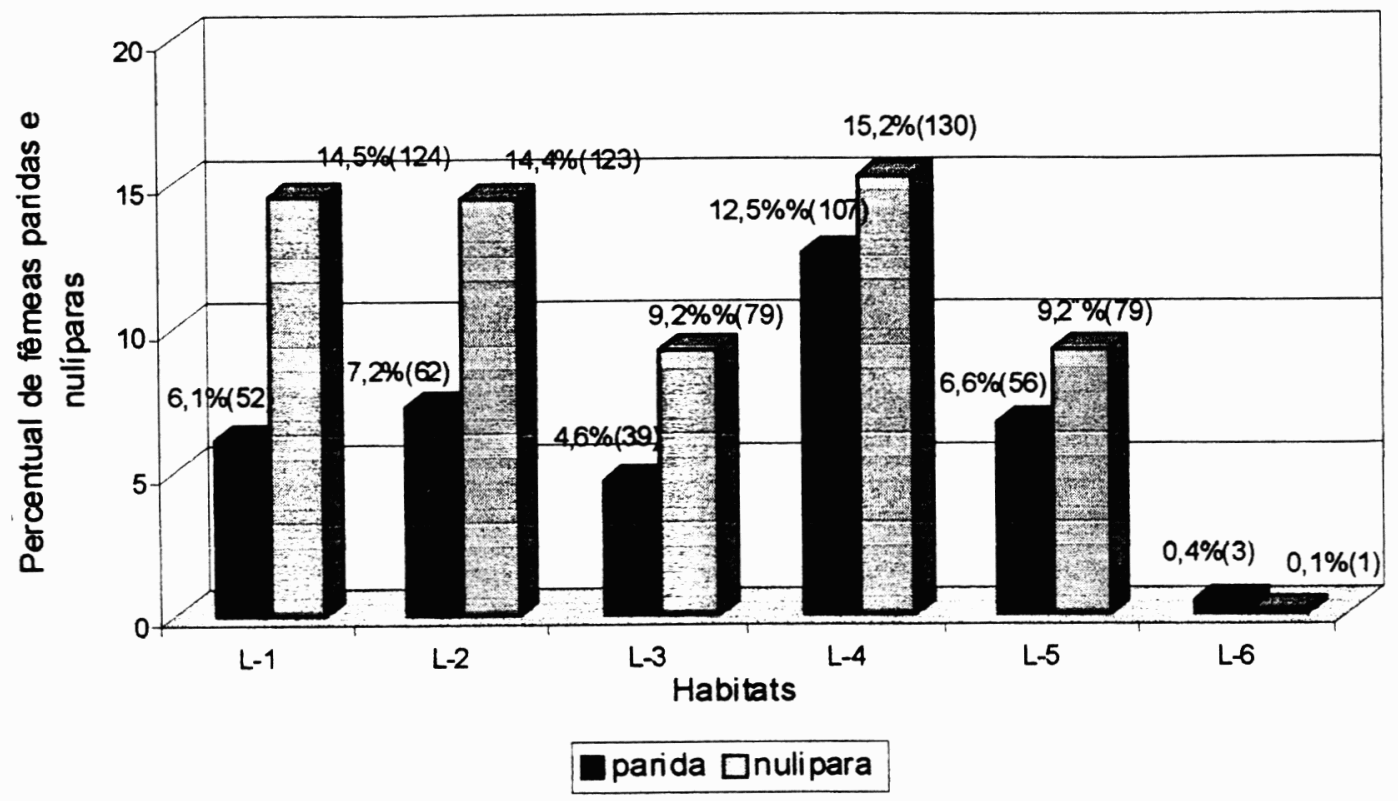

Figura 3. Percentual de fêmeas paridas e nulíparas de Ochlerotatus scapularis coletadas com aspirador em diferentes abrigos do Parque Ecológico do Tietê, na cidade de São Paulo, de 25.II.1999 a 09.I.2001

L- 1 = habitat semi coberto por eucaliptos, $\mathrm{L}-2=$ habitat coberto por mata, $\mathrm{L}-3=$ habitat de margem de mata, L-4- habitat densamente coberto por eucaliptos, L-5 = habitat aberto campo-brejo, L-6 = habitat aberto margem de riacho poluido

4.3 Distribuição de fÊMEAS PARIdas E NuLÍPARAS DE Culex quinquefasciatus E Ochlerotatus scapularis AO LONGO DAS ESTAÇÕES DO ANO NO INTERIOR E PERIFERIA DO PARQUE ECOLÓGICO dO TIETÊ.

Nas figuras 4, 5 e 6, observa-se a distribuição de fêmeas nulíparas e paridas para Culex quinquefasciatus e Ochlerotatus scapularis, agrupada por datas, de coletas realizadas quinzenalmente durante dois anos consecutivos (25.II.1999 a 09.I.2001). As datas foram agrupadas, objetivando confirmar a presença de sazonalidade. 
A significância estatística dos valores proporcionais encontrados para as fêmeas nulíparas e paridas de Ochlerotatus scapularis e Culex quinquefasciatus, ao longo da distribuição sazonal, foi verificada através do teste não paramétrico de Kruskal-Wallis (H).

Por ser o habitat de margem de riacho poluido (periferia), um abrigo muito favorável ao Culex quinquefasciatus, como mencionado em material e métodos, os dados aqui são apresentados agrupados para os habitats do interior do parque em comparação com os dados da periferia.

As fêmeas nuliparas de Culex quinquefasciatus foram registradas ao longo da estação seca (outono-inverno) e chuvosa (primavera-verão), na periferia e interior do Parque Ecológico, apresentando picos durante estes períodos. As fêmeas paridas foram proporcionalmente mais expressivas durante a estação chuvosa (primaveraverão), tanto no interior como na periferia do parque (Figuras 4 e 5 ).

Os valores percentuais máximos registrados para fêmeas paridas de Culex quinquefasciatus na periferia e interior do parque, durante a primavera e início de verão, coincidem com os valores máximos encontrados para o número de fềmeas da espécie, capturadas durante o mesmo periodo (figura 7). Durante a primavera e início de verão, registrou-se médias de temperatura acima de $20^{\circ} \mathrm{C}$ (figura 8).

Os picos de distribuição de fêmeas nuliparas durante os períodos de primavera-verão, foram mais altos comparados aos do outono e inverno. O teste de Kruskal-Wallis indicou para esta diferença valor de $\mathrm{H}=3,3$ e de $\mathrm{p}>0,05(\mathrm{p}=$ 0,0686), revelando que não se trata de uma diferença significativa. Na periferia do parque (figura 5), essa distribuição, como a própria proporção de fêmeas nuliparas indica, foi ainda menos significativa $(\mathrm{H}=2,09$ e $\mathrm{p}=0,148)$ (figura 4). 
Com relação à distribuição de fêmeas paridas de Culex quinquefasciatus, ao longo dos períodos de seca e de chuva, a análise estatística revelou resultados significativos sendo a distribuição da periferia $(H=6,4$ e $p=0,01)$, mais significativa que a do interior do Parque Ecológico $(\mathrm{H}=5,4$ e $\mathrm{p}=0,02)$.

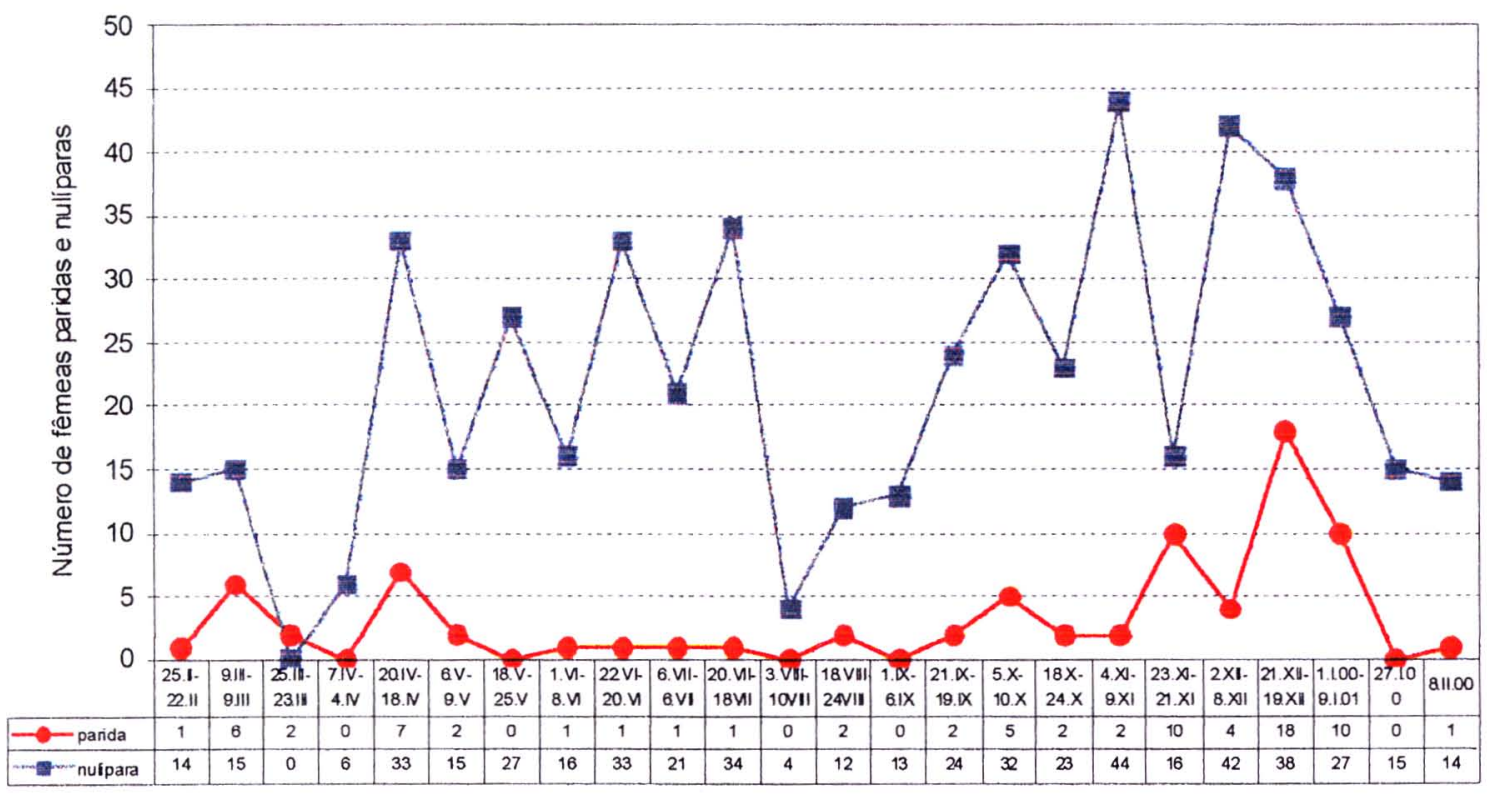

Figura 4. Número de fêmeas paridas e nulíparas de Culex quinquefasciatus, dissecadas de amostras coletadas com aspirador em habitat que representa abrigo, margem de riacho poluído, na periferia do Parque Ecológico do Tietê, cidade de São Paulo, durante o período de 26.II.1999 a 09.I.2001. 
Culex quinquefasciatus

Interior do PET $(L 1+L 2+L 3+L 4+L 5)$

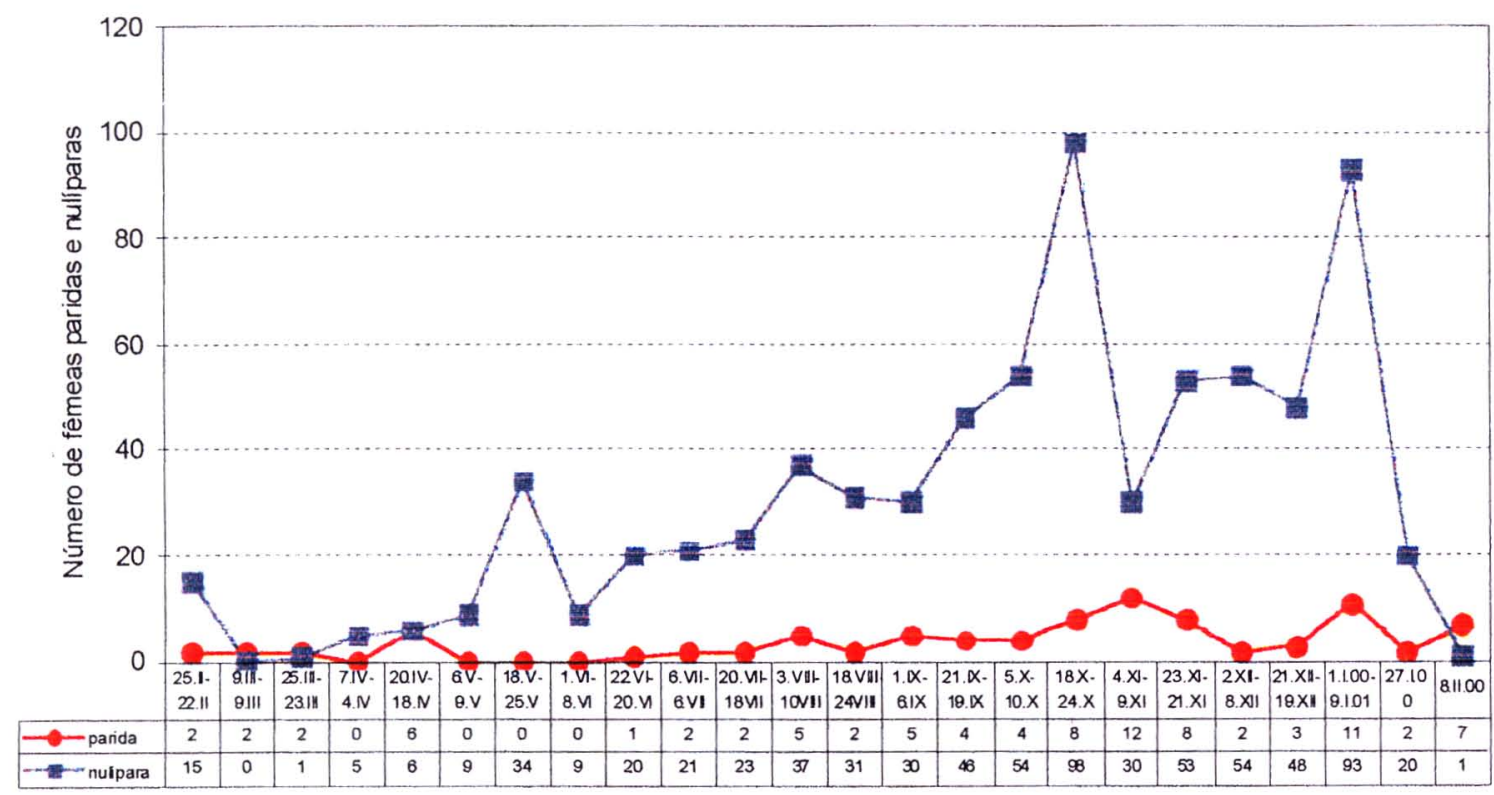

Figura 5. Número de fêmeas paridas e nulíparas de Culex quinquefasciatus, dissecadas de amostras coletadas com aspirador em habitats que representam abrigos no interior do Parque Ecológico do Tietê, na cidade de São Paulo, de 25.II.1999 a 09.I.2001.

Na figura 6, observa-se que as fêmeas paridas e nulíparas de Ochlerotatus scapularis apresentaram o mesmo padrão de variação sazonal. Verificam-se picos durante o período chuvoso (primavera-verão), para os dois estados fisiológicos. As fêmeas paridas foram numericamente mais expressivas durante o final da primavera. Os valores mais altos para as fêmeas nulíparas foram encontrados durante o período do verão, coincidindo com os valores médios mais altos de temperatura $\mathrm{e}$ precipitação pluviométrica (figura 8).

Verifica-se nas figura 7 e 6, que a distribuição sazonal das fêmeas de Ochlerotatus scapularis é semelhante à distribuição de fêmeas nulíparas e paridas para essa espécie. 
Ochlerotatus scapularis

interior do PET $(L 1+L 2+L 3+L 4+L 5)$

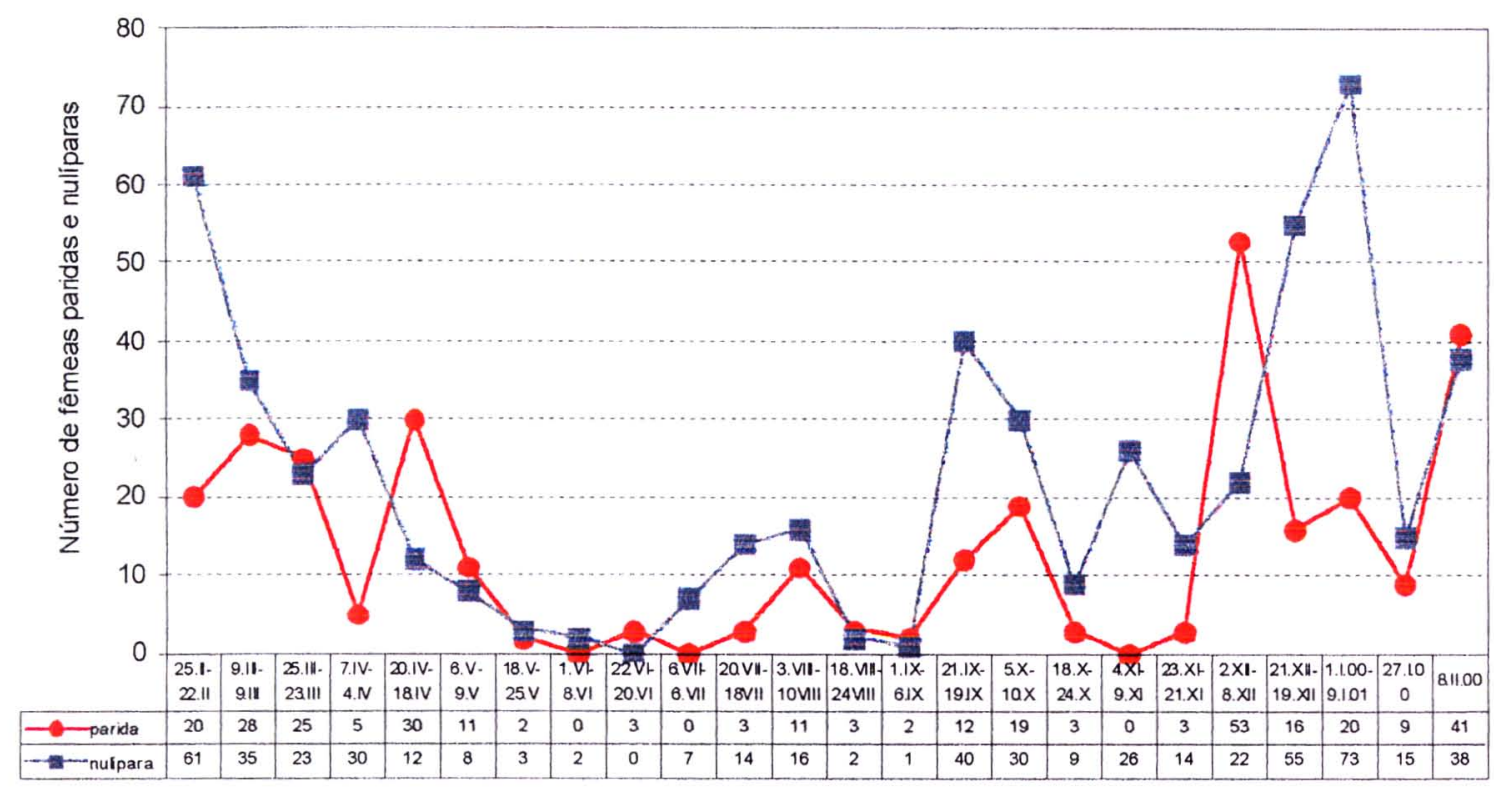

Figura 6. Número de fêmeas paridas e nulíparas de Ochlerotatus scapularis, dissecadas de amostras coletadas com aspirador em habitats que representam abrigos no interior do Parque Ecológico do Tietê, na cidade de São Paulo, durante o período de 25.II. 1999 a 09.I.2001.

Comparando-se o número de fêmeas de Ochlerotatus scapularis paridas em relação ao período seco e chuvoso (variável de agrupamento), através da análise de variância não paramétrica de Kruskal-Wallis, obteve-se um valor de $\mathrm{H}=3,673$ com um grau de liberdade e $p=0,055$. Com relação às fêmeas nulíparas a mesma análise revelou um $\mathrm{H}=10.8$ e $\mathrm{p}=0,001$.

Como o valor assumido para a significância do teste foi o de $p=0,05(5 \%)$, este indicou que existe uma diferença significativa na distribuição de fêmeas nulíparas ao longo dos períodos de seca e de chuva, não acontecendo com as paridas que apresentaram um $\mathrm{p}>5 \%$. 


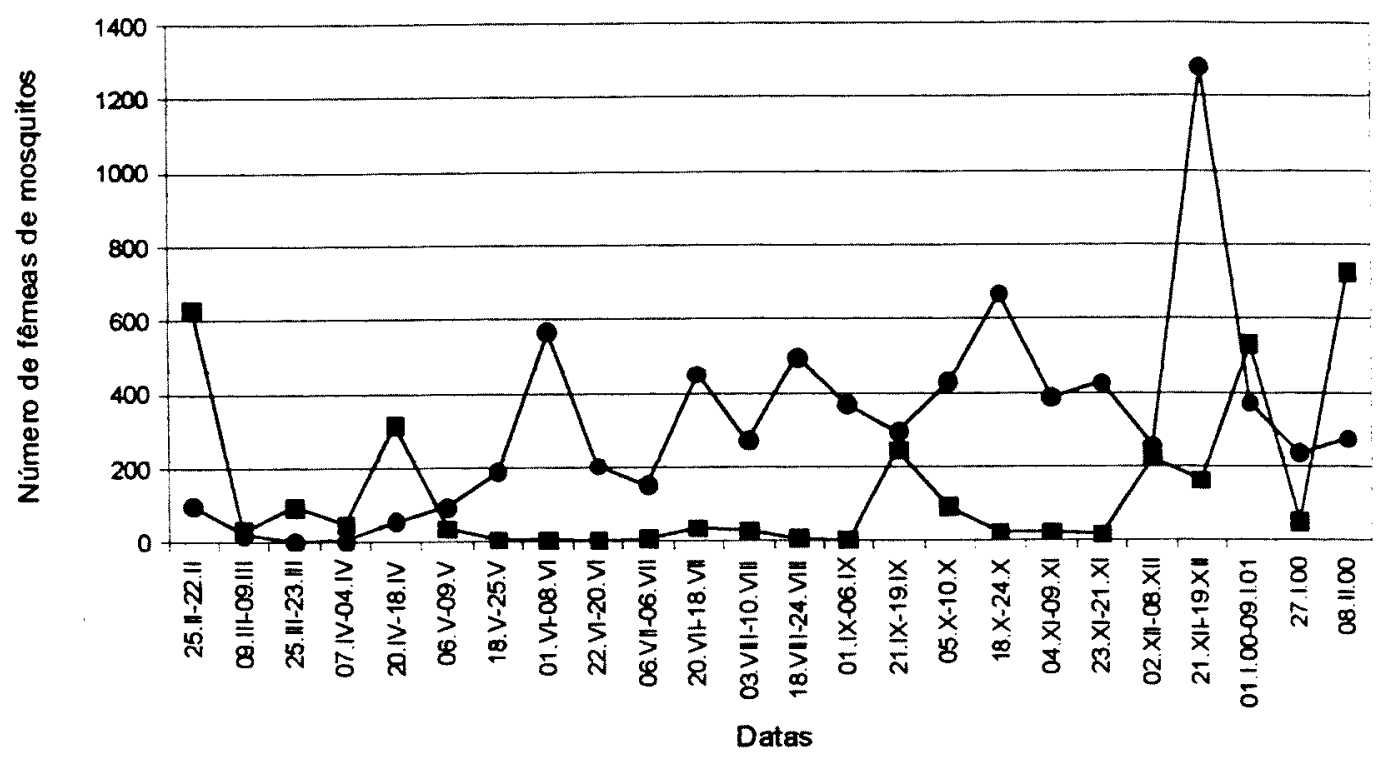

\section{$\rightarrow-$ Culex $\rightarrow$ - Ochlerotatus}

Figura 7. Distribuição sazonal das fêmeas de Ochlerotatus scapularis e Culex quinquefasciatus no Parque Ecológico do Tietê, na cidade de São Paulo, durante o periodo de 25.II.1999 a 09.I.2001.

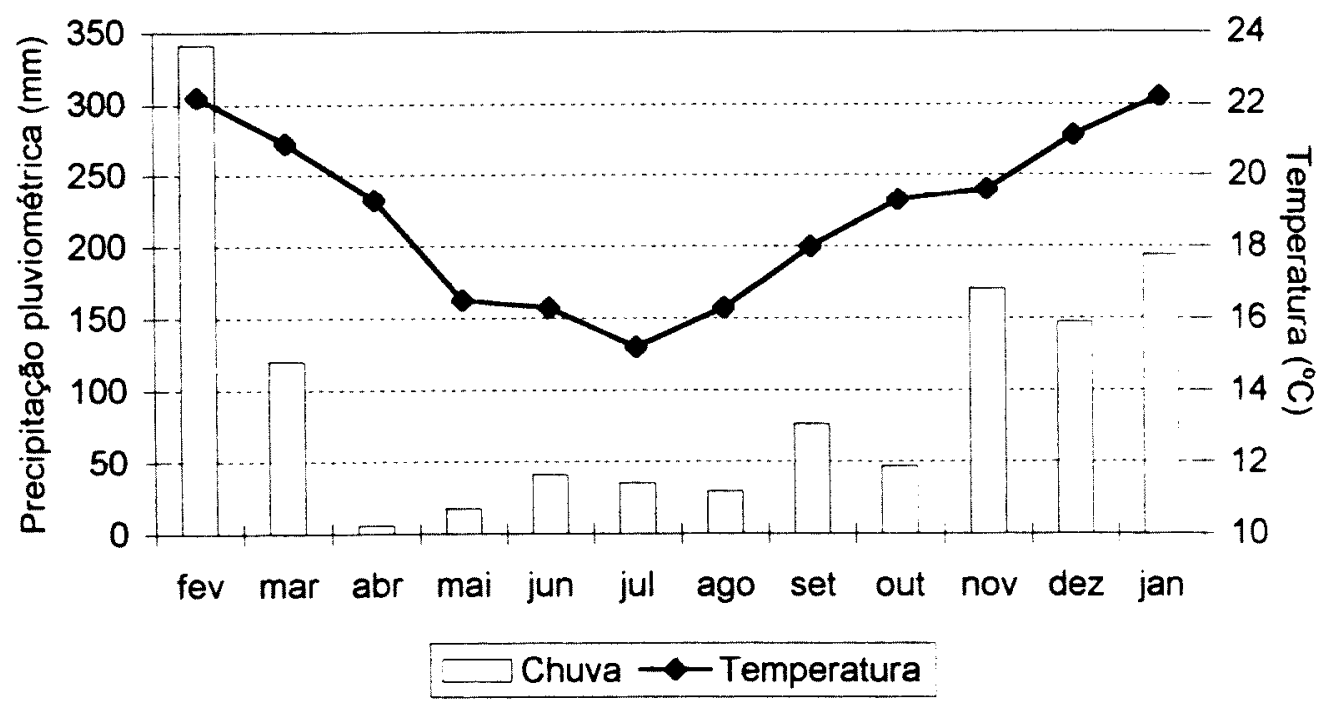

Figura 8. Médias de Temperatura e precipitação pluviométrica registrada entre os periodos de fevereiro de 1999 e janeiro de 2001. 


\subsection{FASES DO DESENVOLVIMENTO OVARIANO DOS MOSQUITOS SEGUNDO OS DIFERENTES ABRIGOS $E$ AO LONGO DAS ESTAÇÕES DO ANO.}

As fases do desenvolvimento folicular de Culex quinquefasciatus e Ochlerotatus scapularis segundo os diferentes habitats (abrigos), estão representadas nas tabelas 3,4 e 5 . A variação sazonal com relação aos diferentes estados fisiológicos pode ser verificada nas tabelas 6, 7 e 8 .

$\mathrm{Na}$ tabela 3, observa-se que do total de 293 fêmeas de Culex quinquefasciatus, provenientes do habitat de margem de riacho poluído, avaliadas em relação às diferentes fases do desenvolvimento ovariolar, $165 \quad(56,3 \%)$ apresentaram os seus folículos na fase V de Christophers e Mer. Foram avaliadas nestas estações climáticas respectivamente: $49(29,7 \%), 43(26,0 \%)$ e $44(26,6 \%)$ fêmeas, para o habitat de margem de riacho poluido, o que é praticamente a mesma proporção de fèmeas, nesta fase do desenvolvimento, distribuida durante as estações de inverno, verão e primavera (tabela 6).

Pôde-se observar também na tabela 3, que $34(11,6 \%)$ das fêmeas de Culex quinquefasciatus encontraram-se na fase IV de Christophers e Mer, 66 (22,5\%) na fase III e $28(9,6 \%)$ nas fases I e II.

Do total das 66 fêmeas avaliadas, para a fase III do desenvolvimento folicular, em relação à margem do riacho poluído: $22(33,3 \%)$ estavam totalmente cheias de sangue, recém alimentadas, e $19(28,8 \%)$ parcialmente cheias de sangue ainda de coloração vermelha (tabela 3). Neste habitat as fêmeas que apresentaram esta fase do desenvolvimento, foram mais freqüentes durante o periodo de inverno, a exemplo das que foram encontradas na fase $\mathrm{V}$ de Christophers e Mer $(15,2 \%$ e $10,6 \%$ ) tabela 6 . Pôde-se observar também a presença de fêmeas que apresentaram 
os folículos na fase III de Christopher e Mer, com o intestino cheio de sangue ou parcialmente cheio de sangue ao longo de todas as estações.

Fêmeas de Culex quinquefasciatus nas fases I e II do desenvolvimento folicular, foram mais expressivas durante a primavera e verão. Apresentaram-se totalmente cheias de sangue durante o verão, primavera e inverno, porém com freqüência maior durante a primavera.

Tabela 3. Fases do desenvolvimento ovariano, segundo Christophers e Mer, de fềmeas de Culex quinquefasciatus abrigadas no habitat de margem de riacho poluido (L-6), na periferia do Parque Ecológico do Tietê na cidade de São Paulo, durante o período de 25.II.99 a 09.I.01.

\begin{tabular}{|c|c|c|c|c|c|c|c|c|c|c|}
\hline \multirow[t]{2}{*}{ Habitat } & \multirow{2}{*}{$\begin{array}{c}\text { digestão de sangue } \\
\text { (Sella) }\end{array}$} & \multicolumn{6}{|c|}{ desenvolvimento folicular (Christophers e Mer) } & \multirow[b]{2}{*}{ fase $\mathrm{V}$} & \multirow[b]{2}{*}{$\%$} & \multirow[b]{2}{*}{ Total } \\
\hline & & fase le II & $\%$ & fase III & $\%$ & fase IV & $\%$ & & & \\
\hline & 1 & 14 & 50 & 2 & 3 & 5 & 14,7 & & & 21 \\
\hline & II & 12 & 42,8 & 22 & 33,3 & 2 & 5,9 & $\overline{1}$ & $\overline{0,6}$ & 37 \\
\hline \multirow[t]{6}{*}{ L-6 } & III & 1 & 3,6 & 19 & 28,8 & 2 & 5,9 & - & & 22 \\
\hline & IV & 1 & 3,6 & 12 & 18,2 & 12 & 35,3 & - & & 25 \\
\hline & v & - & - & 7 & 10,6 & 6 & 17,6 & $\overline{1}$ & 0,6 & 14 \\
\hline & VI & $\overline{-}$ & - & 4 & 6,1 & 7 & 20,6 & 8 & 4,8 & 19 \\
\hline & VII & & & & & & & 155 & 93,9 & 155 \\
\hline & Total & 28 & 9,6 & 66 & 22,5 & 34 & 11,6 & 165 & 56,3 & 293 \\
\hline
\end{tabular}

I = intestino médio sem sangue - ovário não desenvolvido, II = intestino médio cheio de sangue vermelho - recém alimentada, III = intestino parcialmente com sangue vermelho - pós alimentada, IV $=$ intestino médio com sangue escuro -5 a 6 tergitos abdominais livres dele, $\mathrm{V}=$ intestino médio com sangue escuro -6 tergitos e meio livres dele, $\mathrm{VI}=$ intestino médio com sangue escuro visivel somente do lado ventral, VIII = intestino sem sangue - óvulos maduros na fase $V$ de Cris e Mer.

Verifica-se na tabela 7 , que todas as fases do desenvolvimento folicular das fêmeas de Culex quinquefasciatus dissecadas de amostras coletadas em habitats do interior do Parque Ecológico, foram numericamente mais expressivas no decorrer da primavera. Das 86 fêmeas de Culex quinquefasciatus avaliadas para o desenvolvimento folicular na fase III, $46(53,4 \%)$ foram encontradas na primavera, 
sendo que $6(7 \%)$ estavam totalmente cheias de sangue e $15(17,4 \%)$ parcialmente cheias de sangue, o restante apresentou-se com sangue escuro.

O habitat de mata contribuiu com o maior número de fêmeas na fase III de Christopher e Mer, 31 (36\%), do total de fềmeas dissecadas para esta fase do desenvolvimento folicular, sendo que $7(8,1 \%)$ estavam totalmente cheias de sangue vermelho e $11(12,8 \%)$, parcialmente cheias de sangue vermelho (tabela 4 ).

Com relação ao desenvolvimento folicular das fêmeas de Culex quinquefasciatus na fase I e II, observa-se na tabela 7, $36(48 \%)$ das fềmeas durante a primavera. O habitat semi coberto por eucaliptos contribuiu com a maior proporção de fêmeas, nesta fase do desenvolvimento folicular, $29(38,7 \%)$ das fềmeas, comparada ao total de fềmeas dissecadas (tabela 4).

As fêmeas grávidas ocorreram num total de $37(50,0 \%)$ durante a primavera, destas $35(47,3)$ foram encontradas com o intestino médio sem sangue, $1(1,4 \%)$ com o intestino cheio de sangue e $1(1,4 \%)$ apresentando sangue escuro, com 6 a 5 tergitos abdominais visualmente livres dele (tabela 7). O habitat semi coberto por eucaliptos contribuiu com o maior número de exemplares $27(36,5 \%)$, em relação ao total de fêmeas dissecadas nesta fase do desenvolvimento ovariano, comparado aos outros habitats (tabela 4). 
Tabela 4. Fases do desenvolvimento ovariolar de fêmeas de Culex quinquefasciatus abrigadas em diferentes habitats do Parque Ecológico do Tietê na cidade de São Paulo, durante o período de 25.II.99 a 09.I.01.

\begin{tabular}{|c|c|c|c|c|c|c|c|c|c|}
\hline \multirow[b]{2}{*}{ habitats } & \multicolumn{2}{|c|}{ digeståo de sangue } & \multicolumn{7}{|c|}{ deservolvimento folicular (Christophers e Mer) } \\
\hline & (Sella) & fase I e II & $\%$ & fase III & $\%$ & fase IV & $\%$ & fase $V$ & $\%$ \\
\hline \multirow{8}{*}{$L-1$} & $1 \quad T$ & 26 & 34,7 & 1 & 1,2 & - & - & - & - \\
\hline & ॥ & & & 4 & 4,7 & - & - & - & _ \\
\hline & III & 1 & 1,3 & 13 & 15,1 & & & - & - \\
\hline & IV & 1 & 1,3 & 6 & 6,9 & 2 & 7,7 & - & - \\
\hline & V & 1 & 1,3 & 4 & 4,7 & 1 & 3,8 & 2 & 2,7 \\
\hline & VI & - & - & - & - & 1 & 3,8 & & \\
\hline & VII & 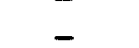 & & & & & & 25 & 33,8 \\
\hline & subtotal & 29 & 38,7 & 28 & 32,6 & 4 & 15,4 & 2 & 2,7 \\
\hline \multirow{8}{*}{ L-2 } & 1 & 8 & 10,7 & & & 4 & 15,4 & - & - \\
\hline & $\|$ & 6 & 8 & 7 & 8,1 & _ & - & - & - \\
\hline & III & 1 & 1,3 & 11 & 12,8 & & & - & _- \\
\hline & IV & - & - & 8 & 9,3 & 5 & 19,2 & - & - \\
\hline & $v$ & - & - & 4 & 4,7 & 2 & 7,7 & - & - \\
\hline & VI & - & - & 1 & 1,2 & - & - & - & - \\
\hline & VII & & . & & & & & 10 & 13,5 \\
\hline & subtotal & 15 & 20 & 31 & 36 & 11 & 42,3 & 10 & 0 \\
\hline \multirow{7}{*}{$L-3$} & 1 & 4 & 5,3 & & & 1 & 3,8 & - & - \\
\hline & II & 1 & 1,3 & 3 & 3,5 & - & - & - & - \\
\hline & III & - & - & 2 & 2,3 & $\overline{-}$ & $\overline{19} 5$ & - & - \\
\hline & IV & & $=$ & 2 & 2,3 & 3 & 17,5 & - & - \\
\hline & $V$ & 1 & 1,3 & - & - & - & - & - & - \\
\hline & $\begin{array}{l}\text { VI } \\
\text { VII }\end{array}$ & - & - & - & - & - & - & $\overline{8}$ & $1 \overline{0,8}$ \\
\hline & subtotal & $\overline{6}$ & 8 & $\overline{7}$ & $\overline{8,1}$ & $\overline{4}$ & $1 \overline{5}, 4$ & 0 & 0 \\
\hline \multirow{8}{*}{ L-4 } & 1 & 12 & 16 & & & - & - & - & - \\
\hline & II & 1 & 1,3 & 1 & 1,2 & - & - & - & - \\
\hline & IIII & - & - & 5 & 5,8 & - & - & - & - \\
\hline & IV & - & - & 2 & 2,3 & - & - & - & - \\
\hline & $v$ & - & - & 1 & 1,2 & - & - & - & - \\
\hline & VI & - & - & - & - & - & - & $\overline{11}$ & \\
\hline & VII & . & 170 & 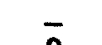 & 40 & - & - & 14 & 18,9 \\
\hline & subtotal & 13 & 17,3 & 9 & 10,5 & - & - & 14 & 18,9 \\
\hline \multirow{8}{*}{ L-5 } & 1 & 9 & 12 & - & _- & - & - & & \\
\hline & $\|$ & 2 & 2,7 & 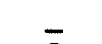 & 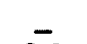 & _ & - & 1 & 1,4 \\
\hline & III & 1 & 1,3 & 2 & 2,3 & & & - & - \\
\hline & IV & - & - & 5 & 5,8 & 2 & 7,7 & 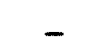 & . \\
\hline & $v$ & - & - & 4 & 4,7 & 2 & 7,7 & 1 & 1,4 \\
\hline & VI & - & - & - & - & 3 & 11,5 & & \\
\hline & VII & - & - & - & - & & - & 13 & 17,5 \\
\hline & subtotal & 12 & 16 & 11 & 12,8 & 7 & 26,9 & 2 & 2,8 \\
\hline
\end{tabular}

$\mathrm{I}$ = intestino médio sem sangue - ovário não desenvolvido, $\mathrm{II}=$ intestino médio cheio de sangue vermelho - recém alimentada, III = intestino parcialmente com sangue vermelho - pós-alimentada, IV $=$ intestino médio com sangue escuro - 5 a 6 tergitos abdominais livres dele, $\mathrm{V}=$ intestino médio com sangue escuro -6 tergitos e meio livres dele, $\mathrm{VI}=$ intestino médio com sangue escuro visivel somente do lado ventral, VII = intestino sem sangue - óvulos maduros na fase $\mathrm{V}$ de Cris e Mer.

L- 1 = hábitat semi coberto por eucaliptos, $L-2=$ habitat de mata, $L-3=$ habitat de margem de mata, L-4 = hábitat densamente coberto por eucaliptos, $L-5=$ habitat aberto campo-brejo. 
Tabela 5. Fases do desenvolvimento ovariolar de fèmeas de Ochlerotatus scapularis abrigadas em diferentes habitats do Parque Ecológico do Tietê na cidade de São Paulo, durante o periodo de 25.II.99 a 09.I.01.

\begin{tabular}{|c|c|c|c|c|c|c|c|c|c|}
\hline \multirow[b]{2}{*}{ Habitats } & \multicolumn{2}{|c|}{ digestão de sangue } & \multicolumn{5}{|c|}{ deservolvimento folicular (Christophers e Mer) } & \multirow[b]{2}{*}{ fase V } & \multirow[b]{2}{*}{$\%$} \\
\hline & (Sella) & fase I e II & $\%$ & fase III & $\%$ & fase IV & $\%$ & & \\
\hline \multirow{8}{*}{ L-1 } & 1 & 43 & 22,1 & & & 1 & 1,5 & & \\
\hline & ॥ & 20 & 10,3 & 17 & 6,1 & & & $\overline{1}$ & 0,8 \\
\hline & III & & & 20 & 7,1 & 2 & 3 & 4 & 3,3 \\
\hline & IV & 1 & 0,5 & 18 & 6,4 & 1 & 1,5 & 1 & 0,8 \\
\hline & v & 1 & 0,5 & 9 & 3,2 & & & & \\
\hline & VI & _ & - & 1 & 0,4 & $\overline{1}$ & $\overline{1,5}$ & $\overline{2}$ & $\overline{1.7}$ \\
\hline & VII & & & & & & & 16 & 13,3 \\
\hline & subtotal & 65 & 33,3 & 65 & 23,2 & 5 & 7,5 & 8 & 20 \\
\hline \multirow{8}{*}{ L-2 } & 1 & 17 & 8,7 & 1 & 0,4 & 7 & 10,6 & - & - \\
\hline & II & 24 & 12,3 & 25 & 8,9 & 2 & 3 & & - \\
\hline & III & - & - & 19 & 6,8 & 5 & 7,6 & 3 & 2,5 \\
\hline & IV & - & 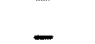 & 8 & 2,8 & 2 & 3 & - & - \\
\hline & $v$ & $\overline{4}$ & $\overline{2,1}$ & 7 & 2,5 & 1 & 1,5 & - & - \\
\hline & VI & _ & _ & 2 & 0,7 & 7 & 10,6 & 2 & 1,7 \\
\hline & VII & & & & & & & 30 & 25 \\
\hline & subtotal & 45 & 23,1 & 62 & 22,1 & 24 & 36,4 & 5 & 29,2 \\
\hline \multirow{8}{*}{ L-3 } & 1 & 17 & 8,7 & & & 2 & 3 & & \\
\hline & ॥ & 18 & 9,2 & 44 & 15,7 & 4 & 6,1 & 1 & 0,8 \\
\hline & III & - & _ & 22 & 7,8 & - & - & 1 & 0,8 \\
\hline & IV & & & 10 & 3,6 & & & 1 & 0,8 \\
\hline & v & $\overline{1}$ & 0,5 & 10 & 3,6 & $\overline{4}$ & 6,1 & & \\
\hline & VI & _ & - & 1 & 0,4 & 2 & 3 & $\overline{1}$ & $\overline{0,8}$ \\
\hline & VII & - & & & & & & 10 & 8,3 \\
\hline & subtotal & 36 & 18,4 & 87 & 31,1 & 12 & 18,2 & 4 & 11,7 \\
\hline \multirow{8}{*}{$L-4$} & 1 & 12 & 6,2 & 1 & 0,4 & 5 & 7,6 & - & _- \\
\hline & $\|$ & 11 & 5,6 & 21 & 7,5 & 3 & 4,5 & - & - \\
\hline & III & 2 & 1 & 13 & 4,6 & 1 & 1,5 & 1 & 0,8 \\
\hline & IV & & & 10 & 3,6 & 3 & 4,5 & 2 & 1,7 \\
\hline & v & 1 & 0,5 & - & - & 3 & 4,5 & & \\
\hline & VI & 2 & 1 & - & - & 6 & 9,2 & 3 & 2,5 \\
\hline & VII & & & & & & & 31 & 25,8 \\
\hline & subtotal & 28 & 14,4 & 45 & 16,1 & 21 & 31,8 & 6 & 30,8 \\
\hline \multirow{9}{*}{ L-5 } & 1 & 7 & 3,6 & & & 1 & 1,5 & - & - \\
\hline & ॥ & 10 & 5,1 & $\overline{9}$ & 3,2 & 2 & 3 & - & - \\
\hline & III & 2 & 1 & 7 & 2,5 & & & - & - \\
\hline & IV & 1 & 0,5 & 4 & 1,4 & 1 & 1,5 & - & - \\
\hline & V & 1 & 0,5 & & & - & - & $\overline{1}$ & $\overline{0}$ \\
\hline & VI & - & & 1 & 0,4 & - & - & 1 & 0,8 \\
\hline & VII & - & & & & - & - & 9 & 7,5 \\
\hline & subtotal & 21 & 10,8 & 21 & 7,5 & 4 & 6,1 & 1 & 8,3 \\
\hline & Total & 195 & & 280 & & 66 & & 120 & \\
\hline
\end{tabular}

I = intestino médio sem sangue - ovário não desenvolvido, II = intestino médio cheio de sangue vermelho - recém alimentada, III = intestino parcialmente com sangue vermelho - pós-alimentada, IV $=$ intestino médio com sangue escuro -5 a 6 tergitos abdominais livres dele, $\mathrm{V}=$ intestino médio com sangue escuro -6 tergitos e meio livres dele, $\mathrm{VI}=$ intestino médio com sangue escuro visivel somente do lado ventral, VII = intestino sem sangue - óvulos maduros na fase V de Cris e Mer.L- 1 = hábitat semi coberto por eucaliptos, L- 2 = habitat de mata, $\mathrm{L}-3=$ habitat de margem de mata, $\mathrm{L}-4=$ hábitat densamente coberto por eucaliptos, L-5 = habitat aberto campo-brejo. 
Na tabela 8, verifica-se uma proporção maior de fêmeas de Ochlerotatus scapularis nas diferentes fases do desenvolvimento folicular, durante as estações de verão, primavera e outono. As fêmeas na fase III de Christophers e Mer, foram numericamente mais expressivas em relação às fêmeas que se encontravam em outras fases do desenvolvimento folicular.

Verifica-se com relação à fase III de Christopher e Mer, uma maior abundância no verão seguida pela estação de outono. Das 280 fềmeas dissecadas nesta fase do desenvolvimento ovariano, o maior número, foi encontrado durante o verão, $45(16,1 \%)$ delas apresentaram o intestino médio totalmente tomado por sangue, $27 \%(9,6 \%)$ foram encontradas com o intestino parcialmente tomado por sangue vermelho, as outras fêmeas apresentaram sangue escuro no intestino. No outono ocorreram $99(35,3 \%)$ de fêmeas, $45(16,1 \%)$ totalmente cheias de sangue e $26(9,3 \%)$ com o intestino parcialmente cheio de sangue (tabela 8 ).

O habitat de margem de mata (tabela 5), foi o que contribuiu com o maior percentual $87(31,1 \%)$, de fêmeas de Ochlerotatus scapularis na fase III do desenvolvimento folicular. Destas 44 (15,7\%) estavam totalmente cheias de sangue, $22(7,8 \%)$ parcialmente com sangue vermelho, $10(3,6 \%)$ apresentando sangue escuro com 5 a 6 tergitos abdominais livres de sangue, o mesmo percentual de fêmeas com 6 tergitos e meio livres de sangue, e uma fêmea com sangue escuro visível somente do lado ventral (tabela 5).

O maior percentual 91 (46,7\%), verificado em relação às 195 fêmeas de Ochlerotatus scapularis que se encontravam na fase I e II de Christophers e Mer, foi observado durante o período de verão. Destas $51(26,2 \%)$ não continham sangue no intestino médio e $36(18,5 \%)$ estavam com o intestino totalmente tomado por sangue 
(tabela 8). O habitat semi coberto por eucaliptos contribuiu com a maior proporção, $65(33,3 \%)$, de fềmeas nesta fase do desenvolvimento (tabela 5).

A maior proporção, 57(47,5\%), de fêmeas grávidas de Ochlerotatus scapularis ocorreu durante o outono (tabela 8). Os habitats, densamente coberto por eucaliptos e de mata contribuíram respectivamente com $37(30,8 \%)$ e $35(29,2 \%)$, fêmeas, apresentando os maiores percentuais de fêmeas nesta fase do desenvolvimento folicular comparados aos outros habitats (tabela 5).

Observa-se ainda, na tabela 8 , que ocorreram fêmeas além da fase III de Christophers e Mer com o intestino totalmente cheio de sangue, ao longo de todas as estações climáticas.

No habitat de margem de riacho poluido, duas fêmeas de Ochlerotatus scapularis foram encontradas na fase I e II de Christophers e Mer, sem sangue no intestino. Duas fêmeas foram encontradas na fase III, sendo uma com o intestino totalmente cheio de sangue e uma com o intestino parcialmente cheio de sangue ainda vermelho. Ainda três fêmeas foram encontradas na fase $\mathrm{V}$ de desenvolvimento folicular, sendo uma com sangue escuro visivel somente do lado ventral do abdomem. 
Tabela 6. Influência da variação sazonal no desenvolvimento folicular de fềmeas de Culex quinquefasciatus dissecadas de amostras coletadas em habitat de riacho poluído, periferia do Parque Ecológico do Tietê, na cidade de São Paulo, de 25.II.1999 a 09.I.2001

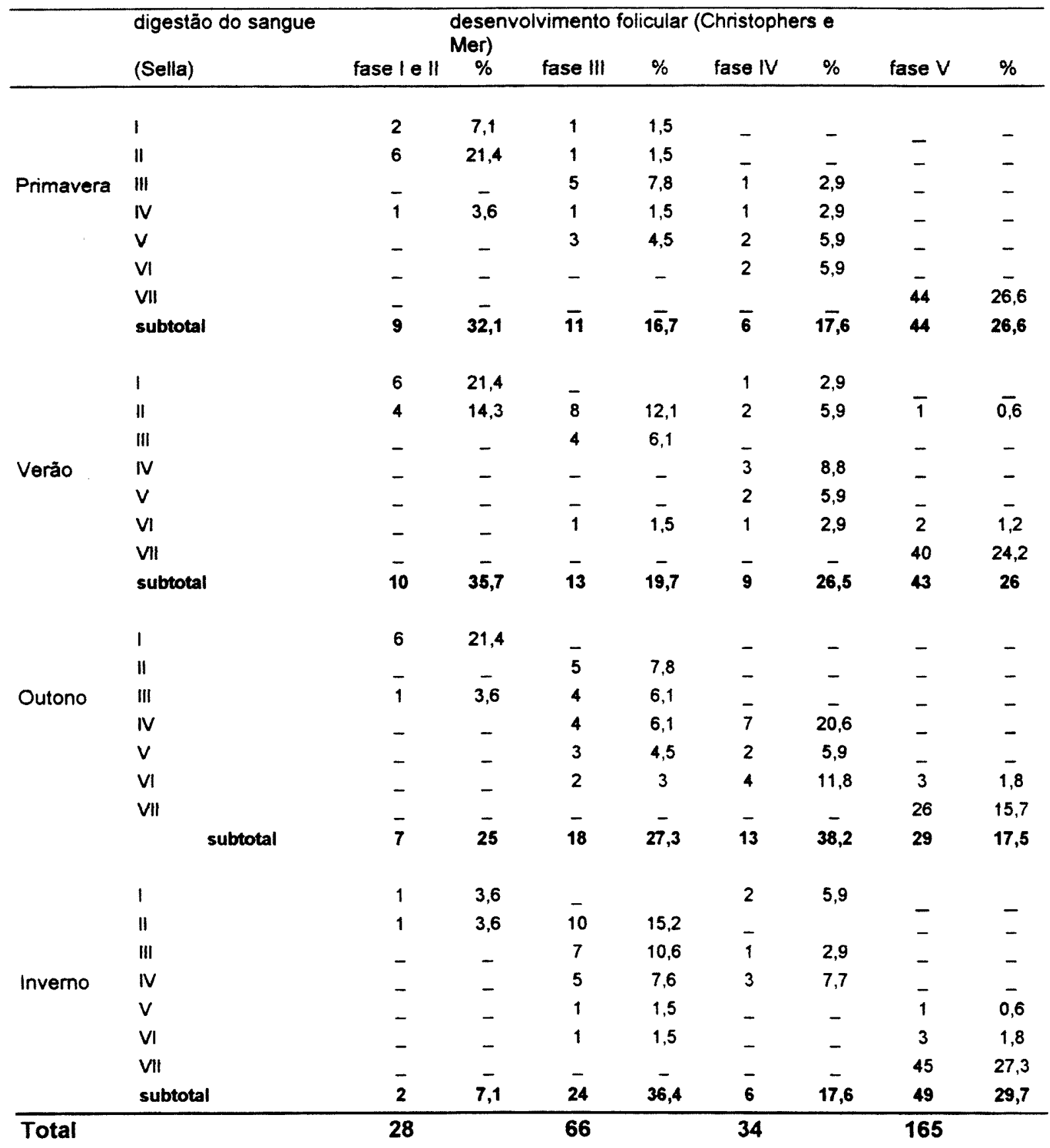

I = intestino médio sem sangue - ovário não desenvolvido, II = intestino médio cheio de sangue vermelho - recém alimentada, III = intestino parcialmente com sangue vermelho - pós-alimentada, IV = intestino médio com sangue escuro -5 a 6 tergitos abdominais livres dele, $\mathrm{V}=$ intestino médio com sangue escuro - 6 tergitos e meio livres dele, $\mathrm{VI}=$ intestino médio com sangue escuro visível somente do lado ventral, VII = intestino sem sangue - óvulos maduros na fase $\mathrm{V}$ de Christophers e Mer.

L- 1 = hábitat semi coberto por eucaliptos, $\mathrm{L}-2$ = habitat de mata $\mathrm{L}-3=$ habitat de margem de mata, L-4 = hábitat densamente coberto por eucaliptos, L-5 = habitat abero campo-brejo. 
Tabela 7. Influência da variação sazonal do desenvolvimento folicular de fêmeas de Culex quinquefasciatus dissecadas de amostras coletadas de diferentes habitats do Parque Ecológico do Tietê, na cidade de São Paulo, de 25.II.1999 a 09.I.2001.

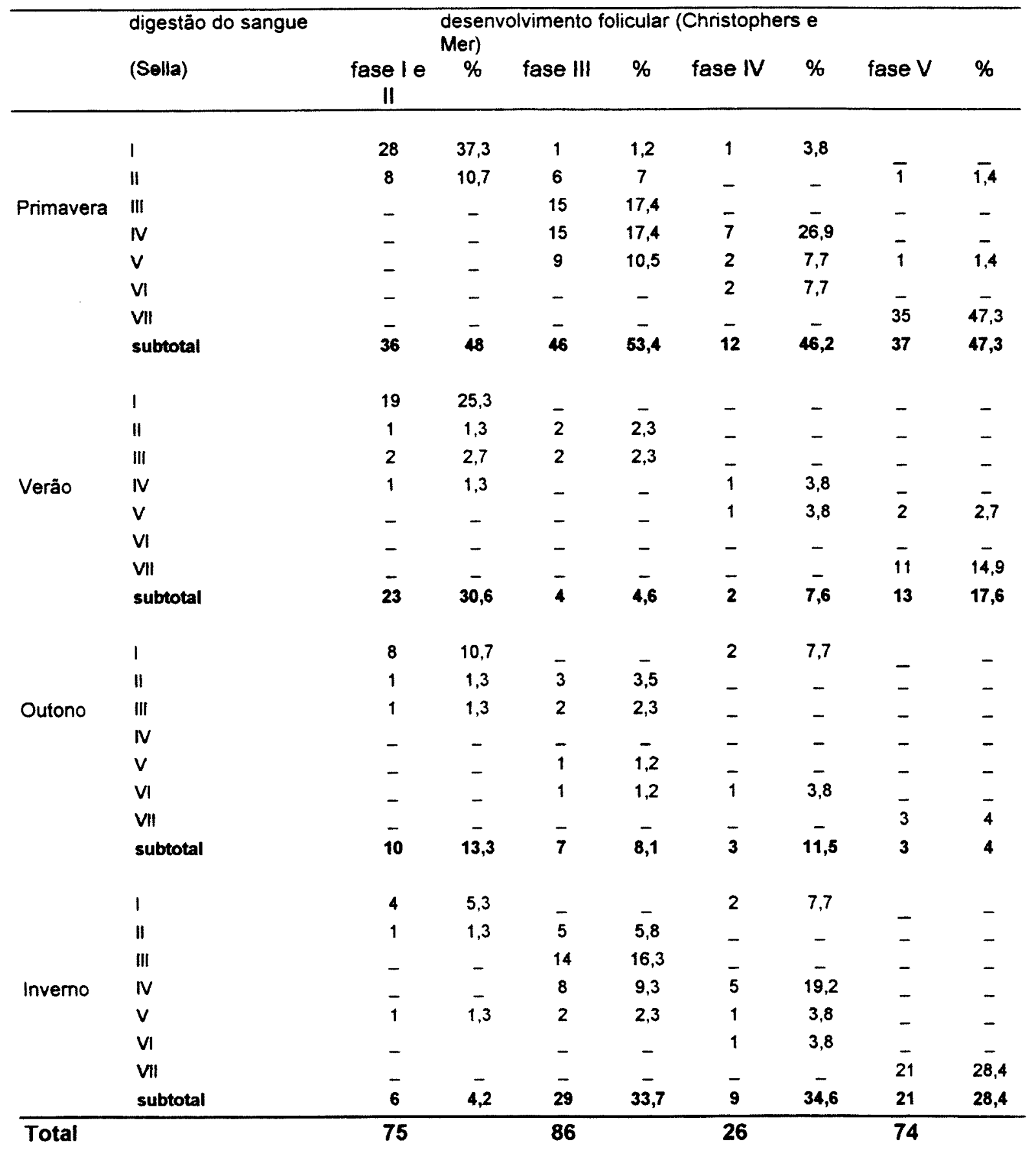

I = intestino médio sem sangue - ovário não desenvolvido, II = intestino médio cheio de sangue vermelho - recém alimentada, III = intestino parcialmente com sangue vermelho - pós-alimentada, IV $=$ intestino médio com sangue escuro -5 a 6 tergitos abdominais livres dele, $\mathrm{V}=$ intestino médio com sangue escuro -6 tergitos e meio livres dele, VI = intestino médio com sangue escuro visível somente do lado ventral, VII = intestino sem sangue - óvulos maduros na fase V de Christophers e Mer. L- 1 = hábitat semi coberto por eucaliptos, L- 2 = habitat de mata, L-3 = habitat de margem de mata, L-4 = hábitat densamente coberto por eucaliptos, $L-5=$ habitat aberto campo-brejo. 
Tabela 8. Variação sazonal do desenvolvimento folicular de fêmeas de Ochlerotatus scapularis dissecadas de amostras coletadas de diferentes habitats do Parque Ecológico do Tietê, na cidade de São Paulo, de 25.II.1999 a 09.I.2001.

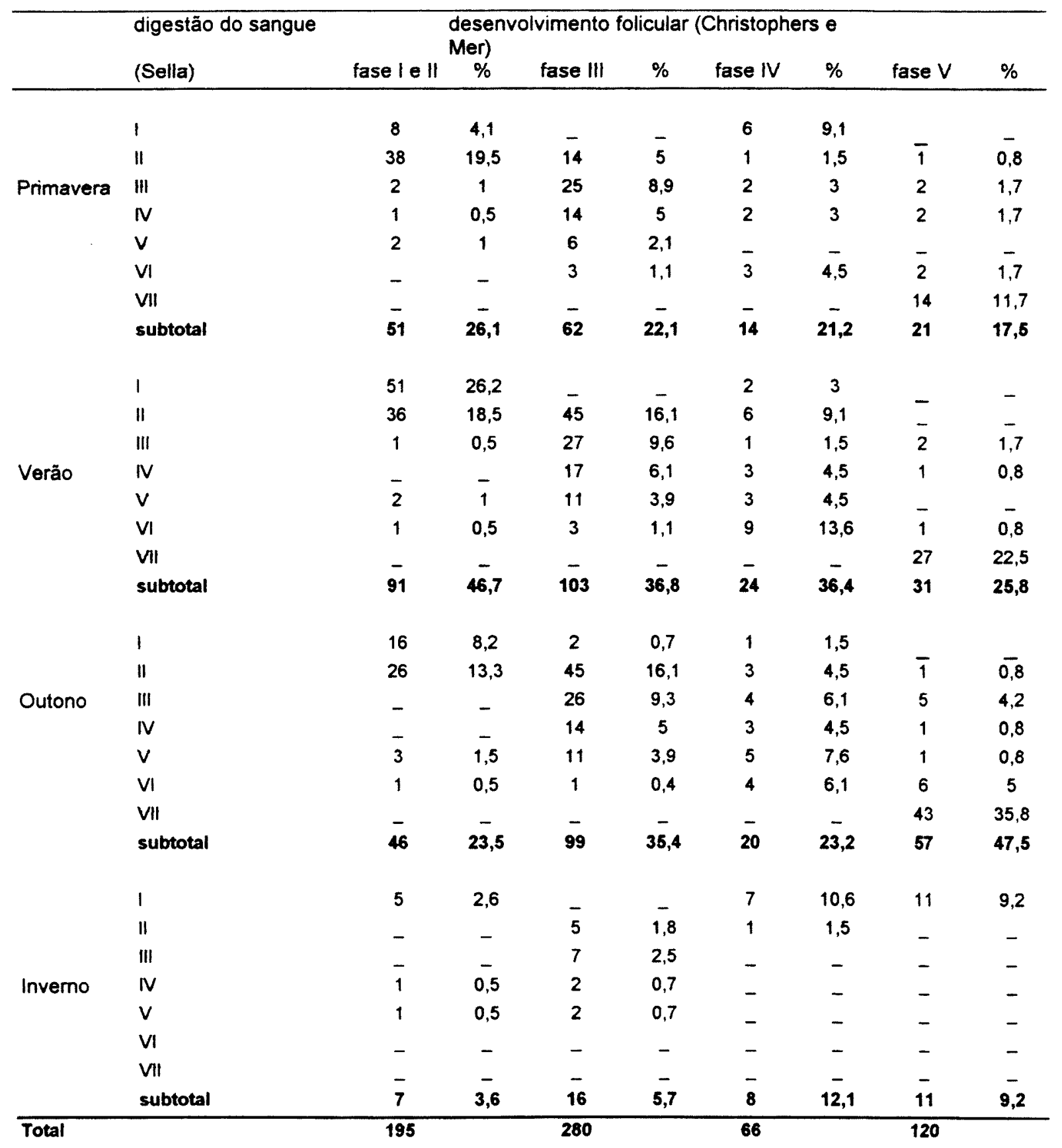

I = intestino médio sem sangue - ovário não desenvolvido, II = intestino médio cheio de sangue vermelho - recém alimentada, III = intestino parcialmente com sangue vermelho - pós-alimentada, IV $=$ intestino médio com sangue escuro -5 a 6 tergitos abdominais livres dele, $\mathrm{V}=$ intestino médio com sangue escuro -6 tergitos e meio livres dele, $\mathrm{VI}=$ intestino médio com sangue escuro visivel somente do lado ventral, VII = intestino sem sangue - óvulos maduros na fase $\mathrm{V}$ de Christophers e Mer L- 1 = hábitat semi coberto por eucaliptos, L- 2 = habitat de mata, L-3 = habitat de margem de mata, L-4 = hábitat densamente coberto por eucaliptos, $\mathrm{L}-5$ = habitat aberto campo-brejo. 


\subsection{INFLUÊNCIA DA VARIAÇÃO SAZONAL NO TAMANHO DOS MOSQUITOS}

A variação sazonal de tamanho corpóreo de Culex quinquefasciatus e Ochlerotatus scapularis ao longo do período de 04.IV.2000 a 09.I.2001 foi aqui avaliada a partir de medidas do comprimento das asas tomadas da base da alula até o ângulo apical da asa e transformadas em médias de comprimento de asas.

Nas tabelas 9 e 10, observa-se o número de mosquitos medidos por data de coleta, as respectivas médias e estatísticas associadas. O coeficiente de variação em torno da média, indicou uma pequena variação de tamanho nas populações de Ochlerotarus scapularis assim como nas populações de Culex quinquefasciatus ao longo do periodo de coleta. Pôde-se observar com relação à média das médias que Culex quinquefasciatus $(3.504 \pm 0,14 \mathrm{~mm})$, foi maior que Ochlerotatus scapularis $(3.213 \pm 0,24 \mathrm{~mm})$.

A análise por postos de KrusKal-Wallis $(\mathrm{H})$, indicou que a diferença de tamanho entre Culex quinquefasciatus e Ochlerotatus scapularis é altamente significativa $(H=244.849$ e $\mathrm{p}<0,001)$.

A figura 9 ilustra a comparação entre as médias do comprimento da asa das populações de Ochlerotatus scapularis e Culex quinquefasciatus durante o periodo de 04.IV.2000 a 09.I.00, compreendendo quatro estações: outono, inverno, primavera e verão. Verifica-se que as duas populações de mosquitos apresentaram maior tamanho durante o período seco, mais especificamente durante o inverno, quando se registrou as menores médias de temperatura e precipitação pluviométrica (figura 10). 
Tabela 9. Média, desvio padrão e coeficiente de variação, do comprimento da asa das fêmeas de Culex quinquefasciatus amostradas de coletas em abrigos do Parque Ecológico do Tietê na cidade de São Paulo, de 04.IV.2000 a 09.I.2001

\begin{tabular}{|c|c|c|c|}
\hline Data de coleta & $\begin{array}{l}N^{\circ} \text { de fêmeas } \\
\text { medidas }\end{array}$ & $\begin{array}{c}\text { Média da Asa } \\
\text { em milimetros (D.P.) }\end{array}$ & C.V. \\
\hline $04 / I V / 00$ & 11 & $3.347(0,24)$ & 0.060 \\
\hline $18 / \mathrm{IV} / 00$ & 23 & $3.346(0,27)$ & 0.074 \\
\hline $09 N / 00$ & 18 & $3.384(0,29)$ & 0.085 \\
\hline $25 N / 00$ & 38 & $3.545(0,32)$ & 0.104 \\
\hline $08 N / / 00$ & 17 & $3.620(0,16)$ & 0.026 \\
\hline $20 N 1 / 00$ & 36 & $3.631(0,20)$ & 0.040 \\
\hline 06 NII/00 & 29 & $3.674(0.19)$ & 0.037 \\
\hline $18 N I I / 00$ & 41 & $3.600(0,25)$ & 0.064 \\
\hline $10 \mathrm{NIII/00}$ & 21 & $3.769(0,28)$ & 0.080 \\
\hline $24 N 111 / 00$ & 18 & $3.606(0,41)$ & 0.168 \\
\hline $06 / 1 \times 100$ & 29 & $3.660(0,35)$ & 0.121 \\
\hline $19 / 1 \times / 00$ & 41 & $3.606(0,25)$ & 0.064 \\
\hline $10 / \times 100$ & 62 & $3.430(0,23)$ & 0.054 \\
\hline $24 / \times 100$ & 72 & $3.290(0,21)$ & 0.043 \\
\hline $09 / \times 1 / 00$ & 28 & $3.427(0,19)$ & 0.036 \\
\hline $21 / X 1 / 00$ & 34 & $3.505(0,14)$ & 0.020 \\
\hline $08 / X 11 / 00$ & 39 & $3.397(0,24)$ & 0.059 \\
\hline $19 / X I 1 / 00$ & 21 & $3.377(0,22)$ & 0.048 \\
\hline $09 / 1 / 01$ & 25 & $3.338(0,13)$ & 0.017 \\
\hline Total & $* 603$ & $3.504(0,14)$ & 0.020 \\
\hline
\end{tabular}

DP = desvio padrão,

$\mathrm{CV}=$ coeficiente de variação,

* média das médias. 
Tabela 10. Média, desvio padrão e coeficiente de variação do comprimento da asa de fêmeas de Ochlerotatus scapularis, amostradas de coletas em abrigos do Parque Ecológico do Tietê na cidade de São Paulo, de 04.IV.2000 a 09.I.2001

\begin{tabular}{|c|c|c|c|}
\hline Data da colet & $N^{\circ}$ de fêmeas & Média da Asa & C.V. \\
\hline $04 / 1 \mathrm{~V} / 00$ & 23 & $2.905(0.33)$ & 0.110 \\
\hline 18/IV/00 & 58 & $3.284(0.26)$ & 0.068 \\
\hline $09 N / 00$ & 33 & $3.216(0,30)$ & 0.088 \\
\hline $25 N / 00$ & 4 & $3.220(0,30)$ & 0.087 \\
\hline $08 \mathrm{NI} / 00$ & 3 & $3.273(0,45)$ & 0.204 \\
\hline $20 \mathrm{~N} / 100$ & 1 & $3.719(0,00)$ & 0.000 \\
\hline $06 N I I / 00$ & - & . & $-2+2$ \\
\hline $18 N I I / 00$ & & & \\
\hline $10 \mathrm{NIII} / 00$ & 10 & $3.489(0,26)$ & 0.066 \\
\hline 24NIII/0O & 5 & $3.485(0,43)$ & 0.185 \\
\hline \multicolumn{4}{|l|}{$06 / 1 \times 100$} \\
\hline $19 / 1 \times / 00$ & 78 & $3.321(0,26)$ & 0.067 \\
\hline $10 / \times 100$ & 74 & $3.269(0,34)$ & 0.118 \\
\hline $24 / \times 100$ & 16 & $3.316(0,30)$ & 0.090 \\
\hline $09 / \times 1 / 00$ & 4 & $2.774(0,42)$ & 0.174 \\
\hline $21 / \times 1 / 00$ & 3 & $2.922(0,51)$ & 0.256 \\
\hline $08 / \times 11 / 00$ & 91 & $3.071(0,28)$ & 0.078 \\
\hline $19 / X 11 / 00$ & 53 & $3.040(0,26)$ & 0.068 \\
\hline $09 / 1 / 01$ & 52 & $3.107(0,21)$ & 0.045 \\
\hline Total & * 508 & $3.213(0,23)$ & \\
\hline
\end{tabular}

DP $=$ desvio padrão,

$\mathrm{CV}=$ coeficiente de variação,

* média das médias. 
Na tabela 11, verifica-se a análise de variância aplicada para as médias do comprimento de asa de Ochlerotatus scapularis durante as estações seca e chuvosa, verão-inverno e outono-primavera. Observa-se que as suposições de normalidade e homocedasticidade foram satisfeitas para a média do comprimento da asa dos mosquitos próxima à mediana e variâncias homogêneas com $95 \%$ de confiança indicados pelo baixo valor de $\chi^{2}$ e alto valor de " $\mathrm{p}$ " do teste de Bartlett, suposições requeridas para a análise de variância.

Ochlerotatus scapularis foi maior durante o inverno. Os valores mais altos de média do comprimento da asa em milímetros $(3.719 \mathrm{~mm}, 3.489 \pm 0,26 \mathrm{~mm}$ e $3.485 \pm$ 0,43 ), foram registrados respectivamente durante as coletas de 20 . VI, 10 .VIII e 24 .VII do ano de 2000 . No verão a média de tamanho registrada foi de $3.107 \pm 0.21$ mm (tabela 10).

Comparando-se as estações extremas, verão e inverno, através da análise de variância, pôde-se observar que a diferença de tamanho das asas das populações de Ochlerotatus scapularis entre as duas estações foi altamente significativa ( $F=41,8 \mathrm{e}$ $\mathrm{p}<0,0001)$

As menores médias de tamanho nas populações de Ochlerotatus scapularis, $2.774 \pm 0.42 \mathrm{~mm}$ e $2.905 \pm 0.33 \mathrm{~mm}$, ocorreram respectivamente em 09/XI/00 e 04/IV/00, primavera-outono (tabela 10). Comparando-se o tamanho de Ochlerotatus scapularis em relação às duas estações, a análise de variância revelou que a diferença de tamanho desse mosquito durante a primavera e outono não é significativa, $(F=0,235$ e $p=0,628)$. 
Comparando-se a diferença da média do comprimento da asa de Ochlerotatus scapularis, apresentada durante o período seco (outono-inverno) contra o período chuvoso (verão-primavera), a análise de variância indicou que a diferença da média é significativa $(F=4.33$ e $p=0,0378)$.

Tabela 11. Análise de variância das médias de comprimento da asa de Ochlerotatus scapularis, coletados em abrigos do Parque Ecológico do Tietê na cidade de São Paulo, durante o período de 04.IV.2000 a 09.I.2001, segundo as diferentes estações do ano.

\begin{tabular}{|c|c|c|c|c|}
\hline \multirow[t]{2}{*}{ Ochlerotatus scapularis } & \multicolumn{2}{|c|}{ Normalidade } & \multirow{2}{*}{$\begin{array}{l}\text { Teste de Bartlett } \\
\text { (homocedasticidade)* }\end{array}$} & \multirow[t]{2}{*}{ ANOVA } \\
\hline & Média $n$ & ediana & & \\
\hline \multirow[t]{2}{*}{ Seco-chuvoso** } & $s=3.168$ & 3.168 & $X^{2}=1.244$ & $F=4.33$ \\
\hline & $c=3.233$ & 3.266 & $\mathrm{p}=0.2647$ & $\mathrm{p}=0.0378$ \\
\hline \multirow[t]{2}{*}{ Verão-inverno } & $v=3.074$ & 3.070 & $X^{2}=1.902$ & $F=41.809$ \\
\hline & $\mathrm{i}=3.483$ & 3.586 & $p=0.1678$ & $\mathrm{p}<0.0001$ \\
\hline \multirow[t]{2}{*}{ Outono-primavera } & $0=3.191$ & 3.257 & $X^{2}=0.010$ & $F=0.235$ \\
\hline & $\mathrm{p}=3.208$ & 3.232 & $p=0.9219$ & $p=0.628$ \\
\hline
\end{tabular}

* variâncias homogêneas com $95 \%$ de confiança.

** outono-inverno / primavera-verão

Culex quinquefasciatus apresentou as maiores médias de comprimento de asa durante o periodo seco (outono-inverno), e início da primavera. O maior valor para a média de comprimento da asa deste mosquito $(3.769 \pm 0.28 \mathrm{~mm})$, foi verificada na coleta de 10/VIII/00, em pleno inverno. O menor valor $(3.290 \pm 0,21 \mathrm{~mm})$, foi registrado em $24 / \mathrm{X} / 00$, na primavera. Durante o verão, especificamente na coleta de 09/01/01, Culex quinquefasciatus apresentou um tamanho médio de $3.338 \pm 0,13$ mm (tabela 9). 
$\mathrm{Na}$ tabela 12, pode-se observar a análise não paramétrica por postos de Kruskal-Wallis. Esta foi utilizada na comparação das médias de tamanho em função da verificação da não homocedasticidade das variâncias, revelada pelo baixo valor de "p" encontrado na comparação das médias durante os períodos seco-chuvoso e verão-inverno.

Culex quinquefasciatus apresentou uma diferença significativa muito além do nivel de significância de 0,001 quando se compara os períodos, seco com chuvoso e verão com inverno. No período seco-chuvoso, a análise de Kruskal-Wallis, indicou uma $H=68,9$ e $p<0,0001$. Para as estações de verão e inverno, $H=49,5$ e $p<$ 0,0001. A diferença de tamanho não foi significativa quando comparou-se outono com primavera. A análise estatistica revelou um valor de p maior que $0,05 \mathrm{com} \mathrm{H}=$ 2.715 e $p=0,099(p=10 \%)$

Tabela 12. Teste de Kruskal-Wallis para as médias de comprimento da asa de Culex quinquefasciatus, coletados em abrigos do Parque Ecológico do Tietê na cidade de São Paulo, durante o periodo de 04.IV.2000 a 09.I.2001, segundo as diferentes estações do ano.

\begin{tabular}{|c|c|c|c|c|}
\hline $\begin{array}{l}\text { Culex } \\
\text { quinquefasciatus }\end{array}$ & $\begin{array}{c}\text { Normali } \\
\text { Média } \mathrm{m}\end{array}$ & $\begin{array}{l}\text { dade } \\
\text { diana }\end{array}$ & $\begin{array}{l}\text { Teste de Bartlett } \\
\text { (heterocedasticidade)* }\end{array}$ & $\begin{array}{l}\text { Kruskal- } \\
\text { Wallis }\end{array}$ \\
\hline Seco-chuvoso** & $\begin{array}{l}\mathrm{s}=3.411 \\
\mathrm{c}=3.582\end{array}$ & $\begin{array}{l}3.434 \\
3.603\end{array}$ & $\begin{array}{l}X^{2}=19.807 \\
p=0.000009\end{array}$ & $\begin{array}{l}H=68.9914 \\
p<0,0001\end{array}$ \\
\hline Verão-inverno & $\begin{array}{l}v=3.356 \\
i=3.650\end{array}$ & $\begin{array}{l}3.340 \\
3.675\end{array}$ & $\begin{array}{l}X^{2}=12.340 \\
p=0.0004\end{array}$ & $\begin{array}{l}H=49.559 \\
p<0,0001\end{array}$ \\
\hline Outono-primavera & $\begin{array}{l}o=3.467 \\
p=3.424\end{array}$ & $\begin{array}{l}3.503 \\
3.453\end{array}$ & $\begin{array}{l}X^{2}=6.972 \\
p=0.0083\end{array}$ & $\begin{array}{l}H=2.715 \\
p=0.099\end{array}$ \\
\hline
\end{tabular}

* As variâncias não são homogêneas

** outono-inverno / primavera-verão 


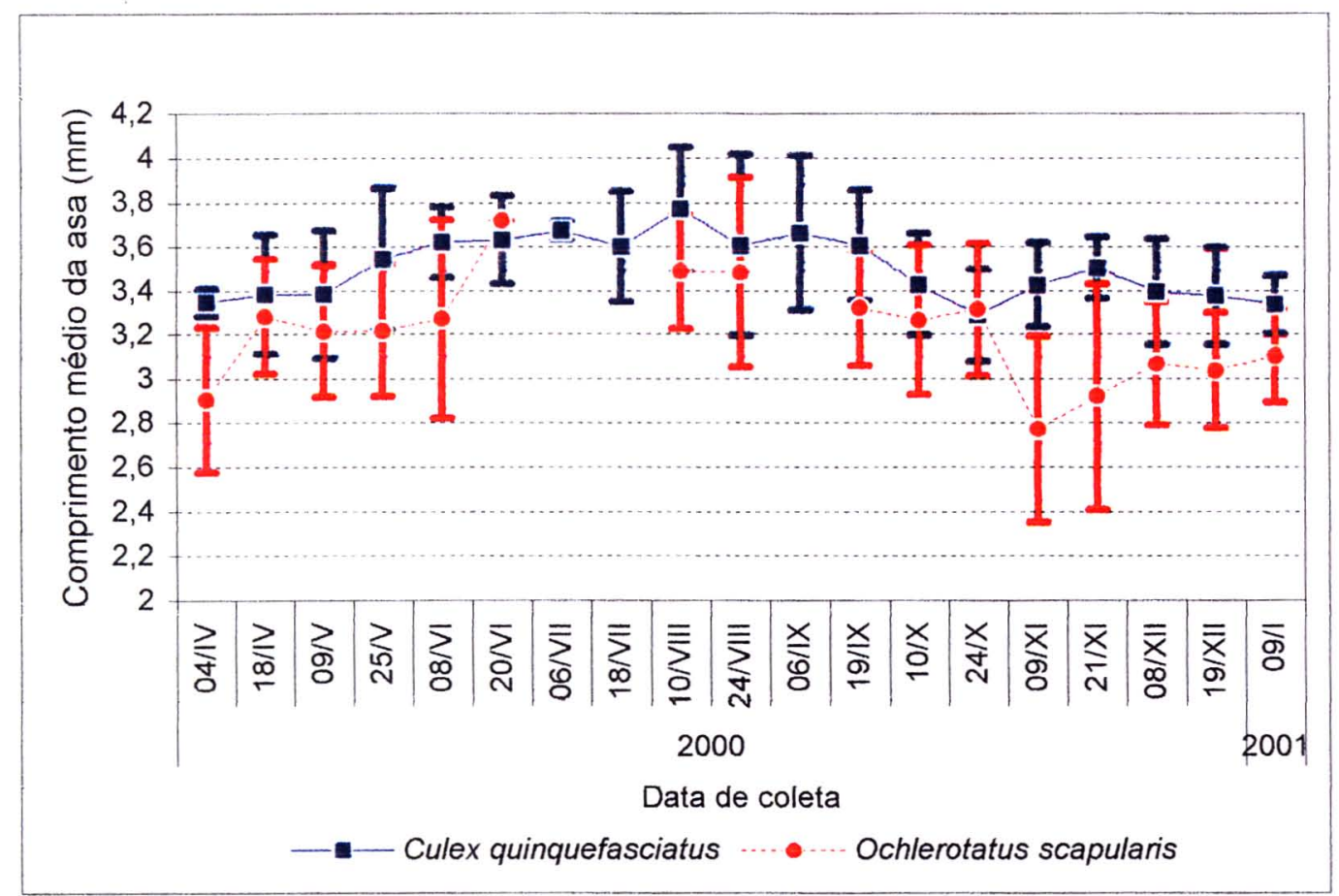

Figura 9. Variação sazonal da média do comprimento da asa em milímetros de Culex quinquefasciatus e Ochlerotatus scapularis coletados em abrigos do Parque Ecológico do Tietê na cidade de São Paulo de 04.IV.200 a 09.I.2001. 


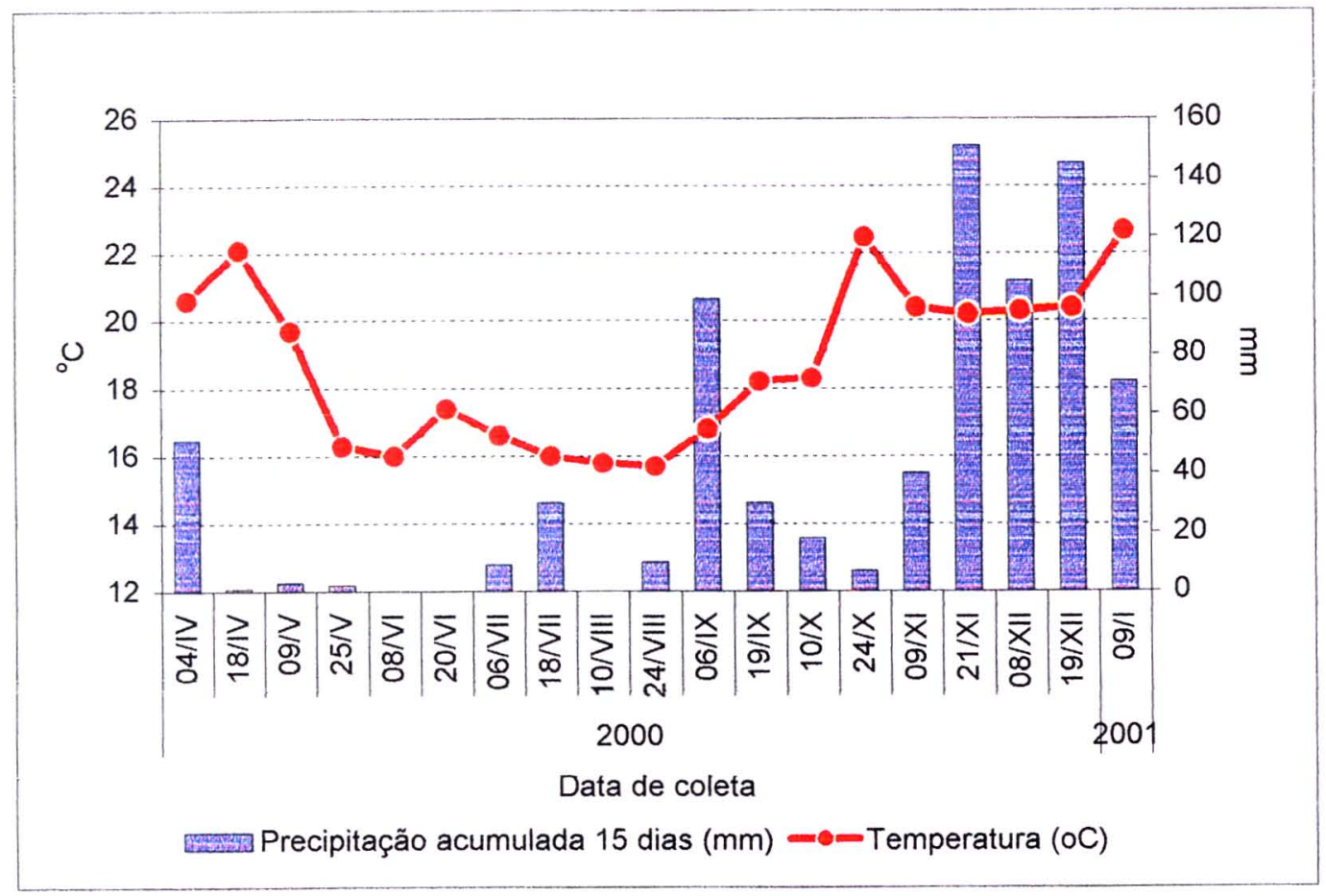

Figura 10. Média de temperatura e precipitação pluviométrica acumulada dos quinze dias que antecedem as datas de coletas, tomados durante o período de 04.IV.2000 à 09.I.2001. 


\subsection{O efeito do tamanho do mosquito no estado de paridade das fêmeas de Ochlerotatus scapularis e Culex quinquefasciatus.}

$\mathrm{Na}$ análise do efeito do tamanho do mosquito das duas populações aqui estudadas em relação ao estado de paridade das mesmas, utilizou-se o modelo de regressão simples comparando-se a variável dependente $(\mathrm{y})$, número de fêmeas paridas por data de coleta com a variável independente (x), média da asa do mosquito também por data de coleta.

Analisando $o$ modelo do número de fềmeas paridas de Culex quinquefasciatus em função da média de tamanho da mesma população, verificou-se que o modelo é adequado, pois o coeficiente de regressão $\left(\beta_{1}\right)$, é diferente de zero com $p=0,01$. A regressão explicou $39 \%\left(r^{\wedge} 2=39 \%\right)$ da variabilidade do número de fêmeas paridas (y) em relação à sua média. Quanto ao resíduo a média foi igual a zero $(\mathrm{p}=0.9985)$. A análise do $\mathrm{z}$ do erro mostrou uma média igual à $-0,2(\mathrm{p}=$ 0.33343 ) e a presença de três "outliers".

Equação estimada da reta: $Y=10.6-14.9$ tamanho

Estatística de Fisher e Snedecor: F $_{\mathbf{1 , 1 5}}=\mathbf{9 . 5 3}$

Coeficiente de correlação: $\mathbf{r}=\mathbf{- 0 , 6 2}$

Coeficiente de determinação: $\mathbf{r}^{\wedge} \mathbf{2}=\mathbf{0 , 3 9}$ 
A figura 11 mostra que, quando a média de tamanho da asa de Culex quinquefasciatus aumenta o número de fềmeas paridas decresce e que a relação pode ser expressa por uma significante regressão linear de forma que $Y=10.6-14.9 x$ onde $\mathrm{x}$ é a média de tamanho em milímetros transformada em $\log (\mathrm{y}+1)$ e y e o número de fềmeas paridas, transformados em $\log (\mathrm{x}+1)$.

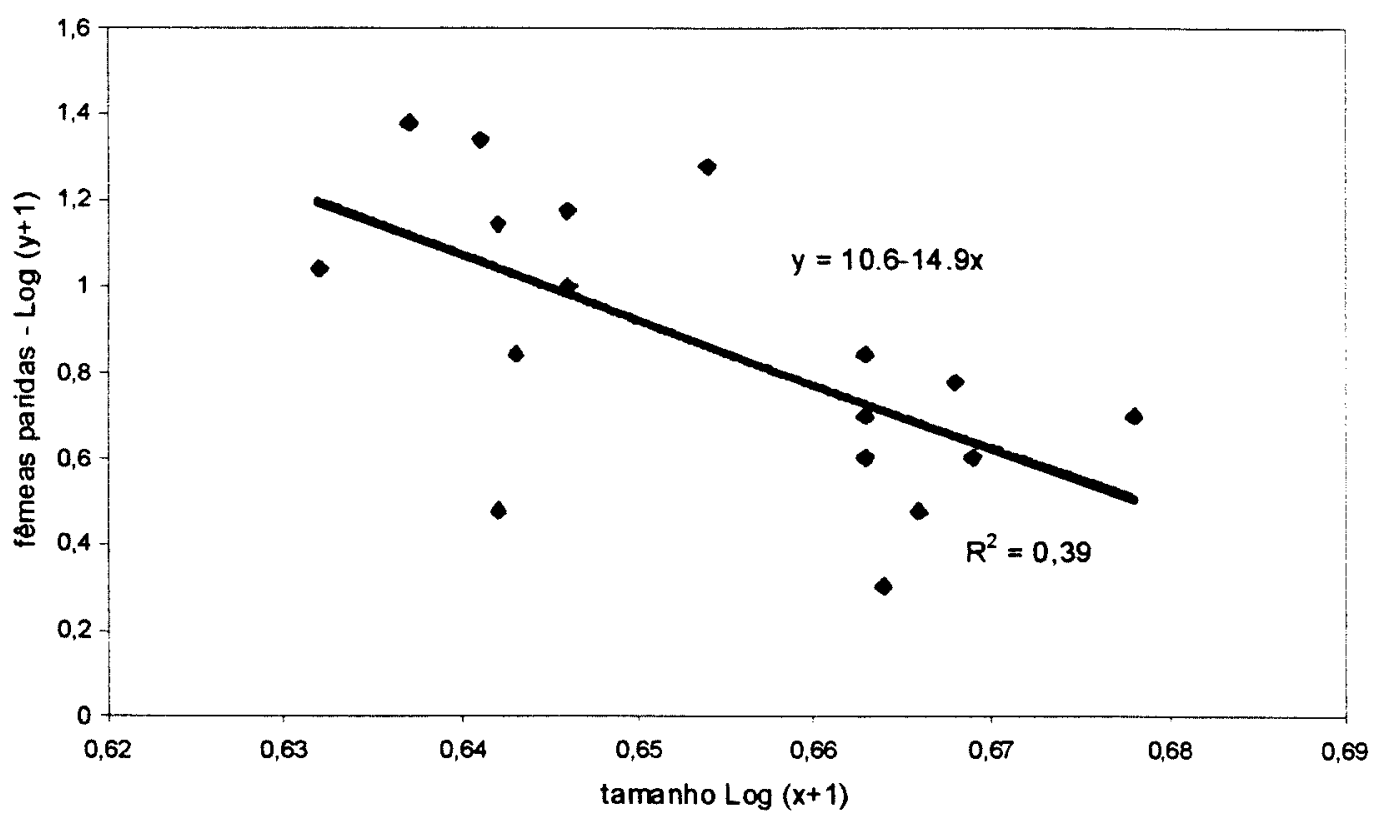

Figura 11. Efeito da média do comprimento da asa de Culex quinquefasciatus em relação ao número de fêmeas paridas, coletadas em diferentes habitats do Parque Ecológico do Tietê, na cidade de São Paulo, durante o período de 04/IV/2000 a $09 / 1 / 2001$.

Analizando-se do modelo do número de fêmeas paridas em função da média do comprimento da asa para Ochlerotatus scapularis verificou-se que a regressão explica apenas $18 \%\left(\mathrm{r}^{\wedge} 2=0,18\right)$, da variabilidade do y (número de fêmeas paridas), em relação à sua média. A função do tamanho não se explicou pelo modelo $\left(\beta_{1}=0\right.$, $p>0,05)$. Na análise do erro a média foi igual a zero com $p=0.9811$. Na análise do $z$ do erro observaram-se quatro "outliers" e a média deste foi igual a zero com $p=$ 0.95988 . 
A Equação estimada da reta: $\quad Y=5.9-7.8$ tamanho

Estatística de Fisher e Snedecor: $\mathbf{F}_{\mathbf{1 , 1 0}}=\mathbf{2 . 1 3}$

Coeficiente de correlação: $\mathbf{r}=\mathbf{- 0 . 4 2}$

Coeficiente de determinação: $\mathbf{r}^{\wedge} \mathbf{2}=\mathbf{0 , 1 8}$

Da análise de regressão para Ochlerotatus scapularis obteve-se o coeficiente de correlação de Pearson $(r=-0.42)$ indicando que existe $42 \%$ de correlação negativa entre tamanho do mosquito e estado de paridade (figura 12).

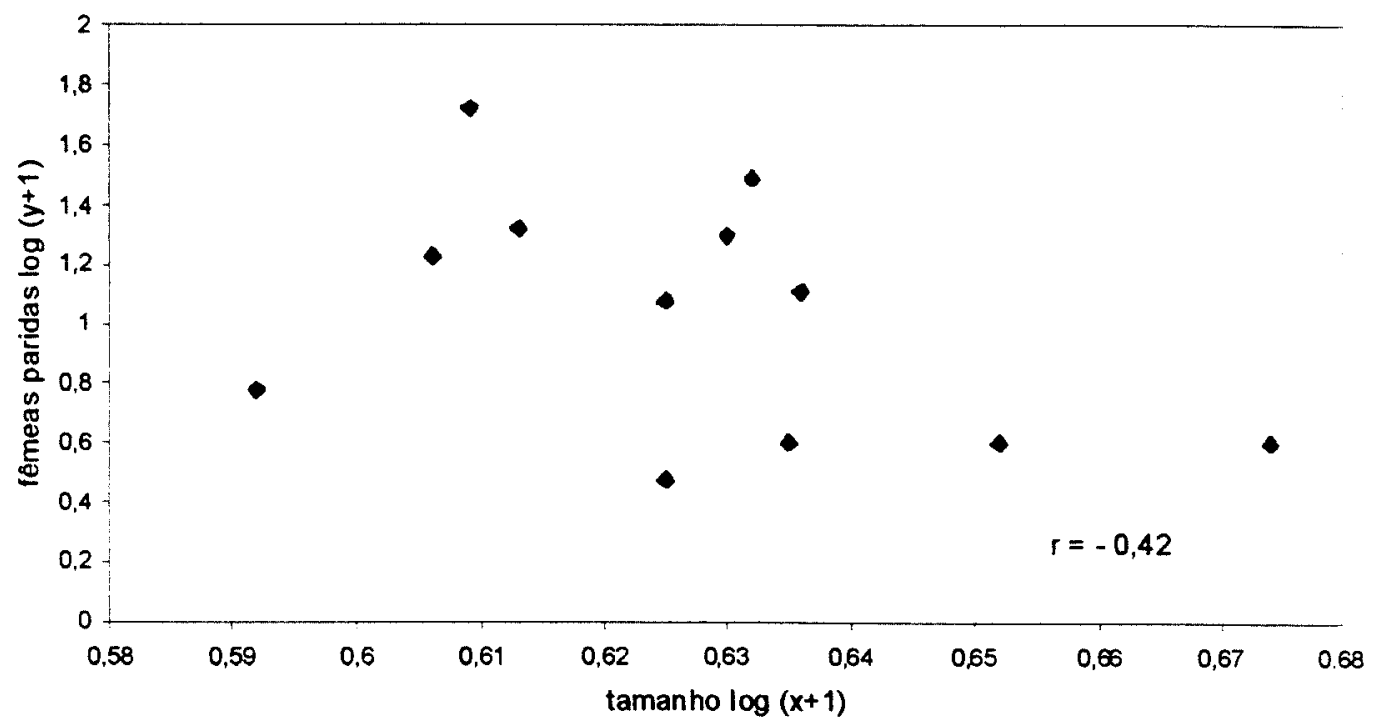

Figura 12. Correlação entre a média do comprimento da asa de Ochlerotatus scapularis e o número de fêmeas paridas coletadas em diferentes habitats do Parque Ecológico do Tietê, na cidade de São Paulo, durante o período de 04/IV 2000 a 09/1/2001. 


\section{DISCUSSÃO}

Como mencionado na introdução, registros científicos para as populações de mosquitos (Diptera:Culicidae), que habitam o Parque Ecológico do Tietê, apontaram Culex quinquefasciatus e Ochlerotatus scapularis como as espécies mais abundantes. Na ausência de um estudo de aspectos bioecológicos direcionado para as duas populações, decidiu-se por abordar esses aspectos determinando e avaliando, a distribuição entre os sexos, a paridade, o estágio fisiológico e o tamanho das fêmeas nessas populações, em seus abrigos e de acordo com as condições climáticas.

Muito provavelmente os aspectos bioecológicos das fêmeas de Culex quinquefasciatus e Ochlerotatus scapularis tenha sido regulado pela quantidade e qualidade do recurso alimentar, pela presença ou ausência de criadouros, ou ainda interações como predação e competição, que não constituiram objeto desse estudo.

\subsection{PARTIÇÃO dOS SEXOS ENTRE OS HABITATS}

Os resultados mostraram que as variáveis qualitativas habitat e sexo do mosquito estiveram associadas de forma significativa para Culex quinquefasciatus e Ochlerotatus scapularis, porém ficou evidenciado que ambas espécies não apresentaram a mesma partição por sexo entre os habitats pesquisados. A diferença de distribuição de machos e fêmeas de Culex quinquefasciatus entre os habitats ou abrigos, foi maior quando se comparou a mesma distribuição para Ochlerotatus scapularis.

A análise de residuos, segundo (PEREIRA 1999), revelou que a diferença entre os sexos foi mais acentuada no habitat densamente coberto por eucaliptos, para Culex 
quinquefasciatus, onde o percentual de machos contribuiu para elevar o valor de quiquadrado. No caso de Ochlerotatus scapularis a distribuição ficou mais acentuada no habitat de margem de mata por conta das fêmeas da espécie.

O predomínio de fêmeas de Ochlerotatus scapularis abrigadas nos habitats coberto por mata, em sua margem e no habitat densamente coberto por eucaliptos, podem indicar que estes locais estejam mais próximos da fonte de alimento e/ou do criadouro para oviposição.

A maior proporção de machos de Culex quinquefasciatus nos diferentes habitats do Parque Ecológico, podem indicar que os habitats amostrados estavam mais próximos aos criadouros para Culex quinquefasciatus. Ou ainda, que as fêmeas de Culex quinquefasciatus preferem se abrigar nos domicílios do interior do parque ou da periferia, onde encontram recurso alimentar da sua "preferência", obviamente trata-se de um mosquito eusinantrópico, a ponto de ser tomado como paradigma por FORATTINI e col. (2000), em estudo de potencial sinantrópico de mosquitos Kerteszia e Culex (Diptera:Culicidae). Nas dependências do Parque Ecológico foi encontrado por COSTA (2000), apresentando Índice de Sinantropia (IS $=31,7$ ), o maior registrado para os mosquitos do parque.

Segundo GOMES E FORATTINI (1990), as formas adultas de mosquitos constumam abrigar-se próximos aos seus criadouros ou às fontes de alimentação, isto ficou evidente para Culex quinquefasciatus, a margem de riacho poluído, adjacente à área urbana, foi o abrigo preferencial desses mosquitos. 


\subsection{DiSTRIBUIÇÃo DE FÊMEAS PARIDAS E NULÍPARAS ENTRE OS HABITATS}

\section{E AO LONGO DAS DIFERENTES ESTAÇÕES CLIMÁTICAS.}

A proximidade dos abrigos em relação aos criadouros para Culex quinquefasciatus ficou mais evidenciada, quando se observou que a proporção de fêmeas nulíparas para esta espécie foi maior nos diferentes habitats do interior do parque, comparada a proporção de nuliparas para Ochlerotatus scapularis nos mesmos habitats. Esta diferença percentual foi altamente significativa $\left(p<0,001\right.$ e $\left.\chi^{2}=31,5\right)$.

Na proximidade de criadouros, a proporção de nuliparas é sempre maior, visto que emergem das pupas constantemente, a exemplo do ocorrido na margem do riacho poluído, e nos habitats do interior do parque, onde a proporção de nuliparas de Culex quinquefasciatus foi superior a de paridas. Para o interior do parque, a diferença entre os dois estados fisiológicos foi muito significante $\left(p<0,001\right.$ e $\left.\gamma^{2}=28,7\right)$. Para a periferia do parque, a própria expressividade numérica, verificada na figura 2 indicou essa diferença significante. O habitat aspirado esta na margem do criadouro que estabelece condições favoráveis para esta espécie.

A alta proporção de fêmeas nulíparas, de acordo com VECRUSSE (1985), também poderia indicar mortalidade dos emergentes.

Segundo KAKITANNI e FORATTINI (2000), concomitantemente as fêmeas nulíparas deva ocorrer um número expressivo de mosquitos machos na proximidade do criadouro, a exemplo do ocorrido para Culex quinquefasciatus, nos habitats do interior e periferia do Parque Ecológico. 
O baixo número de fêmeas paridas de Culex quinquefasciatus abrigadas na periferia do PET, no habitat de margem de riacho poluído, era esperada, e pode indicar que as fêmeas procuram abrigo no interior dos domicilios onde obtêm o contato com o hospedeiro e, portanto com o sangue necessário para o amadurecimento de seus ovos. No interior do PET, não encontrando o alimento de sua "preferência", certa porcentagem dos indivíduos da população podem dispersar para a periferia, em direção aos domicílios, ou mesmo em direção aos domicílios presentes no interior do parque, razão pela qual encontramos também um número baixo de fêmeas paridas abrigadas nos habitats do interior do parque.

Fato é que, as fêmeas de Culex quinquefasciatus, que aparentemente conseguiram obter sucesso alimentar, evidenciado pelo estado físiológico de fêmea parida, estiveram presentes em maior proporção nos habitats de margem de mata, próximo à área administrativa e ao centro de recepção e apreensão de animais, onde a presença do homem é constante, e no habitat de campo brejo, próximo à rodovia Airton Senna, saida para a periferia do Parque Ecológico. Estudos de marcação soltura e recaptura poderiam esclarecer estas suposições.

A maior proporção de fêmeas paridas de Ochlerotatus scapularis, distribuídas nos habitats de vegetação aberta do interior do Parque Ecológico (figura 3), comparada às fêmeas paridas de Culex quinquefasciatus distribuidas pelos mesmos habitats, foi significativa $\left(p=0,01, \chi^{2}=16,6\right)$, sugerindo o caráter hemisinantrópico de Ochlerotatus scapularis já assinalados por COSTA (2000), para esta espécie no interior do Parque Ecológico e por FORATTINI e col. (1993, 1995) em ecossistema rural. 
As fêmeas paridas de Ochlerotatus scapularis apresentaram-se com o mesmo padrão de sazonalidade das nuliparas. Os valores registrados para os dois estados fisiológicos, durante os períodos de seca e de chuvas (figura 6), estiveram em consonância com os picos de densidade para as fêmeas dessa espécie, e com os valores mais altos de temperatura e precipitação pluviométrica (figuras 7 e 8 ).

Ao contrário de Ochlerotatus scapularis, paridas e nulíparas de Culex quinquefasciatus não apresentaram o mesmo padrão de sazonalidade, enquanto as primeiras estiveram em consonância com as altas médias de temperatura, ocorrendo mais durante o periodo de chuvas, as nuliparas estiveram de acordo com o padrão de sazonalidade verificado para as fềmeas da espécie (Figuras 7 e 8).

GOWDA e VIJAYAN (1993), estudando aspectos ecológicos relacionados a Culex quinquefasciatus em Mysore City na Índia, observaram o aumento da taxa de paridade para a espécie durante os meses de junho de 1988 (67,36\%) e janeiro de 1989 $(61,89 \%)$, quando a média de temperatura foi respectivamente $23,7^{\circ} \mathrm{C}$ e $21,9^{\circ} \mathrm{C}$.

A diferença estatística da distribuição de fêmeas nulíparas de Ochlerotatus scapularis durante os periodos de seca e de chuva, altamente significativa ( $p=0,001$ e $H$ $=10.8$, pode estar relacionada ao fato de que, sendo os criadouros de Ochlerotatus scapularis intermitentes, produzir mais mosquitos nos períodos de chuva e, portanto mais fêmeas nuliparas, diferentemente dos criadouros de Culex quinquefasciatus que sofrem menos com os periodos de dessecação produzindo mosquitos e, portanto fêmeas nuliparas, em proporçð̃es semelhantes ao longo das diferentes estaçð̃es. Fato é que, não se observou diferença estatística significante durante o periodo de chuvas e de seca para as nuliparas de Culex quinquefasciatus, encontradas na periferia e interior do Parque 
Ecológico. O teste de Kruskal-Wallis não revelou diferença significativa ( $p=0,0686$ e H $=3,3$ ), para as fêmeas nuliparas do interior do parque e uma diferença ainda menos significativa $(p=0,148$ e $H=2.09)$, para o habitat à margem do criadouro, periferia do parque.

Não consideramos significativa a diferença estatística, entre os períodos de seca e de chuva, encontrada para as fêmeas paridas de Ochlerotatus scapularis $(p=0,055$ e H $=$ 3,673). Notamos que, ao contrário das fêmeas paridas de Culex quinquefasciatus, estas apresentaram um número maior de paridas durante o outono e inverno (figuras 4,5 e 6 ), o que nos faz entender que as fêmeas de Ochlerotatus scapularis desenvolvem bem o seu ciclo gonotrófico mesmo em baixas temperaturas. No entanto, observamos diferença significativa na distribuição de fêmeas paridas de Culex quinquefasciatus entre as estações seca e chuvosa tanto na periferia como no interior do Parque Ecológico, sendo que na periferia a diferença foi ainda mais significativa, o que pode estar associado ao fato de que no verão a densidade de fêmeas de Culex quinquefasciatus foi maior (figura 7), adicionados ao recurso alimentar que é abundante e constante no habitat da periferia, à margem do criadouro.

\subsection{FASES DO DESENVOLVIMENTO OVARIANO DOS MOSQUITOS, SEgUNDO OS} DIFERENTES ABRIGOS E ESTAÇÕES DO ANO.

$\mathrm{O}$ predomínio de fêmeas de Culex quinquefasciatus na fase $\mathrm{V}$ do desenvolvimento folicular, $(165=56,3 \%)$, no habitat de margem de riacho poluído, periferia do Parque Ecológico do Tietê (tabela 3), pode ser explicado pelo fato de que, estando as populações de mosquitos em um habitat periférico a área urbana, tiveram 
sucesso em obter o alimento abundante e constante nas proximidades do criadouro. Fato é que foram freqüentes ao longo de todas as estações climáticas, apresentando praticamente a mesma proporção durante as estações de verão, primavera e inverno.

Segundo NATAL (1991), o maior percentual de fêmeas grávidas nas áreas de campo aberto imediatamente próximas aos criadouros, pode significar um acúmulo destas formas que estariam aguardando o momento da oviposição.

A presença de fêmeas grávidas coletadas ao longo de todas as estações do ano para Culex quinquefasciatus, na periferia do PET, concomitantemente com o alto número de nuliparas (fềmeas jovens), pode indicar uma alta reprodução da espécie ao longo de todas as estações.

Chama a atenção, o fato de que mesmo no inverno $49(29,7 \%)$ das fêmeas de Culex quinquefasciatus, uma proporção um pouco maior comparado às proporções da primavera e verão, apresentaram-se no estágio V de Christophers e Mer (tabela 6). Durante este periodo, as médias de temperatura estiveram abaixo de $20^{\circ} \mathrm{C}$ (figura 8).

Ao contrário dos nossos resultados, REISEN e col. (1992), estudando o efeito da temperatura no ciclo gonotrófico de Culex quinquefasciatus, em Los Angeles, Baía da Califórnia, verificaram aumento significante da maturação do ovário de fềmeas de Culex quinquefasciatus, para o estágio $\mathrm{V}$ de Christophers e Mer, em temperaturas que variaram de $20^{\circ}$ a $30^{\circ} \mathrm{C}$.

A constatação da presença de fềmeas de Ochlerotatus sapularis e Culex quinquefasciatus nas fases III, IV e V do desenvolvimento folicular com intestino médio totalmente cheio de sangue vermelho, ao longo das diferentes estações do ano e habitats do Parque Ecológico representam um indício de discordância gonotrófica para as duas 
populações de mosquitos, ou seja, tudo indica que essas populações tendem a realizar mais de um repasto sanguíneo antes de completar o ciclo gonotrófico. Esta tendência tem sido relatada para algumas espécies de mosquitos culicideos (BRIEGEL e HÖRLER 1993; BARATA e col. 2001).

Segundo BRIEGEL e HÖRLER (1993), muitos repastos sanguíneos realizados por mosquitos com discordância gonotrófica representam uma estratégia adaptativa aos baixos níveis de reservas de glicogênio armazenados pelos mosquitos adultos ao emergir. Os déficits seriam compensados por uma realimentação durante o ciclo gonotrófico (HURD e col. 1995).

Os múltiplos repastos sanguineos realizados por estes mosquitos são importantes na medida que aumentam as chances dos mesmos veicularem arbovírus no interior do parque, ou mesmo do interior para a periferia, o que poderia ser facilitado pelo Culex quinquefasciatus que coloniza os habitats da periferia e interior do Parque Ecológico.

SCOTT e col (1993), afirmam que esses repastos aumentam as chances dos mosquitos vetores, com baixa longevidade, de adquirir ou transmitir um agente etiológico.

Pôde-se observar na tabela 5, que as fêmeas de Ochlerotatus scapularis que se encontravam na fase III de Christophers e Mer, buscaram um suposto segundo repasto sangüineo no habitat de margem de mata, onde foram encontradas em maior percentual, $(44=15,7 \%)$. É possível que essas fêmeas tenham mais oportunidades em obter o alimento, neste habitat, pois o recurso esta representado pelas populações de animais silvestres que vivem livres, bem como, por aquelas que vivem em cativeiro. Como já foi exposto este habitat tem uma área destinada à recepção e apreensão de animais 
silvestres. Os animais livres concentram-se nesta área do parque em busca de alimento (frutas, legumes e verduras) que são levados pelos tratadores de animais, durante o periodo da manhã.

De qualquer forma não podemos nos esquecer que os vertebrados que representam alimento para os mosquitos culicídeos, principalmente as aves, migram entre os habitats no interior do parque, e que os mosquitos dispersam ativamente a procura do alimento ou mesmo passivamente levados pelo vento. Parece-nos que, considerações com relação à obtenção de alimento ficam mais evidenciadas para os habitats que apresentam uma concentração de população hospedeira mais fixa, a exemplo da margem de mata e margem de riacho poluído. Modelos que levassem em consideração os deslocamentos de animais no interior do PET e dos mosquitos bem como o habito alimentar dos mesmos talvez pudessem esclarecer melhor essa questão.

Segundo LYMO E TAKKEN (1993), em condições tropicais fêmeas adultas de mosquitos (Diptera:Culicidae) produzem um lote de ovos a cada repasto sangüineo, processo conhecido como concordância gonotrófica, porém quando a oogênese alcança tardiamente o estágio II, após o primeiro repasto sanguíneo, um segundo repasto seria necessário para a complementação do ciclo gonotrófico. CLEMENTS (1963) denominaria essas fêmeas de pré-grávidas. SINGH e MOHAN (1951) afirmam que esta tendência pode ser atribuída à não inseminação de fêmeas.

A presença de fêmeas na fase IV de Christopher e Mer, sem indícios de alimentação prévia de sangue observada para Culex quinquefasciatus e Ochlerotatus scapularis (tabelas 4,5 e $6-7,8$ e 9), leva-nos a considerar que uma pequena parcela 
dessas populações pode produzir ovos sem uma prévia alimentação de sangue, o que poderia indicar autogenia.

Segundo CHARLWOOD (1980), pode-se inferir autogenia quando o número de nulíparas for muito pequeno ou quando fêmeas grávidas (fase V) ou subgrávidas (faseIV), forem capturadas sem evidências de ter obtido uma prévia alimentação de sangue.

Cabe ressaltar que Ochlerotatus scapularis apresentou fêmeas na fase IV de Christopher e Mer, sem indícios de alimentação de sangue, em todos os habitats e ao longo de todas as estações climáticas (tabelas 5 e 8). Os maiores percentuais foram observados no habitat de mata e durante as estações do inverno e primavera.

Contudo, a grande maioria das fêmeas de Ochlerotatus scapularis e Culex quinquefasciatus, apresentou o intestino contendo sangue desde as fases I e II de Christophers e Mer, tanto em relação à distribuição nos diferentes habitats quanto em relação às estações climáticas, o que é um indício de anautogenia. Segundo (CHARLWOOD e col, 1980), os foliculos não se desenvolvem além da fase II, sem que a fêmea obtenha um repasto sangüineo.

ROSAY (1969), observou dilatações aberrantes no pedicelo ovariolar de fêmeas de Culex pipiens quinquefasciatus, Culex restuans e Culiseta melanura, que nunca tinham se alimentado de sangue, conseqüência de uma contínua formação de folículos pelo germário.

NAYAR E KNIGHT (1981), discutem que a presença de dilatações para Culex nigripalpus em fêmeas nuliparas, poderia estar associada com o desenvolvimento de ovos por autogenia. Repetem as sugestões feitas por ROSAY (1969), para as espécies do 
gênero Culex, e afirmam que a condição de contínua formação de folículo pelo germário, é diferente da observada para os mosquitos do gênero Anopheles e para a maioria dos mosquitos do gênero Aedes, quando a formação do folículo pelo germário cessa após o folículo primário alcançar a fase II, e somente um repasto sangüíneo estimula o desenvolvimento do folículo primário.

\subsection{VARIAÇÃo SAZONAL NO TAMANHO CORPÓREO NAS POPULAÇÕES DE Culex quinquefasciatus E Ochlerotatus scapularis.}

Partindo-se do princípio que o comprimento da asa de um mosquito está relacionado com o tamanho do corpo (CHRISTOPHERS 1960), e que o tamanho do corpo pode variar nas populações de Culex quinquefasciatus e Ochlerotatus scapularis, bem como ao longo das diferentes estações climáticas, foi realizada a mensuração do tamanho médio da asa das populações das duas espécies de mosquitos, provenientes de amostras coletadas em diferentes habitats do Parque Ecológico do Tietê, na cidade de São Paulo, durante o periodo de 04/IV/00 a 09//01.

A análise temporal das médias do comprimento de asa de Culex quinquefasciatus e Ochlerotatus scapularis, revelou pequena variação de tamanho para cada uma dessas populações entre as datas de coleta (tabelas 9 e 10). Contudo, os resultados indicaram que Culex quinquefasciatus foi maior que Ochlerotatus scapularis ao longo das datas de coleta ou das diferentes estações climáticas (figura 9), e que essa diferença foi altamente significativa $(H=244,8$ e $p<0,001)$. 
Observou-se que o tamanho médio de Ochlerotatus scapularis variou ao longo das estações climáticas, porém a amplitude de variação foi maior quando comparamos as estações climáticas com características extremas, como por exemplo, o verão e o inverno. A ANOVA indicou que a diferença de variação de tamanho deste mosquito durante $o$ inverno e verão, foi altamente significante $(F=41,8$ e $p<0,001)$. No entanto, para Culex quinquefasciatus, a diferença de variação foi tão significativa no período de verão e inverno $(H=49,5$ e $p<0,0001)$ quanto durante o periodo seco e chuvoso $(H=68,9$ e $p<0,001)$.

Durante o período seco-chuvoso a variação de tamanho para Ochlerotatus scapularis foi pouco significativa (tabela 11), muito provavelmente porque neste período estão contidas as estações de outono e primavera onde se registrou as menores médias de comprimento de asa para a espécie e que por sua vez determinaram a não significância estatística quando da comparação destas duas últimas estações (tabelas 10 e 11).

A exemplo de Ochleloratus scapularis, não se encontrou diferença de variação significativa no tamanho médio de Culex quinquefasciatus, durante a comparação das estações de primavera e outono.

A diferença de variação significativa registrada na comparação das estações de inverno e verão ocorre, visto que as maiores médias de comprimento da asa para as duas populações de mosquitos coincidem com os periodos de baixa temperatura e precipitação pluviométrica (figura 9). Culex quinquefasciatus e Ochlerotatus scapularis, apresentaram respectivamente $(3.769 \pm 0,28 \mathrm{~mm})$ e $3.719 \mathrm{~mm}$ durante o período do inverno (tabelas 9 e 10). 
Muito provavelmente o tamanho médio do corpo de Culex quinquefasciatus e Ochlerotatus scapularis, esteve relacionado ao desenvolvimento larval que por sua vez é determinado pela oscilação de temperatura no transcorrer das estações climáticas ou por interações nos criadouros como já foi abordado para outros culicídeos por ( LORENZ e col. 1990, HARAMIS 1983, NASCI 1986).

As baixas temperaturas registradas durante o período do inverno (tabela 13), podem ter retardado o desenvolvimento larval de Culex quinquefasciatus e Ochlerotatus scapularis. Provavelmente as larvas permaneceram por mais tempo nos criadouros se alimentando e armazenando energia, dando origem a mosquitos maiores.

A abundância ou escassez de recurso alimentar nos criadouros, bem como a competição pelo alimento, podem ter sido determinantes na variação de tamanho de Culex quinquefasciatus e Ochlerotatus scapularis. LORENZ e col. (1990), estudando Culiseta melanura em condições de laboratório, sugeriu que a competição por alimento pode ser determinante no tamanho dos insetos em condições naturais.

No caso específico de Culex quinquefasciatus, que se desenvolve em criadouro com alto teor de matéria orgânica, por vezes impraticável para outros insetos, a abundância de alimento durante todas as estações climáticas devido à falta de competição (ou menor competição), poderia ter determinado o maior tamanho deste mosquito ou a menor variação de tamanho verificada ao longo de todas as datas de coleta (figura 9), quando se compara com Ochlerotatus scapularis. Talvez o fator que limite o tamanho de Culex quinquefasciatus seja a temperatura, não obstante o recurso alimentar possa ficar mais abundante durante o periodo de inverno quando o criadouro é menos "diluído" pela escassez de chuvas. 
CLEMENTS (1992) e TIMMERMANN (1993), afirmam que o tamanho do corpo do mosquito (medido pelo comprimento da asa), é inversamente relacionado com as condições de temperatura dos criadouros e positivamente relacionado com a nutrição larval.

As menores médias de comprimento da asa registradas durante a primavera respectivamente $(3.290 \pm 0,21 \mathrm{~mm})$ para Culex quinquefasciatus e $(2.774 \pm 0,42 \mathrm{~mm})$ para Ochlerotatus scapularis, contradizem as afirmações de NASCI (1986) e corroboram as de HARAMIS (1983). O primeiro autor, afirma que o efeito da temperatura baixa da água no inverno retarda o desenvolvimento larval, sendo que o mosquito adulto resultante na primavera, proveniente daquelas larvas são maiores. O segundo, afirma que com o aquecimento da água dos criadouros durante a primavera e verão, o desenvolvimento da larva se acelera resultando em adultos menores.

\subsection{O EFEITO DO TAMANHO DO CORPO DE Culex quinquefasciatus E Ochlerotatus}

\section{scapularis SOBRE A PARIDADE DOS MESMOS}

A investigação da variação do tamanho do corpo dos mosquitos relacionado a aspectos da capacidade vetorial a exemplo da longevidade, infectividade, sucesso em obter o alimento no campo, a fecundidade e taxa de paridade, tem sido objeto de estudo de diversos autores pelo mundo (NASCI 1986; CHADEE 1993; LORENZ e col. 1990; MENDOZA e LOURENÇO-DE-OLIVEIRA 1996; LYMO e KOELLA 1992; ULLOA e col. 1997; LYIMO e TAKKEN 1993; LOUNIBOS e col. 1990).

Neste estudo objetivamos verificar o efeito do tamanho das fêmeas de Culex quinquefasciatus e Ochlerotatus scapularis em relação à taxa de paridade para as duas 
populações. Para tanto os valores de média do comprimento da asa em milímetros desses mosquitos foi relacionada com o número de fêmeas paridas, por data de coleta, através do modelo de regressão univariada.

Apesar de alguns estudos indicarem que mosquitos maiores são insistentes sugadores de sangue, portanto apresentam uma taxa de paridade maior quando comparados a mosquitos de tamanho pequeno (NASCI 1986; HARAMIS 1983; PACKER e CORBET 1989), não observamos um efeito crescente da função do tamanho em relação ao número de fêmeas paridas para Culex quinquefasciatus, ao contrario o modelo de regressão mostrou que à medida que aumentou a média do comprimento da asa desse mosquito o número de fêmeas paridas decresceu.

O coeficiente de determinação $\left(\mathrm{r}^{\wedge} 2=0,39\right)$, explicou $39 \%$ do modelo de regressão e foi obtido através de uma transformação logaritmica sugerida por ULLOA e col. (1997), SIEGEL e col. (1992), HU e col. (1993). No modelo também obtivemos que as variáveis, média da asa de Culex quinquefasciatus e número de fêmeas paridas apresentaram $62 \%(r=-0,62)$ de correlação negativa.

A função do tamanho médio de Ochlerotatus scapularis em relação ao número de fềmeas paridas, não se explicou pelo modelo de regressão apesar da transformação logarítmica. Contudo o coeficiente de correlação de Pearson, obtido através do modelo, indicou $42 \%(r=-0,42)$ de correlação negativa entre tamanho médio desse mosquito e número de fêmeas paridas.

Aparentemente nossos resultados indicam que quanto menor o mosquito maior foi à paridade e, portanto maior sucesso em obter o alimento, contudo outras variáveis poderiam estar ajustando o modelo de regressão, a exemplo da média de temperatura 
ambiental e densidade das fêmeas dos mosquitos estudados, uma vez que observamos consonância das fêmeas paridas de Ochlerotatus scapularis e Culex quinquefasciatus, com as médias mais altas de temperatura e altos valores de densidade de fêmeas destes mosquitos. Também as variáveis intrinsecas, como por exemplo, o número de fêmeas grávidas, ou na fase III de Christophers e Mer com intestino cheio de sangue, ou seja, que realizaram mais de um repasto sangüineo para completar a oogênese, poderiam estar ajustando o modelo.

CHAMBERS E KLOWDEN (1990), constataram que as fêmeas de mosquitos Aedes aegypti, de menor tamanho necessitam de dois repastos sangüineos para completar a primeira oogênese, enquanto para as fêmeas maiores apenas um repasto é suficiente. Outras investigaçð̃es ainda revelaram que não existe relação entre tamanho do corpo como medida de freqüência de paridade (LANDRY e col. 1988; WALKER e col. 1987). 


\section{CONCLUSÕES}

- Ficou evidenciado que Culex quinquefasciatus e Ochlerotatus scapularis, não apresentaram a mesma partição por sexo nos habitats pesquisados. A alta proporção de machos e de fêmeas nulíparas para Culex quinquefasciatus nos diferentes habitats amostrados, indicam a proximidade do criadouro em relação aos habitats que se constituíram em abrigos.

- Os habitats que se constituíram em abrigos, diferem com relação a distribuição de fêmeas paridas e nuliparas de Culex quinquefasciatus e Ochlerotatus scapularis, levanta-se a suposição de que esta diferença pode ser devida a proximidade com o criadouro ou com a disponibilidade do recurso alimentar.

- Paridas e nulíparas de Ochlerotatus scapularis, apresentam o mesmo padrão de distribuição sazonal. A diferença da distribuição de nulíparas durante os períodos de seca e de chuva é mais significante do que a das paridas.

-Paridas e nuliparas de Culex quinquefasciatus não apresentam o mesmo padrão de distribuição sazonal. As paridas apresentam os valores máximos durante a primavera e início do verão. Esses valores foram mais significativos comparados aos que ocorreram durante o periodo de seca, tanto para o habitat da periferia, como para os habitats do interior do PET. As nuliparas ocorrem de forma expressiva, tanto durante o período seco quanto durante o período de chuvas. Ficou evidenciado que, não foi significativa a 
diferença da distribuição de fềmeas nulíparas de Culex quinquefasciatus, ao longo dos periodos de seca e de chuva, na periferia e no interior do PET.

- A presença de fêmeas de Culex quinquefasciatus e Ochlerotatus scapularis, nas fases III, IV e V do desenvolvimento folicular, com o intestino totalmente cheio de sangue vermelho, amostradas, nos diferentes habitats do Parque Ecológico do Tietê e ao longo das diferentes estações, indicam que as duas populações de mosquitos apresentam discordância gonotrófica.

- Culex quinquefasciatus é maior em tamanho comparado a Ochlerotatus scapularis. O tamanho médio do corpo dos dois mosquitos é maior durante o periodo seco. As médias de comprimento de asa para as duas populações atingem o valor máximo durante o inveno.

- A relação entre tamanho médio do corpo de Culex quinquefasciatus e Ochlerotatus scapularis e freqüência de fêmeas paridas foi negativa. $\mathrm{O}$ tamanho médio do corpo não produziu efeito positivo sobre o número de fêmeas paridas. Tamanho e paridade estiveram correlacionados negativamente. Quanto maior foi o tamanho menor foi o número de fêmeas paridas. Levanta-se a suposição de que o tamanho do corpo das duas populações não tenha relação com a paridade das mesmas ou que outros fatores. como por exemplo, o percentual de fêmeas que realizam mais de um repasto sangüineo. ou que conseguiram chegar ao $\mathrm{V}$ estágio de desenvolvimento de Christopher e Mer, ou mesmo 
fatores extrinsicos, como por exemplo, a temperatura, poderiam estar correlacionados ajustando o modelo. 


\section{REFERÊNCIAS}

Arnell JH. Mosquitoes studies (Diptera, Culicidae) XXXIII - A revision of scapularis group of Aedes (Ochlerotatus). Contr Am Entomol Inst 1976; 13: 1-144.

Barata EAMF, Costa AIP, Chiaravalloti Neto F, Glasser CM, Barata JMS, Natal D. População de Aedes aegypti (1.) em área endêmica de dengue, Sudeste do Brasil. Rev Saúde Pública 2001; 35(3):1-9.

Barata EAMF. Idade Fisiológica de Anopheles(Kerteszia)cruzii dyar \& Knab, 1909 (Diptera:Culicidae) em populações de campo no Município de Cananéia, São Paulo, Brasil; 1988. [Tese de Mestrado - Instituto de Biociência da USP].

Briegel H, Hörler E. Multiple blood meals as a reproductive strategy in Anopheles (Diptera:Culicidae) J Med Entomol 1993; 30(6):975-985.

Campos JRM, Barbas CSV, Filomeno LTB, Fernandez A, Minamoto H, Barbas Filho JV. Human pulmonary dirofilariasis. Analisis of 24 cases from São Paulo, Brazil. Chest 1997; 112: 729-733. 
Chadee DD. Size of emerging and host-seeking Aedes aegypti and the relationship to containers and blood - feeding success in Trinidad West Indies. Bull Soc Vector Ecol $1993 ; 18(2): 105-108$.

Chambers GM, Klowden MJ. Correlation of nutritional reserves with a critical wight for pupation in larval Ae aegypti mosquitoes. J Am Mosq Control Assoc 6: 394-399.

Charlwood JD, Rafael JA, Wilkes TJ. Métodos de determinar a idade fisiológica em Diptera de importância médica. Uma revisão com especial referência aos vetores de doenças na América do Sul. Acta Amazônica 1980; 10(2): 311-333.

Christophers SR. Aedes aegypti (L): The Yellow fever Mosquito - Its life history, bionomics, and structure. 1960; Cambridge University Press, xii $+739 p$.

Christophers SR. The development of the egg follicle in anophelines. Paludism, 1911; 2:73-89.

Clementes NA. The Physiology of Mosquitoes. Pergamon Press, Oxford; 1963.

Clementes AN. The Biology of Mosquitoes. Chapman \& Hall; 1992.

Consoli RAGB, Lourenço-de-Oliveira R. Principais mosquitos de importância sanitária no Brasil. Rio de Janeiro: FIOCRUZ; 1994 
Costa CBTL. Ecologia de Culicideos em Área Protegida Inserida no Ecossistema Urbano, 1996-1998. Guarulhos. São Paulo; 2000 [Tese de Doutorado - Faculdade de Saúde Pública da USP].

Dean AG, Dean JA, Coulombier D, Brendel KA, Smith DC, Burton AH, Dicker RC, Sullivan KM, Fargan RF, Arner TG. Epi-info, version 6: a word processing data base, and statistics program for epidemiology on microcomputer. Atlanta, Center for Disease Control on Prevention, 1994.

Departamento de Águas e Energia Elétrica (DAEE). Parque Ecológico do Tietê. Uma idéia a ser aprimorada. Rev Águas e Energia 1989; 16: 7-13.

Detinova TS. Methods of determining the physiological age of female. Age grouping methods in Diptera of medical importance. Geneva; 1962 (Wld. Hlth. Org. Monogr N47).

Forattini OP. Entomologia Médica. São Paulo: Edusp; 1962. v.1.

Forattini OP. Ecologia, Epidemiologia e Sociedade. São Paulo: Artes Médicas: Edusp; 1992.

Forattini OP. Culicidologia Médica. São Paulo: EDUSP; 1996. 
Forattini OP, Kakitani I, Massad E, Marucci D. Studies on mosquitoes (Diptera:Culicidae) and anthropic environment. 4-Survey of resting adults and synanthropic behavior in South-Eastern, Brasil. Rev Saúde Pública 1993; 27: 398-411.

Forattini OP, Kakitani I, Massad E. Marucci D. Studies on mosquitoes (Diptera:Culicidae) and anthropic environment 9 - Synantropy and epidemiological vector role of Aedes scapularis in South-Eastern Brazil. Rev Saúde Pública 1995; 29:199-207.

Forattini OP, Kakitani I, Santos R La Corte, Kobayashi KM, Ueno HM, Fernández Z. Potencial Sinantrópico de mosquitos Kesteszia e Culex (Diptera:Culicidae) no Sudeste do Brasil. Rev Saúde Pública 2000 34(6): 1 -9

Gomes AC, Forattini OP. Abrigos de mosquitos Culex (Culex) em zona rural (Diptera:Culicidae). Rev. Saúde Pública 1990; 24(5):394-7.

Gowda NN, Vijayan VA. Biting density, behavior and age distribution of Culex quinquefasciatus, Say in Mysore City, India. Southest Asean J Trop Med Public Health $1993 ; 24(1): 152-156$. 
Grimstad PR, Haramis LD. Aedes Triseriatus (Diptera:Culicidae) and La Crosse vírus III Enhanced oral transmisssion by nutrition-deprived mosquitoes. Journal of Medical Entomology 1984; 21:229-62.

Haramis LD. Increased adult size correlated with parity in Ae. trisseriatus. Mosq News $1983 ; 43(1): 77-8$.

Harbach RE, Dahl C, White GB. Culex (Culex) pipiens Linnaeus (Diptera:Culicidae): concepts, type, and descriptions. Proc Entomol Soc Wash 1985; 87(1):1-24.

Hoc TQ. A method for the rapid recognition of nulliparous and parous females of haematophagous Diptera. Bull Ent Res 1996; 86:137-141.

Hu GY, Lounibos LP, Escher RL. Seazonal abundance, Age Composition, and Body Size of SALT-Marsh Anopheles (Diptera:Culicidae) in South Florida. J Med Entomol $1993 ; 30(5): 883-887$.

Hurd H, Hogg JC, Renshaw M. Interactions between blood feeding fecundity and infection in Mosquitoes. Parasitology Today 1995; 11(11): 411-416.

Kakitani I, Forattini OP. Paridade e desenvolvimento ovariano de Anopheles albitarsis 1.s em área de agroecossistema irrigado. Rev Saúde Pública 2000; 34 (1):1-11. 
Kakitani I. Observações preliminares sobre a paridade de Anopheles(Kerteszia)cruzii São Paulo; 1992. [Tese de Mestrado - Faculdade de Saúde Pública da USP].

Labarthe N, Serrão ML, Melo YF, Oliveira SJ, Lourenço-de-Oliveira R. Potential vectors of Dirofilaria immitis (Leidy, 1856) in Itacoatiara, oceanic region of Niterói Municipality State of Rio de Janeiro, Brasil. Mem Inst Oswaldo Cruz 1998; 93 (4): $425-432$.

Landry SV, De Foliart GR, Hog DB. Adult body size and survivorship in a field population of Aedes triseriatus. J Am Mosq Control Assoc 1988; 4: 121-128.

Lorenz LH, Scott TW, Anderson RA, Edman JD, Grans WJ, Costa SD. The relationship between size parity status of field collected Culiseta Melanura. J Am Mosq Control Assoc 1990; 6(3): 433-440.

Lounibos LP, Larson VL, Morris CD. Parity, Fecundity and Body Size of Mansonia dyari in Florida. J Am Mosq Control Assoc 1990; 6(1):121-126.

Lounibos LP, Nishimura JC, Lourenço-de-Oliveira, R. Life History correlates of adult size in the malaria vector Anopheles darlingi. Mem Inst Oswaldo Cruz 1995; 90(6): 769-774. 
Lyimo EO, Koella JC. Relationship between body size of adult Anopheles gambiae s.l and infection with the malaria parasite Plasmodium falciparum. Parasitology 1992; 10(4):233-237.

Lyimo EO, Takken W. Effects of adult body size on fecundity and the pre-gravid rate of Anopheles gambiae females in Tanzania. Med Vet Entomol 1993; 7: 328-332.

Macedo FC, Labarthe N, Lourenço-de-Oliveira R. Suceptibility of Aedes scapularis (Rondani, 1848) to Dirofilaria immitis (Leidy, 1956), an Emerging Soonosis. Mem Inst Oswaldo Cruz 1998; 93(4):435-437.

Mendoza CF, Lourenço-de-Oliveira R. Bionomics of Anopheles aquasalis Curry 1932, In Guarai, State of Rio de Janeiro, Southeastern Brazil - I. Seasonal Distribution and Parity Rates. Mem Inst Oswaldo Cruz 1996; 91(3): 265-270.

Mer GG. Experimental study on the developmente of the ovary in Anopheles elutus Edw. (Diptera:Culicidae). Bull. Ent. Res. 1936; 27:351-359.

Mitchell CJ, Forattini OP. Experimental transmission of Rocio encephalitis virus by Aedes scapularis (Diptera:Culicidae) from the epidemic zone in Brazil. J Med Entomol $1984 ; 21: 34-7$ 
Nasci RS. A lightweight battery-powered aspirator for collecting resting mosquitoes in the field. Mosq News $1981 ; 41: 808-11$.

Nasci RS. Relationship between adult mosquito (Diptera:Culicidae) body size and parity in field populations. Environ Entomol 1986; 15: 874-6.

Natal D, Paganelli CH, Santos JLF. Composição da população de Culex (Culex) quinquefasciatus Say, 1823 em ecótopos próximos à Represa Edgard de Souza, no Município de Santana do Parnaíba, Estado de São Paulo, Brasil. Rev Bras Ent 1991; 35(3): 539-43,

Nayar JK, Knight JW. Occurrence of Ovariolar Dilatations in Nulliparous Mosquitoes: Culex nigripalpus. Mosq News 1981; 41(2):281-287.

Niebylsk ML, Meek CL. Blood-feeding of Culex mosquitoes in an urban enviroment. $\mathbf{J}$ Am Mosq Control Assoc 1992; 8(2):173-7.

Organización Mundial de la Salud. Lucha contra la filariasis linfática. Genebra; 1988 - (OMS - Manual para personal sanitario).

Packer MJ, Corbet P. Size variation and reproductive success of female Aedes punctor (Diptera:Culicidae) Ecological Entomology 1989; 14:297-309. 
Pereira JCR. Análise de Dados Qualitativos. Estratégias Metodológicas para as Ciências da Saúde, Humanas e Sociais. São Paulo: Edusp; 1999.

Pereira LE, Suzuki A, Coimbra TLM, Souza RP, Chamelet ELB. Arbovírus Ilhéus em aves silvestres (Sporophila caerulescens e Molothrus bonariensis). Rev Saúde Pública $2001 ; 35(2): 1-18$.

Pryor SC, Daly J. Temporal in Morphological and Genetic characteristics within a hybrid population of Culex pipiens (Diptera:Culicidae). J Med Entomol 1991; 28(4): 481-486.

Rachou RG, Lima MM, Neto JAF, Martins CM. Inquérito epidemiológico de filariose bancroftiana em uma localidade de Santa Catarina. Como fase preliminar de uma prova profilática. Constatação de transmissão extradomiciliária por um novo vetor, Aedes scapularis. Rev Bras Malariol Doenças Trop 1955; 7:51-70.

Reinert JF. New Classification for composite genus Aedes (Diptera:Culicidae:Aedini), Elevation of subgenus Ochlerotatus to generic rank, reclassification of the other subgenera, and notes on certain subgenera and species. J Am Mosq Control Assoc $2000 ; 16(3): 175-188$. 
Reisen WK, Milby MM, Presser SB, Hardy JL. Ecology of mosquitoes and st. louis encephalitis virus in Los Angeles Basin of California, 1987-1990. J Med Entomol $1992 ; 29(4): 582-598$.

Rodrigues-Silva R, Moura H, Dreyer G, Rey L. Human pulmonary dirofilariais: a review. Rev Inst Med Trop 1995; 37: 523-530.

Rosay B. Anatomical indicators for assessing age of mosquitoes: Changes in ovarian follicles. Ann Entomol Soc Am 1969; 62:605-611.

Savage HM, Smith GC, Moore CG, Mitchell CJ, Townsed M, Marfin AA. Entomologic investigations of epidemic of St. Louis encephalitis in Pine Bluff, Arkansas, 1991. Am J Trop Med Hyg 1993: 49(1):38-45

Scott TW, Clark GG, Lorenz CLH, Amerasinghe PH, Reiter P, Edman JD. Detection of Multiple Blood Feeding in Aedes aegypti (Diptera:Culicidae) During a Single Gonotrophic Cycle Using a Histologic Techique. J Med Entomol 1993; 30(1):94-99

Siegel JP, Novak RJ, Ruesink WG. Relationship between wing length and dry weigth of mosquitoes. J Am Mosq Control Assoc 1992; 10:186-192.

Siegel JP, Novak RJ, Ruesink WG. Relationship between wing length and dry weight of mosquitoes. J Am Mosq Control Assoc 1994: 10(2): 186-96. 
Siegel S. Estatística Não-Paramétrica - Para as Ciências do Comportamento. Trad. de AA De Farias. New York: Mac Graw Hill; 1981.

Singh J, Mohan BN. Studies on noctournal activity of Anopheles fluviatilis James, 1902. Indian. Journal of Malariology 1951; 5: 513-525.

Sirivanakarn S, White GB. Neotype designation of Culex quinquefasciatus Say (Diptera:Culcidae). Proc Entomol Soc Wash 1978: 80:360-372.

Sokal RR, Rohlf FJ. Biometry - The principles and Practice of Statistics in Biological Research. New York: W.H. Freeman and Conpany; 1981.

Soubihe V. Estudo de populações de mosquitos culicídeos no Parque Ecológico do Tietê, São Paulo, Brasil (Diptera:Culicidae). São Paulo; 1994. [dissertação de mestrado - Instituto de Ciências Biomédicas da USP].

Timmermann SE, Briegel H. Bull Soc Vector Ecol 1993; 18:174-187.

Ulloa A, Rodriguez MH, Rodriguez AD, Roberts DR. A comparison of two collection methods for estimating abundance and parity of Anopheles albimanus in breeding sites and Villages of Southern Mexico. J Am Mosq Control Assoc 1997; 13(3):238-244. 
Vecrusse J. Estimation of the survival rate of Anopheles arabienses in an urban area (Pikine-Senegal). J Anim Ecol 1985; 54: 343-50.

Walker ED, Copeland RS, Paulson SL, Munstermann LE. Adult survivorship, population density, and body size in sympatric populations of Aedes triseriatus and Aedes hendersoni. J Med Entomol 1987; 24:485-493.

World Health Organization. Limphatic filariasis: The disease and its control. Geneva; 1992. (WHO- Fifth Report of the Who Expert Committee on Filariosis). 
Tabela 13. Distribuição do número de fêmeas nulíparas e paridas de Culex quinquefasciatus segundo habitats e datas de coleta.

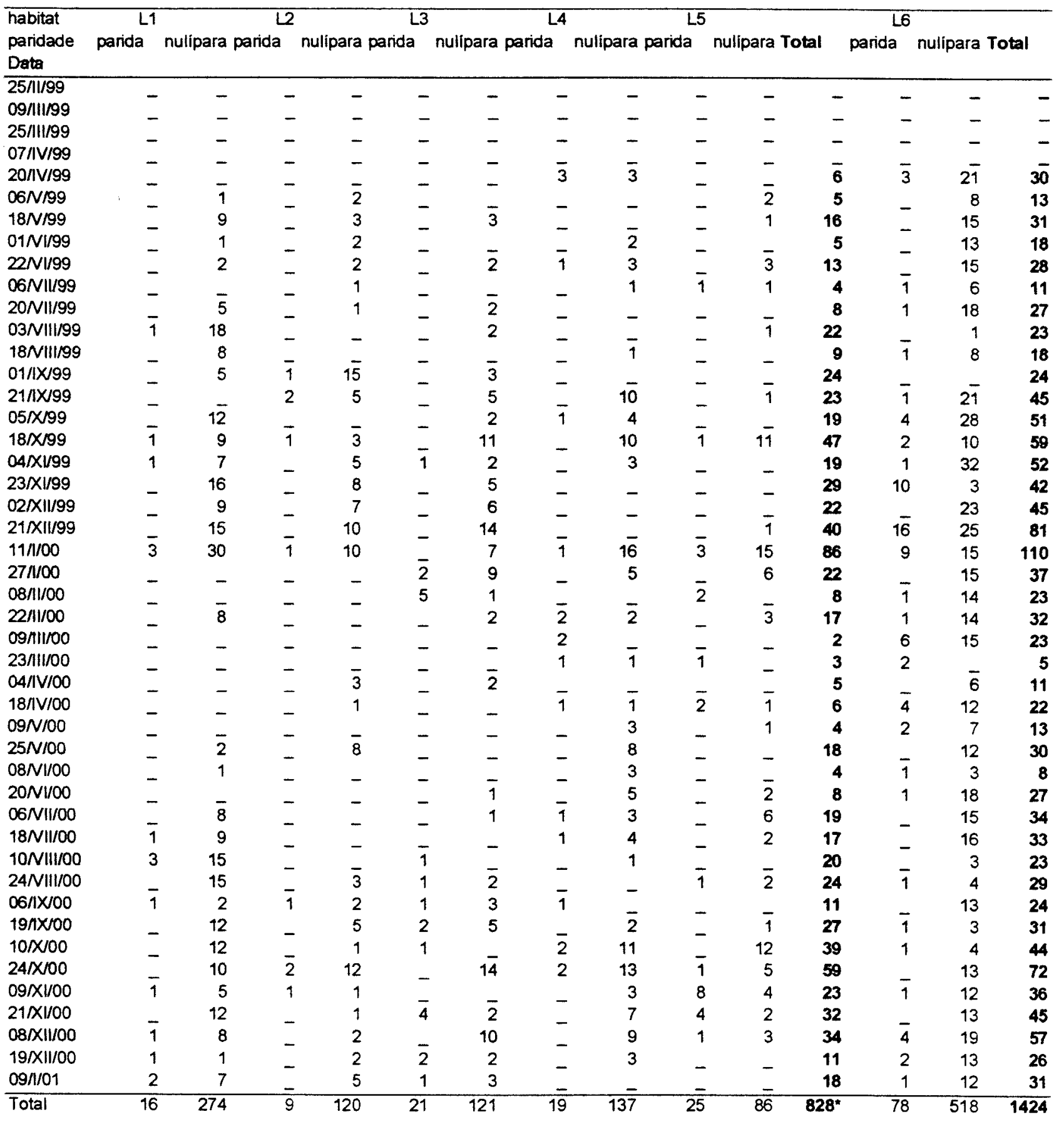

* Total $=(\mathrm{L} 1+\mathrm{L} 2+\mathrm{L} 3+\mathrm{L} 4+\mathrm{L} 5)$.

L-1 - habitat semi coberto por eucaliptos, L-2 - habitat de mata, L-3 - habitat de margem de mata, L-4 - habitat densamente coberto por eucaliptos, L-5 - habitat campo-brejo, L-6 - habitat de margem de riacho poluído. 
Tabela 14. Distribuição do número de fềmeas nuliparas e paridas de Ochlerotatus scapularis segundo habitats e data de coleta.

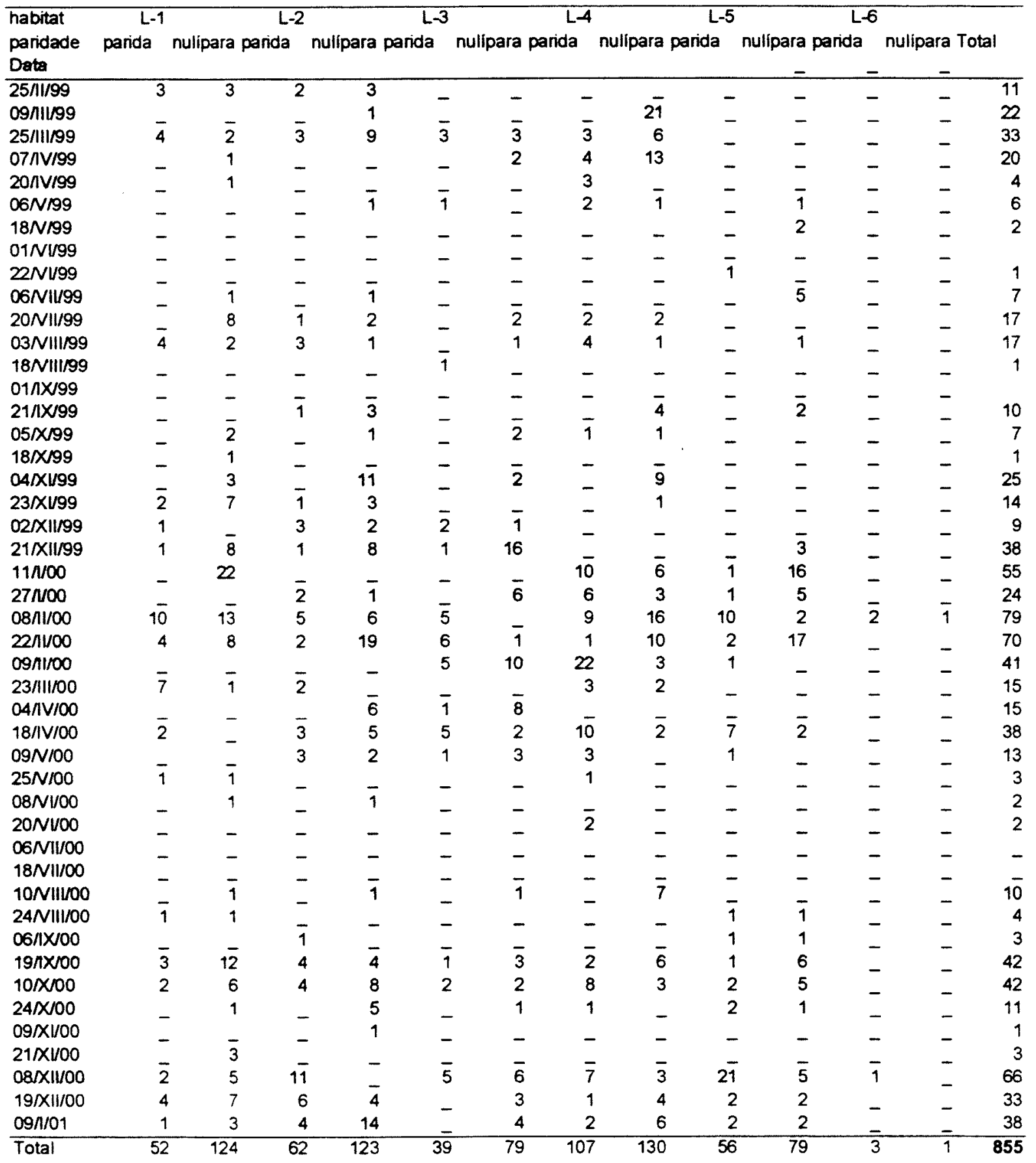

L-1 - habitat semi coberto por eucaliptos, L-2 - habitat de mata, L-3 - habitat de margem de mata, L-4 - habitat densamente coberto por eucaliptos, L-5 - habitat campo-brejo, L-6 - habitat de margem de riacho poluido. 


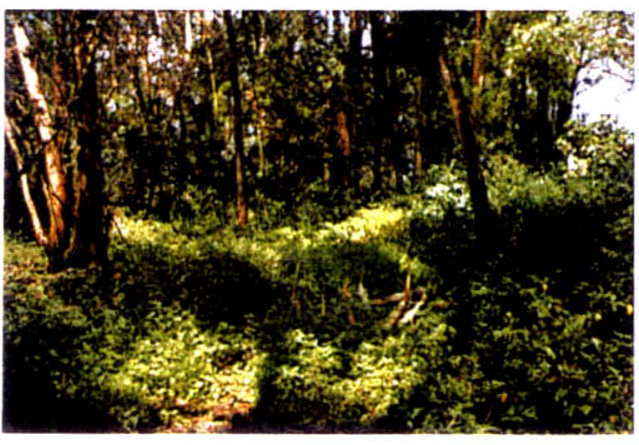

L1- Habitat semi coberto por eucaliptos

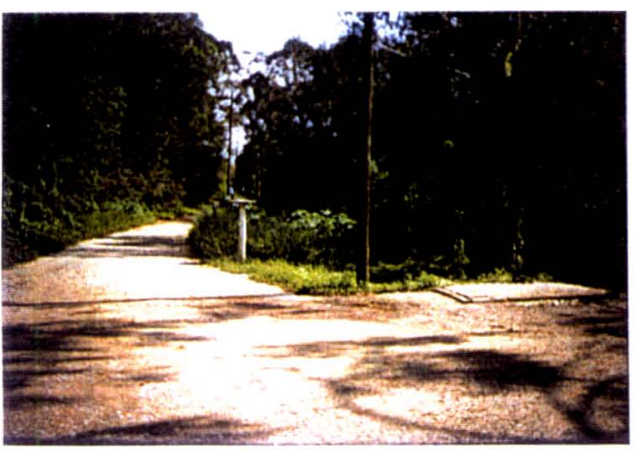

L3- Habitat de margem de mata.

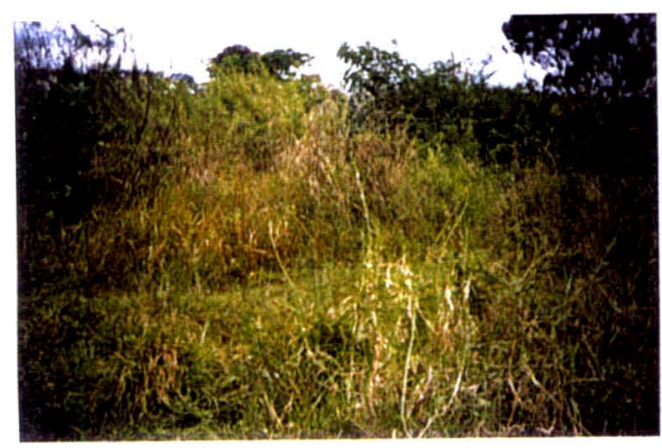

L5- Habitat de campo-brejo.

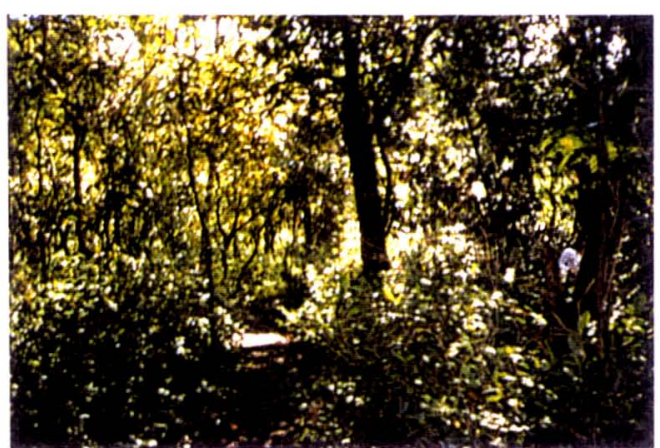

L2- Habitat coberto por mata.

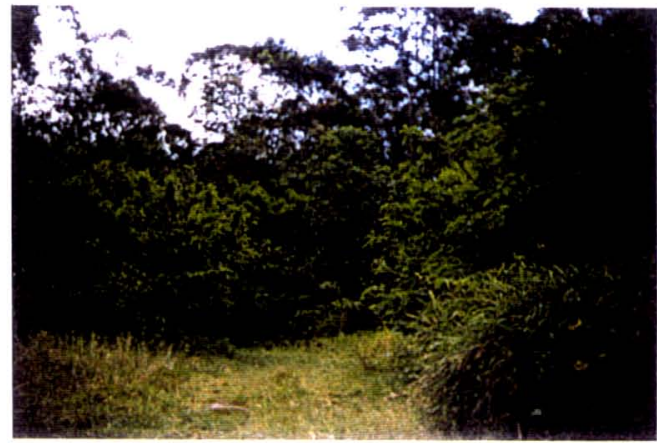

L4- Habitat densamente coberto por eucaliptos.

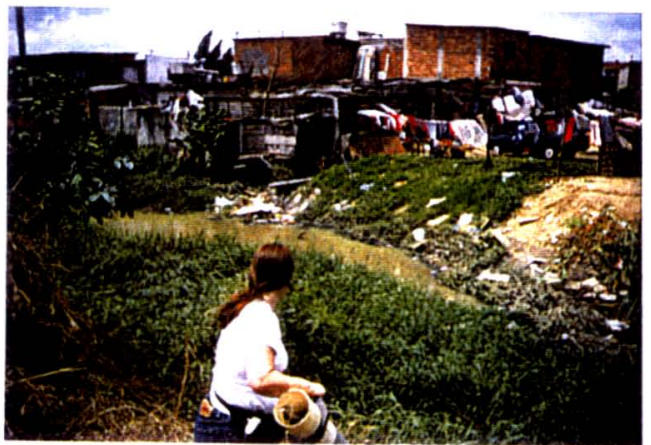

L6- Habitat de margem de riacho poluído.

Figura 13. Habitats considerados como abrigos para mosquitos no Parque Ecológico do Tiête. 


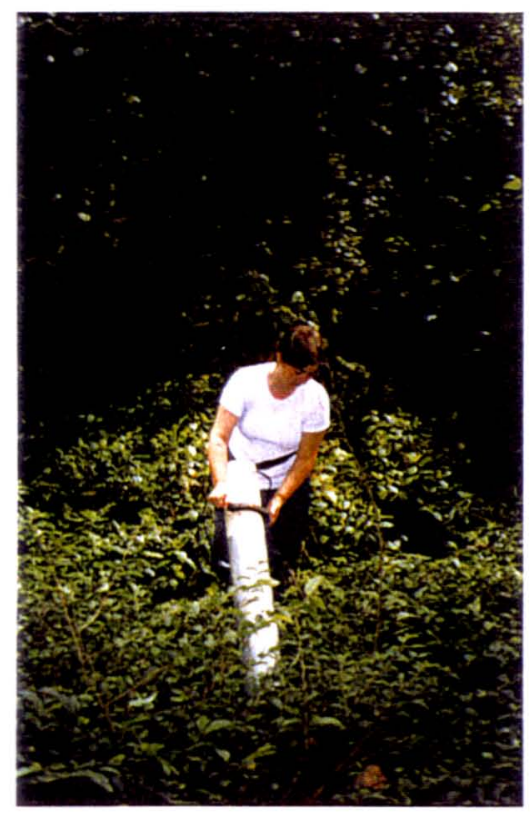

Figura 14. Técnica de aspiração, utilizada em habitat do Parque Ecológico do Tiête. 